UNIVERSIDADE DE SÃO PAULO

FFCLRP - DEPARTAMENTO DE FÍSICA E MATEMÁTICA

PROGRAMA DE PÓS-GRADUAÇÃO EM FÍSICA APLICADA À MEDICINA E BIOLOGIA

\title{
Propriedades críticas estáticas e dinâmicas de modelos com simetria continua e do modelo $Z(5)$
}

\author{
Henrique Almeida Fernandes
}

Tese apresentada à Faculdade de Filosofia, Ciências e Letras de Ribeirão Preto, da Universidade de São Paulo como parte das exigências para a obtenção do título de Doutor em Ciências -Área: Física Aplicada à Medicina e Biologia. 
UNIVERSIDADE DE SÃO PAULO

FFCLRP - DEPARTAMENTO DE FÍSICA E MATEMÁTICA

PROGRAMA DE PÓS-GRADUAÇÃO EM FÍSICA APLICADA À MEDICINA E BIOLOGIA

\section{Propriedades críticas estáticas e dinâmicas de modelos com simetria continua e do modelo $Z(5)$}

Henrique Almeida Fernandes

Tese apresentada à Faculdade de Filosofia, Ciências e Letras de Ribeirão Preto, da Universidade de São Paulo como parte das exigências para a obtenção do título de Doutor em Ciências -Área: Física Aplicada à Medicina e Biologia.

Área de ConcentraÇÃo:

Física Aplicada à Medicina e Biologia

ORIENTADOR:

Prof. Dr. José Roberto Drugowich de Felício 
$\grave{A}$ minha mãe $e$ à minha esposa Ludmila 


\section{Agradecimentos}

Agradeço ao professor Drugowich pela orientação, apoio e pelas discussões sobre os diversos modelos considerados durante meu doutorado.

Ao meu sogro Vandir e minha sogra Sofia pelo incondicional apoio durante toda a minha vida acadêmica.

Aos meus "avós" Nazar e Madalena pelo interesse demonstrado, preocupação e apoio durante todo esse tempo.

Aos meus irmãos Ricardo, Juliana e Fernando.

À Suely, Ésio, Alessandra e Henrique.

Aos colaboradores Everaldo e Roberto e ao amigo Ardiley.

Ao professor Caparica pela colaboração e discussões.

Aos professores Alexandre e Osame.

À FAPESP pelos recursos computacionais.

À CAPES pelo apoio financeiro. 


\section{Resumo}

FERNANDES, H.A. Propriedades críticas estáticas e dinâmicas de modelos com simetria contínua e do modelo Z(5), 74 p. Tese (Doutorado) - Faculdade de Filosofia, Ciências e Letras de Ribeirão Preto, Universidade de São Paulo, Ribeirão Preto, 2006.

Neste trabalho, nós investigamos o comportamento crítico dinâmico de três modelos estatísticos utilizando simulações Monte Carlo em tempos curtos. Inicialmente, estudamos os modelos tridimensionais de dupla-troca e de Heisenberg. O expoente dinâmico de persistência global $\theta_{g}$, bem como o expoente $z$ são estimados através de duas técnicas. Para obter $\theta_{g}$, aplicamos diretamente a lei de potência obtida para a probabilidade de persistência global, $P(t) \sim t^{-\theta_{g}}$, e em seguida fizemos o colapso da função universal $L^{\theta_{g} z} P(t)$ para duas redes de tamanhos diferentes. Para estimar o valor de $z$, nós usamos a função $F_{2}(t)$ que combina resultados de simulações realizadas com diferentes condições iniciais e o cumulante de Binder de quarta ordem dependente do tempo. O expoente dinâmico $\theta$, que governa o comportamento tipo lei de potência da magnetização inicial, é estimado através da correlação temporal da magnetização (modelos de dupla-troca e Heisenberg) e da aplicação direta da lei de potência $m_{0} \sim t^{\theta}$ (modelo de Heisenberg). Os expoentes estáticos $\beta$ e $\nu$ são estimados seguindo o comportamento de escala do parâmetro de ordem e sua derivada, respectivamente. Os resultados confirmam que esses dois modelos pertencem à mesma classe de universalidade. Em seguida, os expoentes críticos dinâmicos $z_{1}$ e $z_{2}$ e os expoentes críticos estáticos $\beta_{1}, \beta_{2}$ e $\nu$ são estimados no ponto de bifurcação do modelo de spin com simetria $Z(5)$ bidimensional. Neste ponto, o modelo apresenta dois parâmetros de ordem diferentes, cada um possuindo um conjunto diferente de índices críticos. Os valores dos expoentes críticos estáticos estão em boa concordância com os resultados exatos. Até onde sabemos, está é a primeira tentativa de se obter os expoentes críticos dinâmicos $z, \theta$ e $\theta_{g}$ para o modelo de dupla troca, $\theta$ e $\theta_{g}$ para o modelo de Heisenberg e $z_{1}$ e $z_{2}$ para o modelo $Z(5)$.

Palavras-chave: Simulações Monte Carlo; dinâmica crítica de tempos curtos; expoentes críticos; classe de universalidade; fenômenos críticos. 


\begin{abstract}
FERNANDES, H.A. Static and dynamic critical properties of models with continuous symmetry and of the $Z(5)$ model, 74 p. Thesis (Doctoral) - Faculdade de Filosofia, Ciências e Letras de Ribeirão Preto da Universidade de São Paulo, Ribeirão Preto, 2006.

In this work, we investigate the dynamic critical behavior of three statistical models by using short-time Monte Carlo simulations. At first, we study the threedimensional double-exchange and Heisenberg models. The global persistence exponent $\theta_{g}$, as well as the exponent $z$ are estimated through two techniques. The dynamical exponent $\theta_{g}$ is obtained by using the straight application of the power law obtained for the global persistence probability, $P(t) \sim t^{-\theta_{g}}$, and by following the scaling collapse of the universal function $L^{\theta_{g} z} P(t)$ for two different lattice sizes. To estimate the value of $z$, we use the function $F_{2}(t)$ which combines results obtained from samples submitted to different initial configurations and the time dependent fourth-order Binder cumulant. The dynamical exponent $\theta$, which governs the power law behavior of the initial magnetization, is estimated through the time correlation of the magnetization (double-exchange and Heisenberg models) and through the straight application of the power law $m_{0} \sim t^{\theta}$ (Heisenberg model). The statical exponents $\beta$ and $\nu$ are estimated through the scaling behavior of the order parameter and its derivative, respectively. The results confirm which those models belong to the same universality class. Following, the dynamical exponents $z_{1}$ e $z_{2}$ and the statical exponents $\beta_{1}, \beta_{2}$, and $\nu$ are estimated at the bifurcation point of the two-dimensional $Z(5)$-symmetric spin model. In this point, the model presents two different order parameters, each one possessing a different set of critical indices. The values of the static critical exponents are in good agreement with the exact results. Our study is, to the best of our knowledge, the first attempt to obtain the dynamic critical exponents $z, \theta$ and $\theta_{g}$ of the double-exchange model, $\theta$ and $\theta_{g}$ of the Heisenberg model, and $z_{1}$ and $z_{2}$ of the $Z(5)$ model.
\end{abstract}

Keywords: Monte Carlo simulations; short-time critical dynamics; critical exponents; universality class; critical phenomena. 


\section{Sumário}

1 Introdução 1

2 Conceitos básicos $\quad 7$

2.1 Transições de fase e fenômenos críticos . . . . . . . . . . . . . . . 7

2.2 Expoentes críticos . . . . . . . . . . . . . . . . . . 10

2.3 Teoria de escala . . . . . . . . . . . . . . . . . . . . . . 12

2.4 Teoria de grupo de renormalização . . . . . . . . . . . . . . . . . 15

3 Simulações Monte Carlo fora do equilíbrio 22

3.1 O expoente crítico dinâmico $z \ldots \ldots \ldots$. . . . . . . . . . 27

3.2 O expoente crítico dinâmico $\theta \ldots \ldots \ldots \ldots$. . . . . . . . . . 29

3.3 O expoente crítico dinâmico $\theta_{g} \ldots \ldots \ldots \ldots$

3.4 Os expoentes críticos estáticos $\nu$ e $\beta \ldots \ldots . \ldots \ldots$. . . . . . . . . 32

4 O modelo de dupla-troca $\quad 33$

4.1 Introdução . . . . . . . . . . . . . . . . . . . . . . . 33

4.2 O expoente crítico dinâmico $z \ldots \ldots \ldots$. . . . . . . . . . . 36

4.3 O expoente crítico dinâmico $\theta \ldots \ldots \ldots$. . . . . . . . . . 38

$4.4 \mathrm{O}$ expoente $\theta_{g}$ da persistência global . . . . . . . . . . . . 40

4.5 Os expoentes críticos estáticos $\nu$ and $\beta \ldots \ldots \ldots \ldots$. . . . . . . . 43

5 O modelo de Heisenberg clássico $\quad 47$

5.1 Introdução . . . . . . . . . . . . . . . . . . . . 47

5.2 O expoente crítico dinâmico $z \ldots \ldots \ldots$. . . . . . . . . . . 48 
5.3 O expoente crítico dinâmico $\theta \ldots \ldots \ldots \ldots$. . . . . . . . . 51

5.4 O expoente $\theta_{g}$ da persistência global . . . . . . . . . . . . . . . . 53

5.5 Os expoentes críticos estáticos $\nu$ and $\beta \ldots \ldots \ldots \ldots \ldots$

6 O modelo $\mathrm{Z}(5) \quad 57$

6.1 Introdução . . . . . . . . . . . . . . . . . . 57

6.2 Os expoentes críticos dinâmicos $z_{1}$ e $z_{2} \ldots \ldots \ldots \ldots$. . . . . . 59

6.3 Os expoentes críticos estáticos $\nu, \beta_{1}$ e $\beta_{2} \ldots \ldots \ldots \ldots$

7 Conclusões $\quad 63$

Referências Bibliográficas $\quad 66$

$\begin{array}{ll}\text { A Artigos publicados } & 74\end{array}$ 


\section{Lista de Figuras}

2.1 A transformação em blocos de spin. O lado esquerdo da figura mostra um sistema de spins e o lado direito mostra esse mesmo sistema após sofrer uma transformação onde cada célula contendo 4 spins gera um único super-spin. 17

3.1 O comportamento qualitativo da evolução temporal da magnetização partindo de um valor não nulo na criticalidade. . . . . . . . . . . . . . . . 26

4.1 A estutura dos compostos de manganita com rede perovskita. . . . . . . . 34

4.2 O cumulante $U_{4}(t)$ para $L_{1}=40$ e $L_{2}=60$ versus o tempo $t$. O cumulante para ambas as redes foi obtido de 5 conjuntos independentes. Para $L_{1}=40$ foram usados 5000 amostras e que para $L_{2}=60,2000$ amostras. . . . . . . 37

4.3 A evolução temporal de $F_{2}(t)$. As barras de erro, calculadas através de 5 conjuntos de 2000 amostras, são menores que os símbolos. . . . . . . . . . 38

4.4 A evolução temporal de $C(t)$ em escala log-log. As barras de erro são menores que os símbolos. Cada ponto representa uma média sobre 5 conjuntos de 2000 amostras. . . . . . . . . . . . . . . . . . . . . 39

4.5 A evolução temporal da probabilidade de persistência global $P_{g}(t)$ para uma rede de tamanho $L=60$ e $m_{0}=0.00125$. Cada ponto e sua respectiva barra de erro foram calculados a partir de 5 conjuntos com 5000 amostras cada. . . . . . . . . . . . . . ...... 41

4.6 O expoente crítico dinâmico $\theta_{g}$ como uma função da magnetização inicial $m_{0}$ para redes cúbicas com $L=60$. 
4.7 O colapso da probabilidade de persistência escalada versus o tempo escalado para $L_{1}=50$ e $L_{2}=60$. As curvas foram obtidas a partir de 5 conjuntos independentes de 5000 amostras. . . . . . . . . . . . . . . . 43

4.8 A evolução temporal da derivada $\left.\partial_{\tau} \ln M(t, \tau)\right|_{\tau=0}$ em escala log-log. As barras de erro são menores que os símbolos. Cada ponto representa uma média sobre 5 conjuntos de 2000 amostras. . . . . . . . . . . . . . . . . 44

4.9 A evolução temporal da magnetização para amostras inicialmente ordenadas $\left(m_{0}=1\right)$. As barras de erro, calculadas através de 5 conjuntos de 2000 amostras, são menores que os símbolos.

5.1 A evolução temporal de $F_{2}$ para uma rede de tamanho $L=50$. As barras de erro, calculadas através de 5 conjuntos de 3000 amostras, são menores que os símbolos. . . . . . . . . . . . . . . . . . .

5.2 O cumulante $U_{4}(t)$ para $L_{1}=40$ e $L_{2}=50$ versus o tempo $t$ com estados iniciais $m_{0}=1$. A linha mostra a rede $L_{2}=50$ reescalada no tempo. $\mathrm{O}$ cumulante para ambas as redes foi obtido a partir de 5 conjuntos independentes de 3000 amostras cada. . . . . . . . . . . . . . . . . . 50

5.3 A evolução temporal da magnetização para uma rede $L=50$ e $m_{0}=0.002$. As barras de erro, calculadas a partir de 5 conjuntos de 3000 amostras, são menores que os símbolos. O gráfico no interior mostra o expoente $\theta$ para três magnetizações iniciais diferentes, bem como seu valor extrapolado. . . 51

5.4 A correlação temporal da magnetização para amostras com $\langle M(t=0)\rangle=0$. As barras de erro foram calculadas a partir de 5 conjuntos de 3000 amostras. 52

5.5 A evolução temporal da probabilidade de persistência global $P_{g}(t)$ para uma rede de tamanho $L=50$ e $m_{0}=0.002$. As barras de erro foram calculadas através de 5 conjuntos de 3000 amostras. . . . . . . . . . . . 53

5.6 O colapso da probabilidade de persistência global para $L_{1}=40$ e $L_{2}=50$. As curvas foram obtidas a partir de 5 conjuntos de 3000 amostras cada. . . 54 
5.7 A evolução temporal da derivada $\left.\partial_{\tau} \ln M(t, \tau)\right|_{\tau=0}$ em escala log-log. As barras de erro são menores que os símbolos. Cada ponto representa uma média sobre 5 conjuntos de 3000 amostras. . . . . . . . . . . . . . . 55

5.8 A evolução temporal da magnetização para amostras inicialmente ordenadas $\left(m_{0}=1\right)$. As barras de erro, calculadas através de 5 conjuntos de 3000 amostras, são menores que os símbolos. . . . . . . . . . . . . . . . 56

6.1 A evolução temporal de $F_{2}(t)$ para os dois parâmetros de ordem. As barras de erro são menores que os símbolos. Cada ponto representa uma média sobre 5 conjuntos de 30000 amostras. . . . . . . . . . . . . . . 59

6.2 A evolução temporal da derivada $\left.\partial_{\tau} \ln M_{i}(t, \tau)\right|_{\tau=0}$ (onde $i$ se refere ao parâmetro de ordem 1 ou 2) em escala log-log no processo dinãmico iniciando de um estado ordenado $\left(m_{0}=1\right)$. As barras de erro são menores que os símbolos. Cada ponto representa uma média sobre 5 conjuntos de 30000 amostras. . . . . . . . . . . . . . . . . . 60

6.3 A evolução temporal das magnetizações para amostras inicialmente ordenadas $\left(m_{0}=1\right)$. As barras de erro, calculadas sobre 5 conjuntos de 30000 amostras, são menores que os símbolos. . . . . . . . . . . . . . . . . . 61 


\section{Lista de Tabelas}

4.1 O expoente crítico dinâmico $z$ para o modelo de dupla troca. . . . . . . . . 38

4.2 O expoente crítico dinâmico $\theta$ para o modelo de dupla troca. . . . . . . . . 39

4.3 O expoente de persistência global $\theta_{g}$ obtido através do comportamento em lei de potências para diferentes magnetizações iniciais $m_{0}$ para redes pares. 42

4.4 O expoente de persistência global $\theta_{g}$ a partir do melhor colapso para o modelo de dupla troca. . . . . . . . . . . . . . . . . . . . . . . 43

4.5 Os expoentes críticos $1 / \nu z$ e $\beta / \nu z$ para o modelo de dupla troca. . . . . . . 44

4.6 Os expoentes $\theta_{g}$ e $\alpha_{g}$ para vários modelos. . . . . . . . . . . . . . 46

5.1 O expoente crítico dinâmico $\theta$ encontrado a partir da Eq. (3.2) para diferentes magnetizações iniciais $m_{0}$. . . . . . . . . . . . . . . . . 52

5.2 O expoente de persistência global $\theta_{g}$ encontrado a partir da Eq. (3.14) para diferentes magnetizações iniciais $m_{0}$. . . . . . . . . . . . . . . 54

5.3 O expoente de persistência global $\theta_{g}$ para o melhor colapso das curvas $L_{1}$ e $L_{2} \ldots \ldots \ldots \ldots \ldots \ldots \ldots \ldots$ 


\section{Capítulo 1}

\section{Introdução}

O estudo de fenômenos críticos teve seu início com o trabalho experimental de Andrews [1] em 1869 que observou, através de medidas do comportamento crítico do dióxido de carbono, um forte espalhamento de luz nas proximidades do ponto crítico. Esse fenômeno que veio a ser chamado de opalescência crítica* fornece uma das mais interessantes manifestações do ponto crítico. Quatro anos mais tarde, van der Waals introduziu a primeira teoria bem sucedida sobre fenômenos críticos [2], antes mesmo do surgimento da mecânica estatística ${ }^{\dagger}$. Em sua descrição, van der Waals apresentava uma equação de estado aproximada onde um único tipo de interação entre moléculas de um fluido era capaz de descrever diferentes fases termodinâmicas.

Em 1907, Pierre Weiss [3] desenvolveu uma teoria do ferromagnetismo que explicou o desaparecimento da magnetização no ponto crítico, ou temperatura de Curie. Em sua teoria, Weiss supôs que os momentos magnéticos constituintes interagem via um campo molecular que é proporcional à magnetização média. Mais tarde, essas teorias que são de caráter de campo médio, foram generalizadas por Landau que partiu de uma expressão para o potencial termodinâmico escrito como uma série que tem como parâmetro de expansão a magnetização.

Apesar de tratarem de problemas diferentes, essas duas teorias têm muitos pontos em comum. Elas não descrevem corretamente os sistemas físicos, falhando princi-

\footnotetext{
*Este fenômeno foi também discutido por vários teóricos, dentre eles Einstein, Ornstein e Zernike.

${ }^{\dagger}$ A mecânica estatística foi sistematizada por Gibbs em 1902 no livro Elementary Principles of Statistical Mechanics.
} 
palmente na região crítica onde as flutuações são essenciais $[4,5]$, pois não dependem da dimensão do sistema e não levam em conta as flutuações do parâmetro de ordem. Mas as duas teorias levam aos mesmos expoentes críticos que são conhecidos como expoentes clássicos.

Tanto os resultados obtidos experimentalmente quanto os teóricos da técnica de expansão em série [6] introduzida por Domb, Rushbrooke, Fisher e outros mostraram desvios dos resultados clássicos de van der Waals e Weiss.

Em 1925, Ernst Ising [7] publicou o artigo, com a solução para o caso unidimensional daquele que se tornaria o mais conhecido e citado modelo em mecânica estatística dos cinqüenta anos seguintes, o modelo de Ising. Entretanto, os resultados não mostravam a existência de transição de fase para o caso unidimensional. O argumento usado por Ising de que não existiria transição de fase tampouco para dimensões maiores, levou a um esquecimento temporário do modelo. Alguns anos mais tarde, Peierls [8] mostrou que havia um erro no argumento de Ising e Onsager [9] comprovou oito anos depois essas expectativas, quando obteve a função de partição para o modelo bidimensional na ausência de campo magnético externo. Contudo, a solução exata para o caso bidimensional com campo externo e o caso tridimensional ainda são desafios para a mecânica estatística.

A solução de Onsager mostrou porque a teoria de Landau, apesar de qualitativamente correta, estava quantitativamente errada. A razão é que a energia livre tem uma singularidade no ponto crítico, o que não permite a expansão em série de potências no parâmetro de ordem. Mesmo assim, houve uma grande resistência em aceitar os resultados de Onsager por se tratar de um sistema bidimensional e, é claro, não se sabia realmente quais seriam os resultados corretos em três dimensões. Os resultados experimentais para o expoente crítico do parâmetro de ordem eram diferentes dos resultados teóricos preditos de acordo com o campo médio: os expoentes do campo médio eram 1/2 e dos experimentos, $1 / 3$, mas a solução de Onsager dava o valor $1 / 8$. Conceitualmente isso só veio a ser resolvido pela teoria de escala e a teoria de grupo de renormalização que surgiram nos anos 60 e 70 do século passado com Leo Kadanoff et al. [10], K. Wilson [11] e M. Fisher [12], que explicaram de forma definitiva a diferença encontrada entre os expoentes 
críticos obtidos experimentalmente e os valores clássicos da teoria de Landau. O grupo de renormalização está baseado na idéia de invariância de escala, introduzida por Widom e Kadanoff e no conceito de universalidade. Ao redor de um ponto crítico, sistemas experimentais ou modelos teóricos possuem comportamento universal, que depende de poucos parâmetros, entre eles a dimensionalidade do parâmetro de ordem e a dimensionalidade do sistema, não dependendo em geral dos detalhes da interação.

Uma forma de se estudar modelos em mecânica estatística é através de simulações numéricas. Com a invenção dos computadores e o seu subsequente avanço tecnológico, as simulações computacionais se tornaram um método essencial e poderoso no estudo de sistemas de muitos corpos, fazendo um papel intermediário entre modelos teóricos e experimentos.

Embora esse método tenha se tornado importante por volta de 1950, os primeiros estudos estocásticos de sistemas físicos datam do final do século XIX e início do século XX.

Todavia, esses trabalhos eram pontuais devido principalmente à dificuldade de realizar as simulações com variáveis aleatórias. A partir de 1945, com o advento dos computadores e geradores de números aleatórios de alta qualidade, os trabalhos envolvendo números aleatórios deixaram de ser pontuais. O método Monte Carlo passou então a ser considerado como uma técnica numérica universal, sendo por exemplo essencial nas simulações exigidas para o projeto Manhattan. O seu nascimento data de 1949 quando Metropolis e Ulam publicaram o artigo intitulado como The Monte Carlo Method [13]. Basicamente, esse método substitui um problema determinístico por seu análogo probabilístico (também chamado de estocástico). Seu nome é uma referência ao famoso Cassino Monte Carlo que está localizado no distrito que leva esse mesmo nome, no principado de Mônaco.

A primeira simulação Monte Carlo em larga escala de um problema de muitos corpos foi realizada em Los Alamos por Metropolis et al. no ano de 1953 [14]. Embora o computador tenha evoluído significativamente desde então, os fundamentos da técnica computacional permanecem, em grande parte, como eles foram sugeridos por Metropolis 
et al.

A principal limitação desse método é quando se estuda os fenômenos críticos de um determinado sistema. Como a nova configuração do sistema é obtida através de uma série de operações locais e como nas proximidades da temperatura crítica o comprimento de correlação é da ordem do tamanho do sistema, as configurações obtidas com as operações locais ficam muito correlacionadas, ocorrendo assim o chamado critical slowing down, ou alentecimento crítico que pode conduzir a uma quebra artificial de ergodicidade. Esse problema decorre da divergência da correlação na temperatura crítica (no limite termodinâmico) e dificulta a geração de configurações descorrelacionadas para se calcular as médias termodinâmicas. Muitos esforços foram feitos para driblar essa dificuldade. Em 1987, Swendsen e Wang desenvolveram o primeiro algoritmo de cluster (aglomerado) [15] que reduziu significativamente o alentecimento crítico. Esse algoritmo se mostrou muito eficiente no estudo das propriedades estáticas dos sistemas. Todavia, nesse caso, os valores dos expoentes críticos dinâmicos são alterados.

Outra maneira de se eliminar o alentecimento crítico foi proposta por Janssen, Schaub e Schimittmann [16] e independentemente por Huse [17] em 1989. Baseados na teoria de grupo de renormalização e em simulações numéricas, respectivamente, eles mostraram que além do bem conhecido comportamento universal no regime de tempos longos (sistemas no equilíbrio ou regime estacionário), existe um estágio universal muito antes que o sistema atinja o equilíbrio termodinâmico. Esse novo regime, chamado de regime de tempos curtos, proporcionou novas alternativas para obter as propriedades críticas estáticas e dinâmicas de sistemas, como por exemplo, o expoente crítico dinâmico $z$, tão difícil de ser encontrado pelos métodos conhecidos até então (simulação Monte Carlo no equilíbrio, métodos de grupo de renormalização etc). Para o modelo de Ising por exemplo, esses métodos obtém em duas dimensões $2.10<z<2.52$ e em três dimensões $1.95<z<2.35$. Já nas simulações Monte Carlo no regime de tempos curtos, onde os expoentes estáticos e dinâmicos são obtidos no estágio inicial da relaxação dinâmica do sistema, o comprimento de correlação ainda é pequeno quando comparado com o tamanho do sistema, tornando possível a investigação tanto das propriedades críticas dinâmicas 
como das estáticas sem os incômodos do critical slowing down. Nesse regime, o expoente $z$ pode ser obtido com melhor precisão, sendo que no caso bidimensional seu valor fica em torno de 2.15 e em três dimensões $z \sim 2.04$.

Além dos expoentes encontrados no equilíbrio, novos expoentes críticos dinâmicos independentes são encontrados nesse estágio universal fora do equilíbrio. O expoente $\theta$ introduzido para descrever o comportamento anômalo da magnetização inicial do sistema resfriado bruscamente e colocado em banho térmico a $T=T_{c}$ é um novo índice crítico, independente de todos os demais (estáticos e dinâmico). Também o expoente $\theta_{g}$ que descreve o comportamento em lei de potência da probabilidade de persistência global na criticalidade, tem se revelado independente dos demais, o que comprova o caráter não Markoviano da relaxação [18]. O estudo dos modelos no regime de tempos curtos, além de ensejarem o conhecimento de novos expoentes críticos, tem permitido caracterizar modelos que apresentam não-universalidade [19,20] e diferenciar modelos que aparentemente pertencem à mesma classe de universalidade, como é o caso do Potts com 4 estados e do modelo de Baxter-Wu, mas que têm expoentes sub-dominantes distintos [21].

Neste trabalho, nós realizamos simulações Monte Carlo em tempos curtos para estudar o comportamento crítico dinâmico de dois modelos tridimensionais: os modelos de dupla troca (double-exchange) e de Heisenberg; e de um modelo bidimensional: o modelo $Z(5)$. Para os modelos tridimensionais, nós seguimos a evolução temporal de várias quantidades durante os primeiros 500 passos de sua relaxação para obter os expoentes críticos dinâmicos $z, \theta$ e $\theta_{g}$ e os expoentes críticos estáticos $\beta$ e $\nu$. Os resultados permitem afirmar que o modelo de dupla troca pertence à mesma classe de universalidade do modelo de Heisenberg e que os modelos com simetria contínua exibem a maior disparidade entre os valores de $\theta_{g}$ obtidos pelas simulações e pela equação que o referido expoente obedeceria se a relaxação fosse Markoviana. Os expoentes encontrados estão em concordância com os valores da literatura quando eles existem. Em seguida, os expoentes críticos dinâmicos $z_{1}$ e $z_{2}$ e os expoentes críticos estáticos $\nu, \beta_{1}$ e $\beta_{2}$ foram estimados no ponto de bifurcação do modelo de spin com simetria $Z(5)$ bidimensional. Neste ponto, conhecido como ponto de Fateev-Zamolodchikov, o modelo apresenta dois parâmetros de ordem diferentes, cada 
um possuindo um conjunto diferente de índices críticos. Os valores dos expoentes críticos estáticos estão em boa concordância com os resultados exatos.

Este trabalho está organizado da seguinte forma: no próximo capítulo fazemos uma breve revisão sobre transições de fase e fenômenos críticos, a teoria de escala que descreve o comportamento de grandezas termodinâmicas nas proximidades do ponto crítico, e finalmente introduzimos o conceito de grupo de renormalização fenomenológico. No Capítulo 3, apresentamos o método Monte Carlo que extrai resultados relevantes sobre fenômenos críticos no estágio inicial de relaxação e mostramos diversas maneiras (ou técnicas) de se obter os expoentes críticos. Nos Capítulo 4, 5 e 6, nós definimos os modelos considerados e apresentamos todos os nossos resultados. Finalmente, no Capítulo 7 apresentamos as conclusões e algumas sugestões para trabalhos futuros. No Apêndice A nós apresentamos nossos artigos publicados. 


\section{Capítulo 2}

\section{Conceitos básicos}

Neste capítulo, os conceitos teóricos básicos envolvendo o estudo de transições de fase e fenômenos críticos são apresentados, embora de maneira sucinta, como uma introdução ao estudo de sistemas críticos fora do equilíbrio, tema principal desta tese.

Há aproximadamente 50 anos, a teoria moderna de transições de fase e fenômenos críticos estava sendo construída com a introdução dos conceitos básicos de universalidade, comportamento de escala das funções termodinâmicas e da teoria de grupo de renormalização [22]. Como será mostrado a seguir, essas teorias foram e ainda são de fundamental importância no desenvolvimento de técnicas e métodos analíticos e/ou numéricos no âmbito da mecânica estatística.

\subsection{Transições de fase e fenômenos críticos}

Sistemas termodinâmicos podem apresentar diferentes comportamentos macroscópicos de acordo com as condições externas impostas a ele. Esses comportamentos são conhecidos como fases do sistema* e podem diferir dramaticamente de sistema para sistema, como por exemplo na água que possui as fases gasosa, líquida e várias modificações do gelo, e o carbono com as fases grafite, diamante, fulereno e nanotubos.

Alterando as condições externas, ou melhor, as variáveis intensivas do sistema

*Uma fase é um estado de agregação da matéria caracterizada pela densidade, mobilidade, estrutura cristalina etc. 
(temperatura por exemplo) é possível ocorrer uma mudança de fase (transição de fase) em algum valor crítico dessas variáveis. Neste ponto, os potenciais químicos e as temperaturas devem ser iguais, a energia livre de Gibbs tem o mesmo valor e portanto as fases podem coexistir. Variando as condições externas novamente pode-se encontrar outros pontos onde ocorrem exatamente a mesma coisa. Desta forma, obtém-se linhas onde as fases podem coexistir, conhecidas como linhas de coexistência de fases.

O potencial químico $\mu$ é dado por

$$
\mu=\left(\frac{\partial \mathcal{G}}{\partial N}\right)_{Y, T}
$$

onde $\mathcal{G}$ é a energia livre de Gibbs, $N$ é o número de partículas e as quantidades $Y$ e $T$ (temperatura) são as variáveis intensivas do sistema.

Todavia nenhuma restrição é colocada sobre as derivadas

$$
X=\left(\frac{\partial \mathcal{G}}{\partial Y}\right)_{T, N} \quad \text { e } \quad S=\left(\frac{\partial \mathcal{G}}{\partial T}\right)_{Y, N} .
$$

O comportamento destas derivadas que é usado para classificar as transições de fase. Ehrenfest definiu uma transição de fase como uma transição de ordem $n$ quando, no ponto de transição

$$
\left(\frac{\partial^{n} \mathcal{G}_{1}}{\partial T^{n}}\right)_{Y, N} \neq\left(\frac{\partial^{n} \mathcal{G}_{2}}{\partial T^{n}}\right)_{Y, N} \quad \text { e } \quad\left(\frac{\partial^{n} \mathcal{G}_{1}}{\partial Y^{n}}\right)_{T, N} \neq\left(\frac{\partial^{n} \mathcal{G}_{2}}{\partial Y^{n}}\right)_{T, N}
$$

Os índices 1 e 2 referem-se às diferentes fases do sistema. Nesse caso, as derivadas de ordem $n-1$ são iguais. Um exemplo bem conhecido é a transição de segunda ordem da supercondutividade. No entanto, muitos exemplos de transições de fase não podem ser descritos desta forma pois as derivadas de ordens superiores são infinitas e por isso a teoria proposta por Ehrenfest fracassa, como por exemplo, a transição em ferromagnetos, a transição em ligas binárias e a transição $\lambda$ no hélio líquido que são caracterizadas por uma divergência logarítmica na segunda derivada da energia livre de Gibbs. As transições de fase são, em linguagem moderna, divididas em duas classes: as de primeira ordem, onde 
as primeiras derivadas de $\mathcal{G}$ são descontínuas (caracterizadas pela mudança descontínua de estado) e as de segunda ordem, onde as primeiras derivadas são contínuas (mudança contínua de estado). Para um sistema de um componente, uma transição de segunda ordem ocorre somente num ponto crítico (por exemplo, o modelo de Ising). Mas num sistema de 2 componentes, pode-se encontrar linhas de transições de fase de segunda ordem, as chamadas linhas críticas (por exemplo, modelo de Ashkin-Teller).

Numa transição de primeira ordem existe uma diferença de entalpia $\Delta E$ dada por

$$
\Delta E=\left\{\left(\frac{\partial \mathcal{G}_{2}}{\partial T}\right)_{Y, N}-\left(\frac{\partial \mathcal{G}_{1}}{\partial T}\right)_{Y, N}\right\} .
$$

$\Delta E$ é conhecido como calor latente numa transição de primeira ordem onde parâmetros extensivos do sistema variam descontinuamente e ele absorve ou libera uma quantidade finita de calor.

Em alguns casos, a curva ou linha de transição de fase de primeira ordem (linha de coexistência) termina num certo ponto, onde a distinção entre as fases se perde. Após esse ponto, que corresponde ao estado em que as duas fases se tornam idênticas, o sistema fica homogêneo, dando lugar às transições de segunda ordem. Este ponto é conhecido como ponto crítico.

No momento é interessante introduzir a noção de parâmetro de ordem que é uma quantidade macroscópica cuja propriedade mais importante é assumir o valor nulo para $T>T_{c}$ (fase desordenada ou de maior simetria) e um valor não nulo para $T<T_{c}$ (fase ordenada ou de menor simetria). Como exemplos podemos citar a magnetização espontânea para sistemas ferromagnéticos, a diferença de densidade do líquido e do vapor numa transição líquido-vapor, a diferença da densidade de zinco ou de cobre numa transição ordem-desordem de uma liga binária zinco-cobre, a polarização espontânea de um material ferroelétrico etc. Nestes exemplos, o parâmetro de ordem é ora escalar, ora vetor. Na realidade, o parâmetro de ordem pode ser um tensor, um número complexo, uma função (complexa) [23].

Quando um sistema se aproxima de seu ponto crítico do lado de altas temperaturas (fase desordenada) começa a haver um ajustamento em nível microscópico. 
Estes ajustes aparecem na forma de grandes flutuações na densidade, magnetização etc. Na região próxima ao ponto crítico algumas grandezas termodinâmicas podem se tornar infinitas como o calor específico, a susceptibilidade etc.

Uma discussão mais detalhada do que acontece quando o sistema se aproxima do ponto crítico pode ser encontrada na referência [22], que utiliza uma analogia entre um fluido e um sistema ferromagnético para introduzir o conceito de opalescência crítica que está associada com as enormes flutuações nas proximidades do ponto crítico.

\section{$2.2 \quad$ Expoentes críticos}

A natureza das diversas funções termodinâmicas de sistemas que possuem transição de fase contínua quando se aproximam do ponto crítico é descrita por um conjunto de expoentes críticos. Essas funções podem divergir, ir a zero (parâmetro de ordem) ou mesmo permanecer finitas.

No momento é conveniente introduzir um parâmetro de expansão

$$
\varepsilon=\frac{T-T_{c}}{T_{c}}
$$

que é uma variável adimensional que mede o desvio da temperatura em relação à temperatura crítica $T_{c}$.

Nas proximidades do ponto crítico todas as funções termodinâmicas podem ser escritas na forma

$$
f(\varepsilon)=A \varepsilon^{\lambda}\left(1+B \varepsilon^{x}+\cdots\right)
$$

onde $A, B, \lambda$ e $x$ são constantes, com $x>0$. O expoente $\lambda$ definido como

$$
\lambda=\lim _{\varepsilon \rightarrow 0} \frac{\ln f(\varepsilon)}{\ln (\varepsilon)}
$$

e é conhecido como o expoente crítico de $f(\varepsilon)$.

Quando $\lambda$ é igual a zero existe as possibilidades de, por exemplo, $f(\varepsilon)$ ter uma 
divergência logarítmica da forma

$$
f(\varepsilon)=A|\ln (\varepsilon)|+B
$$

ou uma dependência em $\varepsilon$ da forma

$$
f(\varepsilon)=A+B \varepsilon^{\frac{1}{2}}
$$

Se $\lambda$ é negativo, $f(\varepsilon)$ diverge no ponto crítico, mas se é positivo, $f(\varepsilon)$ vai a zero no ponto crítico.

Os seis expoentes críticos mais conhecidos que são comumente utilizados para descrever as propriedades termodinâmicas de sistemas magnéticos são os expoentes $\beta, \alpha$, $\gamma, \delta, \eta$ e $\nu$. Os quatro primeiros são definidos como segue:

- Parâmetro de ordem: $M \sim|\varepsilon|^{\beta}$;

- Capacidade térmica: $C \sim|\varepsilon|^{-\alpha}$;

- Susceptibilidade: $\chi \sim|\varepsilon|^{-\gamma}$;

- Equação de estado $(\varepsilon=0): M \sim H^{\frac{1}{\delta}}$.

Na primeira relação, não faz sentido calcular o expoente crítico para $T>$ $T_{c}\left(T^{+}\right)$, pois o parâmetro de ordem é definido, como vimos anteriormente, somente para $T \leq T_{c}$. Nas duas relações seguintes, foi confirmado tanto teoricamente quanto experimentalmente que seus expoentes críticos são os mesmos quando se aproxima de $T_{c}$ por cima $\left(T^{+}\right)$ou por baixo $\left(T^{-}\right)$.

Os últimos dois expoentes envolvem a função de correlação

$$
\Gamma(r) \longrightarrow r^{-p} e^{-\frac{r}{\xi}}
$$

onde

$$
\xi \sim|\varepsilon|^{-\nu}
$$

é o comprimento de correlação, $p=d-2+\eta$ e $d$ é a dimensionalidade do sistema. 


\subsection{Teoria de escala}

A teoria de escala de Widom [24] leva em consideração o comportamento das grandezas termodinâmicas nas proximidades do ponto crítico, onde as flutuações do parâmetro de ordem são enormes.

De acordo com essa teoria, o valor da grandeza termodinâmica num certo ponto do diagrama de fase pode ser obtido a partir de outro apenas por uma mudança de escala, mas esta mudança deve ter o ponto crítico como o ponto de referência [25].

Nesse sentido, Widom percebeu que para se obter as leis de escala, era suficiente supor que a parte singular da energia livre de Gibbs $\mathcal{G}_{s}$ era uma função homogênea generalizada da temperatura reduzida $\varepsilon$ e do campo magnético $H$, por exemplo. Considerando-se a seguinte transformação de escala

$$
(\varepsilon, H) \longrightarrow\left(\lambda^{x} \varepsilon, \lambda^{y} H\right)
$$

que liga dois pontos no diagrama de fase, as partes singulares da energia livre de Gibbs correspondentes a esses pontos estão ligadas por uma transformação de escala, ou seja,

$$
\lambda \mathcal{G}_{s}(\varepsilon, H)=\mathcal{G}_{s}\left(\lambda^{x} \varepsilon, \lambda^{y} H\right) .
$$

O parâmetro $\lambda$ é um fator de multiplicação e, como será mostrado logo a seguir, $x$ e $y$ são quantidades que estão ligadas aos expoentes críticos do sistema.

A Eq. (2.13) expressa a homogeneidade de $\mathcal{G}_{s}(\varepsilon, H)$ relativamente a $\varepsilon$ e $H$ e é válida para quaisquer valores positivos de $\lambda$.

Para uma função ser homogênea, suas derivadas também devem ser funções homogêneas. De fato, a derivada da Eq. (2.13) em relação ao campo magnético $H$ fornece

$$
\lambda \frac{\partial \mathcal{G}_{s}(\varepsilon, H)}{\partial H}=\lambda^{y} \frac{\partial \mathcal{G}_{s}\left(\lambda^{x} \varepsilon, \lambda^{y} H\right)}{\partial H},
$$

ou seja,

$$
\lambda M(\varepsilon, H)=\lambda^{y} M\left(\lambda^{x} \varepsilon, \lambda^{y} H\right),
$$


onde $M=\partial \mathcal{G}_{s} / \partial H$ é a magnetização do sistema.

A função homogênea da susceptibilidade magnética é obtida com a derivada da Eq. (2.14) em relação ao campo magnético,

$$
\lambda \chi(\varepsilon, H)=\lambda^{2 y} \chi\left(\lambda^{x} \varepsilon, \lambda^{y} H\right) .
$$

Na temperatura crítica $(\varepsilon=0)$ e escolhendo $\lambda^{y} H=1$, a Eq. (2.14) resulta em

$$
M(0, H)=H^{(1-y) / y} M(0,1)=H^{1 / \delta} M(0,1),
$$

ou seja,

$$
\delta=\frac{y}{1-y}
$$

Considerando agora $H=0$ e $\lambda^{x} \varepsilon=-1$ nessa mesma equação, obtém-se

$$
M(\varepsilon, 0)=(-\varepsilon)^{(1-y) / x} M(-1,0)=(-\varepsilon)^{\beta} M(-1,0),
$$

e com isso,

$$
\beta=\frac{1-y}{x}
$$

Considerando ainda $H=0$ e $\lambda^{x} \varepsilon=-1$ para a Eq. (2.16), obtém-se

$$
\chi(\varepsilon, 0)=(-\varepsilon)^{(1-2 y) / x} \chi(-1,0)=(-\varepsilon)^{-\gamma} \chi(-1,0),
$$

ou seja

$$
\gamma=\frac{2 y-1}{x}
$$

O expoente $\gamma$ também é obtido quando se multiplica $\beta$ por $\delta-1$,

$$
\frac{1-y}{x}\left(\frac{y}{1-y}-1\right)=\frac{2 y-1}{x}
$$

ou seja,

$$
\beta(\delta-1)=\gamma
$$


que é uma das relações de escala mais tradicionais, conhecida como lei de Widom.

De forma similar, é fácil mostrar que a segunda derivada da Eq. (2.13) em relação a $\varepsilon$, é dada por

$$
\lambda \frac{\partial^{2} \mathcal{G}_{s}(\varepsilon, H)}{\partial \varepsilon^{2}}=\lambda^{2 x} \frac{\partial^{2} \mathcal{G}_{s}\left(\lambda^{x} \varepsilon, \lambda^{y} H\right)}{\partial \varepsilon^{2}},
$$

que pode ser reescrita na forma

$$
\lambda C(\varepsilon, H)=\lambda^{2 x} C\left(\lambda^{x} \varepsilon, \lambda^{y} H\right),
$$

onde $C=\partial^{2} \mathcal{G}_{s} / \partial \varepsilon^{2}$ é a capacidade térmica do sistema.

Para $H=0$ e $\lambda^{x} \varepsilon=-1$, tem-se que

$$
C(\varepsilon, 0)=(-\varepsilon)^{(1-2 x) / x} C(-1,0)=(-\varepsilon)^{-\alpha} C(-1,0),
$$

e portanto,

$$
\alpha=\frac{2 x-1}{x} .
$$

Fazendo agora a soma $\alpha+2 \beta+\gamma$ obtém-se

$$
\frac{2 x-1}{x}+2 \frac{1-y}{x}+\frac{2 y-1}{x}=2,
$$

ou seja,

$$
\alpha+2 \beta+\gamma=2
$$

que é a conhecida lei de Rushbrooke.

Seguindo esse raciocínio, outras leis de escala podem ser facilmente obtidas. As relações de escala mais conhecidas são mostradas abaixo:

- Lei de Fisher: $\gamma=\nu(2-\eta)$;

- Lei de Rushbrooke: $\alpha+2 \beta+\gamma=2$;

- Lei de Widom: $\gamma=\beta(\delta-1)$; 
- Lei de Josephson: $\nu d=2-\alpha$.

A confirmação experimental destas relações da forte suporte à hipótese de escala para os sistemas nas proximidades do ponto crítico. Sendo assim, os expoentes críticos não são independentes, mas satisfazem certas relações, de forma que somente dois deles são de fato independentes.

Em suma, nas proximidades do ponto crítico, flutuações ocorrem sobre longas e longas distâncias. O único comprimento característico do sistema é o comprimento de correlação que passa a ser da ordem de magnitude macroscópica, e portanto, detalhes microscópicos do sistema tornam-se irrelevantes, significando que existe universalidade nos fenômenos críticos. Tanto experimentalmente, como nas teorias de Landau e de escala, obtém-se universalidade nos expoentes críticos, ou seja, sistemas completamente diferentes (por exemplo, nas transições ferromagnética-paramagnética, líquido-gás, tipos diferentes de fase de mistura binária), com temperaturas críticas diferindo por ordens de magnitude, têm expoentes críticos idênticos. Dizemos que esses sistemas pertencem à mesma classe de universalidade. Outros sistemas podem pertencer a classes de universalidade diferentes (por exemplo, modelo de Heisenberg, superfluidos etc). Essa conjectura foi sugerida através da teoria de grupo de renormalização (RG), que diz que os índices críticos são os mesmos somente dentro de uma classe de universalidade. Essa teoria será mostrada na próxima seção.

Uma evidência experimental de escala e universalidade foi feita por Guggenheim em 1945 [26]. Nesse trabalho, as curvas de coexistência de 8 fluidos num gráfico $T / T_{c}$ versus $P / P_{c}$ foi considerada e como resultado, uma única curva foi encontrada.

\subsection{Teoria de grupo de renormalização}

Antes de entrar no mérito da teoria do grupo de renormalização, mostraremos as idéias desenvolvidas por Kadanoff [10], os chamados blocos de spins em modelos do tipo Ising. Essas idéias dão suporte intuitivo à hipótese de escala. Seu trabalho prediz não somente as relações envolvendo os expoentes críticos para funções termodinâmicas, 
mas também certas relações entre os expoentes da função de correlação.

Considere um modelo de Ising $d$-dimensional, com spins que interagem via primeiros vizinhos através da constante de acoplamento $J$ e que estão imersos num campo magnético $H$. Utilizando as quantidades adimensionais

$$
K=\frac{J}{k_{B} T} \quad \text { e } \quad h=\frac{\mu H}{k_{B} T}
$$

a hamiltoniana adimensional é dada por

$$
\beta \mathcal{H}=-K \sum_{\langle i, j\rangle} s_{i} s_{j}-h \sum_{i=1}^{N} s_{i}
$$

onde $N$ é o número de spins de Ising, $s_{i}$ é o spin no sítio $i, \sum_{\langle i, j\rangle}$ é sobre sítios de primeiros vizinhos, $k_{B}$ é a constante de Boltzmann e $T$ é a temperatura. Como a temperatura crítica é uma medida direta da intensidade da interação $J$, pode-se fazer

$$
\varepsilon=\frac{J-J_{c}}{J_{c}}
$$

A função de partição é então dada por

$$
Z_{N}(\varepsilon, h)=\exp \{-N \mathcal{G}(\varepsilon, h)\}=\sum_{\{s\}} \exp (-\beta \mathcal{H})
$$

onde $\mathcal{G}(\varepsilon, h)$ é a energia livre de Gibbs por spin.

Agora, como mostra a Figura 2.1, para se conseguir os blocos de spin basta dividir a rede em células de lado ba ( $a$ é a constante de rede e $b$ é um número inteiro arbitrário mas muito maior que a unidade). Desta forma, o sistema passa a ter

$$
N^{\prime}=\frac{N}{b^{d}}
$$

blocos, cada um contendo $b^{d}$ spins.

Quando a temperatura do sistema está próxima da temperatura crítica $T_{c}$, o comprimento de correlação $\xi$ é muito maior que o comprimento de uma célula, isto 

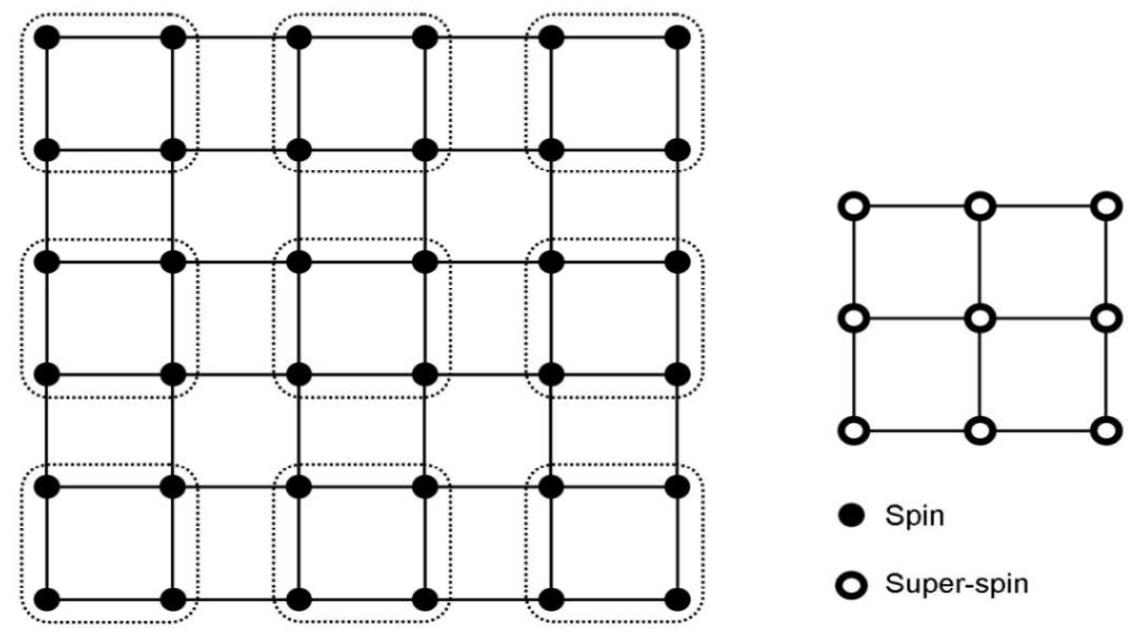

Figura 2.1: A transformação em blocos de spin. O lado esquerdo da figura mostra um sistema de spins e o lado direito mostra esse mesmo sistema após sofrer uma transformação onde cada célula contendo 4 spins gera um único super-spin.

é, $\xi \gg b a$, ou seja, $1 \ll b a \ll \xi$. Uma observação importante é que, o argumento de Kadanoff é aplicável somente em temperaturas próximas de $T_{c}$.

Com os blocos de spin em mente, pode-se introduzir a idéia do super-spin $\left(s^{\prime}\right)$. Nesta suposição, deve-se levar em conta a maioria dos spins em um bloco, ou seja, $s^{\prime}$ é \pm 1 se a maior parte dos spins do bloco são \pm . No caso de igualdade, definimos arbitrariamente $s^{\prime}=s_{1}$, onde $s_{1}$ é um spin particular (por exemplo, o spin do canto esquerdo do bloco). Temos então que $s^{\prime}=1$ se $S>0, s^{\prime}=-1$ se $S<0$ e $s^{\prime}=s_{1}$ se $S=0$, onde $S$ é o somatório de todos os spins do bloco.

Depois desta alteração, o número de spins no sistema é reduzido por um fator $b^{d}$. Nesta suposição as células se comportam da mesma maneira que os spins de Ising. Kadanoff mostrou que suficientemente próximo da temperatura crítica, a hamiltoniana escrita em termos dos super-spins tem forma similar à hamiltoniana (2.32) para o modelo de sítio, exceto, é claro, que os parâmetros $K$ e $h$ podem ser diferentes,

$$
\beta \mathcal{H}^{\prime}=-K^{\prime} \sum_{\langle i, j\rangle} s_{i}^{\prime} s_{j}^{\prime}-h^{\prime} \sum_{i=1}^{N} s_{i}^{\prime} .
$$


A função de partição para o modelo de super-spin é

$$
Z_{N^{\prime}}\left(\varepsilon^{\prime}, h^{\prime}\right)=\exp \left\{-N^{\prime} \mathcal{G}\left(\varepsilon^{\prime}, h^{\prime}\right)\right\}=\sum_{\left\{s^{\prime}\right\}} \exp \left(-\beta \mathcal{H}^{\prime}\right)
$$

Como as hamiltonianas são similares, as funções de partição nos dois modelos devem ser iguais

$$
Z_{N}(\varepsilon, h)=Z_{N^{\prime}}\left(\varepsilon^{\prime}, h^{\prime}\right)
$$

Usando As Eqs. (2.34), (2.35) e (2.37) pode-se escrever

$$
\begin{gathered}
\exp \{-N \mathcal{G}(\varepsilon, h)\}=\exp \left\{-N^{\prime} \mathcal{G}\left(\varepsilon^{\prime}, h^{\prime}\right)\right\} \\
-N g(\varepsilon, h)=-N^{\prime} \mathcal{G}\left(\varepsilon, h^{\prime}\right) \\
\mathcal{G}(\varepsilon, h)=b^{-d} \mathcal{G}\left(\varepsilon^{\prime}, h^{\prime}\right),
\end{gathered}
$$

onde $\mathcal{G}\left(\varepsilon^{\prime}, h^{\prime}\right)$ é a energia livre de Gibbs por super-spin. Aplicando a hipótese de similaridade novamente a $\varepsilon^{\prime}$ e $h^{\prime}$ obtém-se

$$
\varepsilon^{\prime}=b^{x} \varepsilon \quad h^{\prime}=b^{y} h
$$

e então

$$
\mathcal{G}(\varepsilon, h)=b^{-d} \mathcal{G}\left(b^{x} \varepsilon, b^{y} h\right)
$$

Esta equação diz que a energia livre de Gibbs por spin é uma função homogênea generalizada. Assim, a construção de Kadanoff leva à hipótese de escala para funções termodinâmicas, e portanto, derivando $\mathcal{G}(\varepsilon, h)$ em relação a $\varepsilon$ e $h$, encontra-se as mesmas relações de escala obtidas na seção anterior.

A idéia de Kadanoff é então fazer uma transformação de escala diminuindo os graus de liberdade do sistema. Essa transformação conduz a uma nova hamiltoniana mas não altera a função de partição. Isto se justifica porque na criticalidade o comprimento de correlação infinito garante a invariância do comportamento físico do sistema diante de 
mudanças na escala de comprimentos. A transformação de $\mathcal{H}$ para $\mathcal{H}^{\prime}$ é conhecida como uma transformação de grupo de renormalização, formalmente indicada por

$$
\mathcal{H}^{\prime}=R \mathcal{H}
$$

No limite de um sistema infinito, os conjuntos de spins e super-spins tornam-se os mesmos e somente as constantes de acoplamento $K$ mudam em uma transformação de grupo de renormalização. Desta forma, é mais apropriado representar esta transformação por

$$
K^{\prime}=R K
$$

As transformações de grupo de renormalização são assim chamadas porque elas renormalizam as constantes de acoplamento.

Seja $K^{(n)}$ a constante de acoplamento resultante de $n$ aplicações sucessivas de uma transformação do grupo de renormalização. Estas constantes de acoplamento obedecem a relação de recorrência

$$
K^{(n+1)}=R K^{(n)}
$$

Após um certo número de aplicações das relações de recorrência, devemos atingir um ponto fixo $K^{*}$ da transformação ${ }^{\dagger}$, ou seja,

$$
K^{*}=R K^{*}
$$

A hamiltoniana $\mathcal{H}^{*}$ correspondente a $K^{*}$ é chamada de hamiltoniana de ponto fixo. Um ponto fixo poderia ser fisicamente interessante, porque ele é um ponto em que o sistema torna-se invariante sob uma mudança no comprimento de escala. Isto quer dizer que o comprimento de correlação é ou zero ou infinito. O último corresponde a um ponto crítico, que é o caso fisicamente interessante. O caso com o comprimento de correlação zero, corresponde a uma temperatura infinita, e usualmente pode ser reconhecido e

\footnotetext{
${ }^{\dagger}$ Supondo que $K^{(n)}$ aproxima de um ponto fixo quando $n \rightarrow \infty$.
} 
rejeitado.

Subtraindo (2.45) de (2.44) temos

$$
K^{(n+1)}-K^{*}=R K^{(n)}-K^{*}
$$

Para $n$ muito grande, podemos fazer uma aproximação linear

$$
R K^{(n)}=R K^{*}+R Q=K^{*}+\mathbf{L} Q
$$

onde $\mathbf{L}$ é um operador linear. Vamos agora escrever $Q$ numa representação diagonal em relação aos autovetores de $\mathbf{L}$

$$
Q=\sum_{j} h_{j} Q_{j}
$$

tal que

$$
\mathbf{L} Q=\Lambda_{j} Q_{j}
$$

onde $\left\{Q_{j}\right\}$ é um conjunto de operadores de base, enquanto o conjunto de $\left\{h_{j}\right\}$ serve para parametrizar a hamiltoniana inicial. Assim temos

$$
K^{(n)}=K^{*}+\sum_{j} h_{j} \Lambda_{j} Q_{j}
$$

e escrevendo $\Lambda_{j}=b^{\lambda_{j}}$, obtemos

$$
K^{(n)}=K^{*}+\sum_{j} h_{j} b^{n \lambda_{j}} Q_{j}
$$

As sucessivas iterações das relações de recorrência definem linhas de fluxo no espaço dos parâmetros e os valores de $\lambda_{j}$ definem a importância do operador $Q_{j}$ na hamiltoniana. Numa transformação de grupo de renormalização, $\lambda$ é dito ser um fator de escala. Se $\lambda>1, Q_{j}$ é chamado operador relevante porque conduz a hamiltoniana para longe do ponto fixo. Se $\lambda<1$, o operador $Q_{j}$ é dito irrelevante e faz com que o sistema se mova para o ponto crítico independentemente das condições iniciais. O 
caso $\lambda=0$ corresponde a um operador marginal, o qual depende das propriedades do sistema. Neste caso, os expoentes críticos podem variar continuamente em função dos acoplamentos. Alguns dos exemplos da teoria de grupo de renormalização são mostrados na referência [27]. 


\section{Capítulo 3}

\section{Simulações Monte Carlo fora do equilíbrio}

Com o advento e a larga disponibilidade de computadores, as simulações computacionais têm se tornado um método essencial e poderoso no estudo de sistemas de muitos corpos, fazendo um papel intermediário entre modelos teóricos e experimentos. A idéia básica é que, com um computador pode-se seguir explicitamente a trajetória de um sistema que envolve um grande número de graus de liberdade e com isso, obter um prognóstico significativo de suas propriedades.

Embora esse método tenha se tornado importante por volta de 1950, os primeiros estudos estocásticos de sistemas físicos datam do final do século XIX e início do século XX. Na segunda metade do século XIX algumas pessoas realizaram experimentos para obter o valor de $\pi$, como por exemplo A. Hall num artigo cujo título é $O n$ an experimental determination of $\pi$ [28]. Vinte e seis anos mais tarde, Lord Rayleigh mostrou que uma caminhada aleatória unidimensional sem barreiras absorventes poderia fornecer uma solução aproximada para uma equação diferencial parabólica [29]. Em 1908, W.S. Gosset, mais conhecido como Student, usou uma amostragem experimental para descobrir a distribuição do comprimento de correlação [30] e derivar a conhecida distribuição $t$ de Student [31]. Ainda no início do século XX, alguns autores estudaram a relação entre processos estocásticos Markovianos e certas equações integro-diferenciais [32-34]. Den- 
tre todos os trabalhos que usaram essa técnica (até então conhecida como amostragem estatística), talvez um dos mais famosos seja o de Enrico Fermi, que por volta de 1930 usou um método aleatório para calcular as propriedades do nêutron. Uma interessante revisão pode ser encontrada no trabalho de Edoardo Amaldi de 1984 [35] intitulado From the discovery of the neutron to the discovery of nuclear fission.

Até 1945, esses trabalhos eram pontuais e um dos principais motivos era a dificuldade de simular variáveis aleatórias. Com a construção do primeiro computador eletrônico e o seu posterior avanço tecnológico, esse panorama mudou. Agregando-se a isso, a elaboração de geradores de números aleatórios de alta qualidade, a simulação computacional passou a ser considerada uma técnica universal, sendo por exemplo essencial no desenvolvimento do projeto Manhattan. Devido à seu caráter estocástico, ela passou a ser chamada de método Monte Carlo, como uma referência ao famoso cassino Monte Carlo localizado no principado de Mônaco, no distrito de Monte Carlo.

O método Monte Carlo foi desenvolvido por John Von Newmann, Stanislaw Marcin Ulam, Enrico Fermi, Nicholas Metropolis, Arianna Rosenbluth, Marshall Rosenbluth, Augusta Teller e Edward Teller, entre outros, levando à construção da bomba atômica no final da segunda guerra mundial. Este trabalho envolveu uma simulação direta dos problemas probabilísticos (estocásticos) envolvidos com a difusão aleátória de neutron em material radioativo. Em 1949, Metropolis e Ulam publicaram o artigo intitulado The Monte Carlo Method [13] e esse ano passou a ser lembrado como o ano do nascimento desse método. Quatro anos mais tarde, Metropolis et al. realizaram em los Alamos a primeira simulação Monte Carlo em larga escala de um problema de muitos corpos [14]. Embora o computador tenha evoluído significativamente desde então, os fundamentos da técnica computacional permanecem, em grande parte, como eles foram sugeridos por Metropolis et al.

O método Monte Carlo tem sido usado em várias áreas do conhecimento, como por exemplo, na física, química e biologia. Na física, ele é aplicado com sucesso a uma grande extensão de problemas, desde a física de partículas elementares, passando pela física estatística, quântica, biofísica até chegar à astronomia. Outros problemas que po- 
dem ser resolvidos com esse método são, por exemplo, problemas na teoria de transporte, medicina nuclear, finança, meios porosos, química computacional, ciência de materiais, aerodinâmica, filmes gerados computacionalmente, efeitos especiais em filmes e projeto de armas nucleares.

Em física estatística, o método Monte Carlo tem servido como uma técnica padrão para tratar problemas de muitos corpos [36], particularmente quando se trata do estudo de transições de fase e fenômenos críticos, bem como das propriedades termodinâmicas de modelos estatísticos e sistemas reais.

Até recentemente, as propriedades críticas de sistemas estatísticos, como a temperatura crítica e os expoentes críticos, eram obtidos somente a partir de configurações no equilíbrio. Obter numericamente esses valores não era uma tarefa muito fácil, pois como se sabe, simulações numéricas próximas da criticalidade sofrem do chamado critical slowing down ou alentecimento crítico. Esse problema é caracterizado pela divergência do comprimento de correlação, que dificulta a geração de configurações descorrelacionadas para se calcular as médias termodinâmicas. Muitos esforços foram feitos para driblar essa dificuldade. Em 1987, Swendsen e Wang desenvolveram o primeiro algoritmo de cluster (aglomerado) [15] que conseguiu reduzir significantemente o alentecimento crítico. Esse algoritmo se mostrou muito eficiente no estudo das propriedades estáticas dos sistemas. Todavia, nesse caso a classe de universalidade dinâmica original é violada produzindo valores normalmente pequenos para os expoentes críticos dinâmicos. Tomando como exemplo o modelo de Ising, o expoente crítico dinâmico z (que mede a extensão do critical slowing down) foi reduzido de $\sim 2.15$ para $z \leq 0.35$ [15]. Posteriormente, outros algoritmos de cluster foram propostos, incluindo o algoritmo de Wolff [37], o algoritmo de cluster invadido [38,39] e o algoritmo de cluster generalizado de Niedemayer [40]. Alguns outros métodos também se destacam, como por exemplo, o método do ensemble multicanônico [41-44] proposto por Berg et al., a técnica do ensemble entrópico proposto por Lee [45] e o método de histograma de Ferrenberg e Swendsen [46,47], o método do broad histogram de de Oliveira et al. [48-50], o método do histograma plano [51] e o algoritmo de Wang e Landau [52,53]. 
Outra maneira de se eliminar os problemas com o alentecimento crítico foi proposta por Janssen, Schaub e Schimittmann [16]. Eles mostraram que além do bem conhecido comportamento universal no regime de tempos longos (sistemas em equilíbrio estacionário), existe um estágio universal bem antes que o sistema atinja o equilíbrio. Esse novo regime, chamado de regime de tempos curtos, proporcionou novas alternativas para se obter as propriedades críticas dinâmicas, como por exemplo, o expoente crítico dinâmico $z$, tão difícil de ser encontrado no equilíbrio. Para o modelo de Ising por exemplo, existem trabalhos cujos valores de $z$ variam de forma considerável: em duas dimensões $2.10<z<2.52$ e em três dimensões $1.95<z<2.35$. Já com a nova técnica, o valor disponível é $z \sim 2.15$ para o caso bidimensional [54-57] e $z \sim 2.04$ em três dimensões $[57-59]$

Uma nova forma de escala dinâmica foi então encontrada através da análise de grupo de renormalização até segunda ordem em $4-d$ (onde $d$ é a dimensão do sistema) para sistemas de tamanho finito. Para o $k$-ésimo momento da magnetização ela é dada por $[54]$

$$
M^{(k)}\left(t, \varepsilon, L, m_{0}\right)=b^{-\frac{k \beta}{\nu}} M^{(k)}\left(b^{-z} t, b^{1 / \nu} \varepsilon, b^{-1} L, b^{x_{0}} m_{0}\right)
$$

onde $t$ é o tempo de evolução dinâmico, $\varepsilon=\left(T-T_{c}\right) / T_{c}$ é a temperatura reduzida, $L$ é o tamanho linear da rede e $b$ é um fator de escala espacial arbitrário. Os expoentes $\beta$ e $\nu$ são os conhecidos expoentes críticos estáticos, relacionados respectivamente com o parâmetro de ordem e o comprimento de correlação, e z é o expoente crítico dinâmico que caracteriza correlações temporais no equilíbrio.

Além dos expoentes mencionados acima, um novo expoente crítico dinâmico independente é encontrado nesse novo estágio universal. Quando se escolhe o fator de escala $b=t^{1 / z}$ na Eq. (3.1), se obtém para o primeiro momento da magnetização

$$
M(t) \sim m_{0} t^{\theta}
$$

onde $m_{0}$ representa a magnetização inicial do sistema na temperatura crítica $(\varepsilon=0)$ e o expoente $\theta$ caracteriza o critical initial slip (ou escorregão crítico inicial), o comporta- 
mento anômalo da magnetização quando o sistema é levado de regiões de alta temperatura para a temperatura crítica $T_{c}$. Como deduzido por Janssen et al. [16], o comportamento de escala inicial surge em pontos fixos sobre a transformação de grupo de renormalização. De fato, pode-se ver dois pontos fixos para os estados iniciais, $m_{0}=0$ e $m_{0}=1 \mathrm{e}$ em geral, as simulações são executadas em torno desses dois pontos.

O critical initial slip é a conseqüência de uma competição entre o crescimento de domínios e a flutuação do sistema. Longe do equilíbrio, o tamanho do domínio e a flutuação são pequenos mas o domínio cresce rapidamente devido a um efeito do tipo campo médio. Esse inesperado crescimento de domínios, que foi inicialmente previsto por Janssen et al. [16] e depois observado por vários autores [17,60,61], se dá logo no início da evolução temporal e o efeito global é um surpreendente crescimento da magnetização, como é mostrado na Figura 3.1. O valor máximo da magnetização é atingido quando

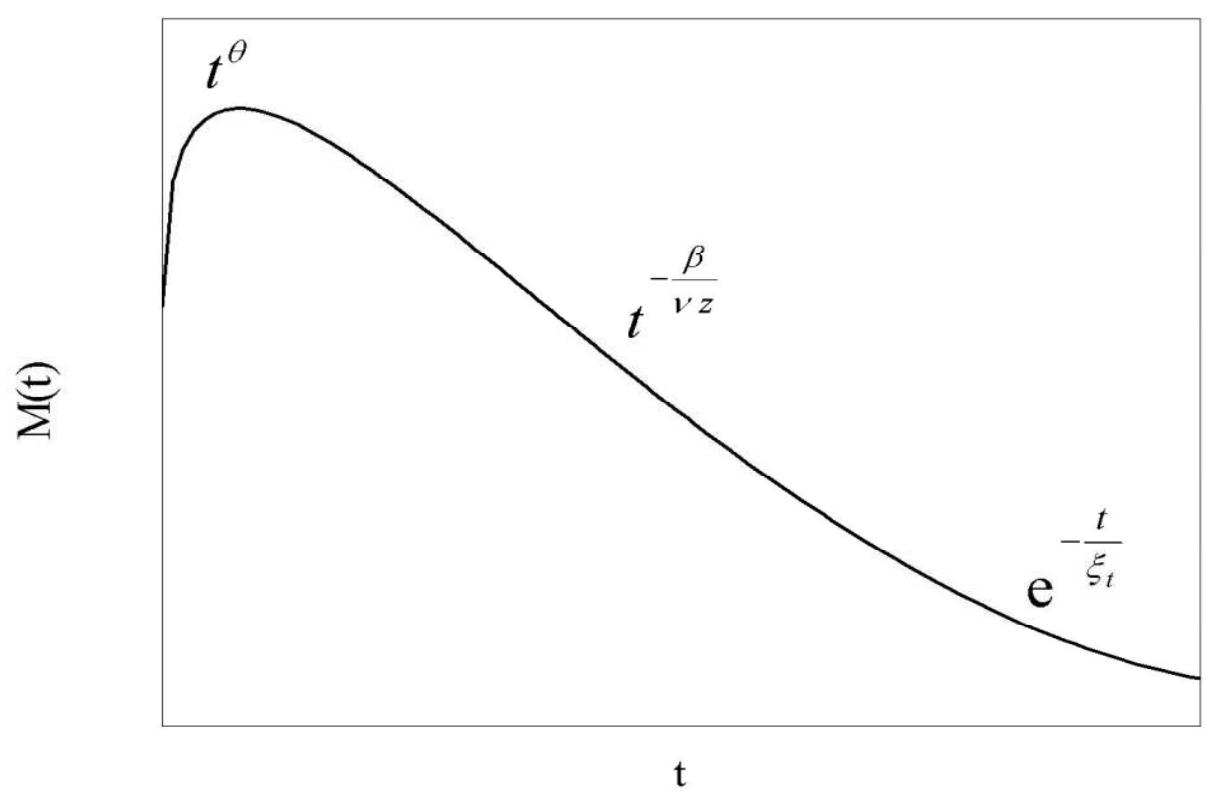

Figura 3.1: O comportamento qualitativo da evolução temporal da magnetização partindo de um valor não nulo na criticalidade.

esses domínios se saturam e as flutuações se tornam mais fortes. Depois disso, ela passa a decrescer de acordo com o conhecido comportamento universal do regime de tempos 
longos. Primeiramente um decaimento em lei de potências,

$$
M(t) \sim t^{-\frac{\beta}{\nu z}}
$$

e em seguida um decréscimo exponencial

$$
M(t) \sim \mathrm{e}^{-\frac{t}{\xi_{t}}}
$$

onde $\xi_{t}$ é o comprimento de correlação temporal.

Como será mostrado no Capítulo 6, embora um valor positivo fosse inicialmente associado ao expoente $\theta$, resultados mais recentes têm mostrado que em alguns modelos, $\theta$ pode ser negativo. Esta possibilidade foi observada para os modelos de Blume-Capel [62,63], Baxter-Wu [64], Potts com quatro estados [65,66] e para o modelo de Ising com interações de três spins em uma direção [21,67].

Além do novo expoente $\theta$, o expoente $x_{0}$ que representa a dimensão anômala da magnetização inicial $m_{0}$ é introduzido para descrever a dependência do comportamento de escala sobre as condições iniciais do sistema. Este expoente está relacionado à $\theta$ pela equação

$$
x_{0}=\theta z+\frac{\beta}{\nu}
$$

Em resumo, as simulações Monte Carlo em tempos curtos têm se mostrado muito eficientes na obtenção da temperatura crítica e dos conhecidos expoentes críticos estáticos e dinâmicos encontrados no regime de tempos longos, e vai além, porque amplia o entendimento dos fenômenos críticos, uma vez que outros expoentes são necessários para descrever o comportamento de escala dinâmica no início da evolução temporal.

\subsection{O expoente crítico dinâmico $z$}

Como já mencionado anteriormente, no equilíbrio os sistemas sofrem do chamado critical slowing down ou alentecimento crítico. Este problema, que dificulta a geração de configurações independentes nas proximidades do ponto crítico, está relacionado 
às correlações temporal $(\tau)$ e espacial $(\xi)$ pela expressão

$$
\tau \sim \xi^{z}
$$

onde $z$ é o expoente crítico dinâmico que caracteriza esse comportamento slowing down do sistema. Nas proximidades da temperatura crítica, o comprimento de correlação é da ordem to tamanho do sistema, ou seja $\xi \sim L$. Para um sistema onde $z>1$, por exemplo o modelo de Ising bidimensional $(z \sim 2.15)$, a correlação temporal aumenta rapidamente com o tamanho da rede e, conseqüentemente, as configurações do sistema (durante a sua evolução) ficam muito correlacionadas, provocando assim o alentecimento crítico.

No regime de tempos curtos, o expoente $z$ pode ser estimado usando-se várias técnicas diferentes. As técnicas utilizadas nesta tese são o cumulante de Binder de quarta ordem dependente do tempo $[54,68]$ e uma técnica que combina resultados obtidos de amostras submetidas a diferentes condições iniciais [56]. O cumulante de Binder pode ser obtido tanto com $m_{0}=0$ como com $m_{0}=1$ e é dado por $[54,68]$

$$
U_{4}(t, L)=1-\frac{M^{(4)}}{3\left[M^{(2)}\right]^{2}},
$$

onde $M^{(k)}$ é a média do $k$-ésimo momento da magnetização sobre diferentes amostras. Na temperatura crítica, esta equação depende somente de $t / L^{z}$, de acordo com as leis de escala válidas no início da evolução. Neste caso, com a relação de escala dada pela Eq. (3.1), os cumulantes obtidos com duas redes diferentes, $L_{1}$ e $L_{2}$, obedecem a equação

$$
U_{4}\left(t, L_{1}\right)=U_{4}\left(b^{-z} t, L_{2}\right)
$$

$\operatorname{com} b=L_{2} / L_{1}$. Esta equação mostra que o expoente $z$ pode é obtido encontrando o fator de reescala temporal $b^{-z}$ que colapse as curvas para as duas redes de tamanhos diferentes. No segundo método, o expoente $z$ é obtido a partir de simulações realizadas com diferentes condições iniciais $\left(m_{0}=1\right.$ e $\left.m_{0}=0\right)$ da seguinte forma: para o cálculo do 
segundo momento da magnetização,

$$
M^{(2)}(t) \sim t^{\frac{d-2 \beta / \nu}{z}}
$$

as amostras são preparadas com $m_{0}=0$ e para o cálculo da magnetização,

$$
M(t) \sim t^{-\frac{\beta}{\nu z}}
$$

as amostras são preparadas com $m_{0}=1$. De acordo com a referência [56] a função $F_{2}(t)$, dada por,

$$
F_{2}(t)=\frac{M^{(2)}(t)}{[M(t)]^{2}}
$$

se comporta como $t^{\alpha}$, onde $\alpha=d / z$ e $d$ é a dimensão do sistema. Este método tem se mostrado muito eficiente na obtenção do expoente $z$ para diversos modelos onde foi testado $[21,56,63,64,66,69,70]$.

\subsection{O expoente crítico dinâmico $\theta$}

O expoente crítico $\theta$ tem sido habitualmente calculado usando a Eq. (3.2) ou através da autocorrelação

$$
A(t)=\langle S(0) S(t)\rangle \sim t^{\theta-\frac{d}{z}}
$$

onde $d$ é a dimensão do sistema. No primeiro caso, além de um delicado limite de $m_{0} \rightarrow$ 0, é essencial preparar cuidadosamente as configurações iniciais do sistema com uma magnetização inicial pequena $\left(m_{0} \sim 0\right)$. Já na autocorrelação, o expoente $\theta$ não é obtido diretamente, sendo necessário obter previamente o valor de $z$.

Em 1998, um outro método foi proposto por Tomé e de Oliveira [71]. Eles mostraram que a correlação temporal da magnetização

$$
C(t)=\langle M(0) M(t)\rangle
$$

comporta-se como $t^{\theta}$ na temperatura crítica. Nessa equação, a média é sobre um conjunto 
de configurações iniciais aleatórias, sendo a única exigência que $\langle M(0)=0\rangle$. A média $\langle\cdot\rangle$ é feita sobre as amostras em $t=0$. Inicialmente, esta proposta parecia ser válida somente para modelos que exibiam simetria up-down [71]. Contudo, foi demonstrado recentemente que a Eq. (3.13) é mais geral, podendo incluir modelos com outras simetrias [72].

Quando comparado com as outras duas técnicas (Eq.(3.2) e Eq. (3.12)), este método tem no mínimo duas vantagens. Além de não ser necessário uma preparação cuidadosa das configurações iniciais $\left(m_{0} \sim 0\right)$ nem de um delicado limite $m_{0} \rightarrow 0$, não é preciso conhecer antecipadamente o expoente $z$ (veja a Eq. (3.12)), que é uma ordem de magnitude maior do que $\theta$. Naquele caso, um pequeno erro relativo em $z$ induz um grande erro em $\theta$.

\subsection{O expoente crítico dinâmico $\theta_{g}$}

Longe do equilíbrio, outro expoente crítico dinâmico foi recentemente proposto [18] para descrever o comportamento da probabilidade de persistência global $P(t)$, a probabilidade que o parâmetro de ordem tem de não mudar seu sinal até o tempo $t$. Tomando como exemplo o modelo de Ising, o parâmetro de ordem é a magnetização e $P(t)$ é a fração de amostras que ainda não mudaram de sinal até o tempo $t$.

Na criticalidade, $P(t)$ decai algebricamente como

$$
P(t) \sim t^{-\theta_{g}}
$$

onde $\theta_{g}$ é o expoente de persistência global. Desde então, o estudo do comportamento de persistência tem atraido um enorme interesse, desempenhando um papel importante em sistemas fora do equilíbrio [18, 21,66,73-85].

Como a evolução temporal do parâmetro de ordem não é, em geral, um processo Markoviano, esse novo expoente crítico é independente dos demais expoentes. Todavia, como argumentado por Majumdar et al. [18], se o parâmetro de ordem for descrito por um processo Markoviano, $\theta_{g}$ não será independente, sendo relacionado a outros expoentes 
críticos pela relação

$$
\theta_{g}=\alpha_{g}=-\theta+\frac{d}{z^{2}}-\frac{\beta}{\nu z}
$$

A probabilidade de persistência global $P(t)$ pode ser definida como

$$
P(t)=1-\sum_{t^{\prime}=1}^{t} \rho\left(t^{\prime}\right),
$$

onde $\rho\left(t^{\prime}\right)$ é a fração das amostras que mudaram seu estado pela primeira vez no instante $t^{\prime}$

O expoente dinâmico $\theta_{g}$ que governa o comportamento de $P(t)$ na criticalidade é obtido através de dois diferentes métodos: a aplicação direta do comportamento em lei de potências da Eq. (3.14) e por meio do colapso de duas curvas obtidas com redes de tamanhos diferentes.

No primeiro método a relação de escala dada pela Eq. (3.14) é utilizada para obter $\theta_{g}$ como função de $m_{0}$ para vários valores da magnetização inicial. De forma similar à Eq. (3.2), aqui é necessário trabalhar com um valor pequeno e preciso da magnetização inicial, $m_{0} \sim 0$ e a estimativa final de $\theta_{g}$ é obtida extrapolando essas séries para o limite em que $m_{0} \rightarrow 0$.

No segundo método, usa-se o fato de que a dependência de $P(t)$ sobre a magnetização inicial pode ser perdida na seguinte relação de escala de tamanho finito [18]

$$
P(t)=t^{-\theta_{g}} f\left(t / L^{z}\right)=L^{-\theta_{g} z} \tilde{f}\left(t / L^{z}\right),
$$

onde $z$ é o expoente dinâmico. Assim, a quantidade $L^{\theta_{g} z} P(t)$ é uma função universal do tempo escalado $\left(t / L^{z}\right)$ e o valor desejado de $\theta_{g}$ é aquele que satisfaz essa condição para diferentes redes.

Diferente do primeiro método e parecido com a correlação temporal da magnetização [veja a Eq. (3.13)], no método do colapso o expoente $\theta_{g}$ é obtido sem a necessidade de uma preparação cuidadosa da magnetização inicial e nem do limite $m_{0} \rightarrow 0$. A única exigência nesse caso é que $\langle M(0)=0\rangle$ onde $\langle\cdot\rangle$ é uma média feita sobre as amostras 
em $t=0$. Por outro lado, o método do colapso requer que o expoente dinâmico $z$ seja conhecido antecipadamente.

\subsection{Os expoentes críticos estáticos $\nu$ e $\beta$}

O expoente estático $\nu$ pode ser obtido fixando-se $b=t^{1 / z}$ e $k=1$ na Eq. (3.1),

$$
M(t, \varepsilon)=t^{-\beta / \nu z} M\left(1, \varepsilon^{1 / \nu z}\right)
$$

e diferenciando $\ln M(t, \varepsilon)$ com respeito a $\varepsilon$ na temperatura crítica. Considerando amostras com configurações iniciais ordenadas $\left(m_{0}=1\right)$, obtém-se a seguinte lei de potência:

$$
D(t)=\left.\partial_{\varepsilon} \ln M(t, \varepsilon)\right|_{\varepsilon=0} \sim t^{1 / \nu z}
$$

Usando o expoente $z$ obtido anteriormente (por exemplo com $U_{4}(t), F_{2}(t)$ ou $R(t)$ ), o expoente $\nu$ pode ser obtido através de um simples cálculo.

Tendo agora os valores de $1 / \nu z$ em mãos, é possível obter o expoente $\beta$ encontrado através da lei de escala para a magnetização, no ponto crítico,

$$
M(t) \sim t^{-\beta / \nu z}
$$

Esta relação pode ser facilmente obtida da Eq. (3.1), considerando redes grandes e fazendo $b=t^{1 / z}$ na temperatura crítica $\varepsilon=0$.

Usando os resultados obtidos para $1 / \nu z$, encontra-se o valor do expoente estático $\beta$. 


\section{Capítulo 4}

\section{O modelo de dupla-troca}

\subsection{Introdução}

Durante os últimos anos, um grande número de trabalhos teóricos e experimentais tem sido publicados sobre manganitas perovskitas do tipo $A_{1-x} B_{x} \mathrm{MnO}_{3}$, onde $A$ é uma terra rara tal como La, Pr e Nd, B é um elemento divalente tal como Ca, Ba, Pb e Sr, e $x$ é a concentração de $B$. Tal atenção é devido principalmente ao redescobrimento da magnetoresistência colossal (MRC) [86-89], uma mudança extremamente grande de resistividade quando um campo magnético é aplicado na vizinhança da temperatura crítica $T_{c}$. Além do efeito de MRC, esses óxidos de manganês possuem transições metal-isolante, bem como uma rica variedade de propriedades físicas (propriedades óticas, elétricas e magnéticas) e aplicações tecnológicas, como por exemplo, em sensores magnéticos e tecnologia de memória para computadores, chegando a ter atividades comparadas às dos metais nobres [90].

A manganita é um mineral cinza-azulado ou preto que ocorre como minério de manganês e a perovskita se refere à forma cristalina que a manganita pode tomar (veja a Figura 4.1).

Nesses compostos, a transição metal-isolante associada com um alinhamento ferromagnético dos spins tem sido usualmente estudada através da teoria de dupla troca [91-95]. A idéia básica dessa teoria é que cada íon de manganês $\left(\mathrm{Mn}^{3+}\right)$ possui um spin $S$, e uma fração $(1-x)$ desses íons tem um elétron extra nos orbitais $e_{g}\left(\mathrm{Mn}^{4+}\right)$ com 


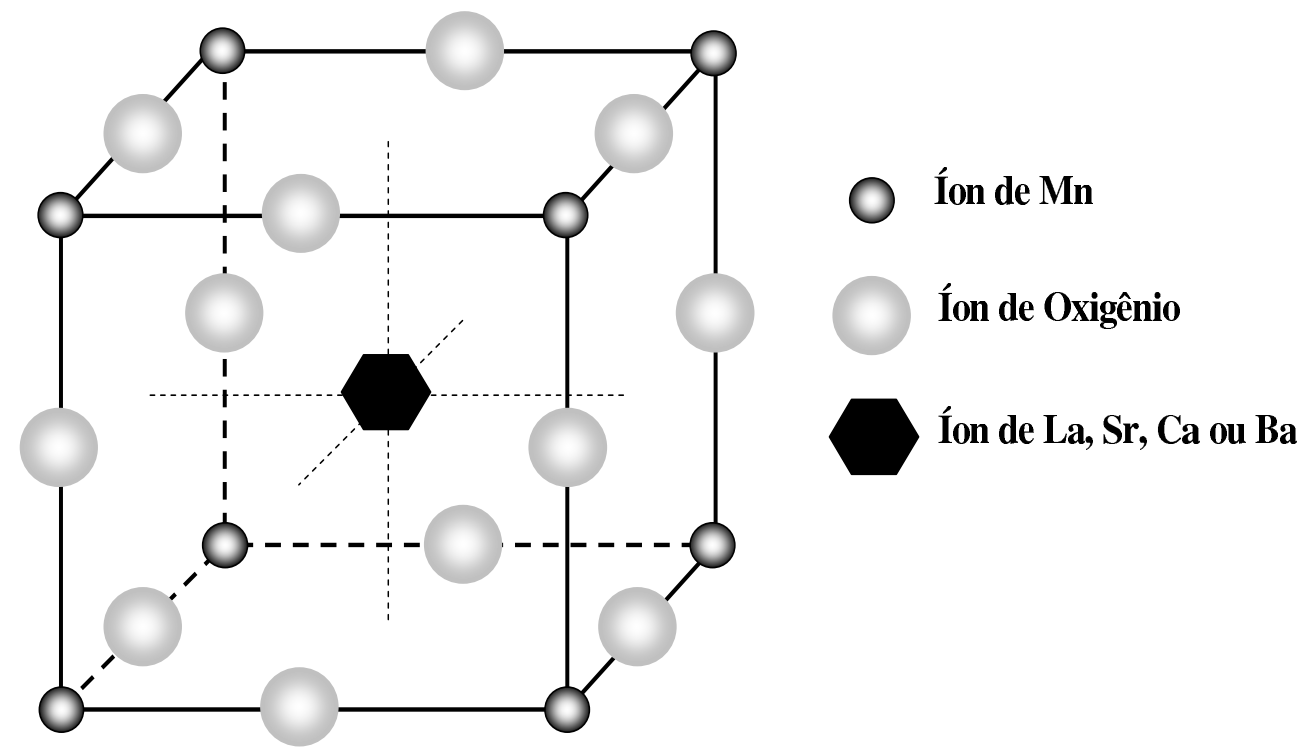

Figura 4.1: A estutura dos compostos de manganita com rede perovskita.

spin paralelo ao spin $S$ devido a uma forte troca intra-sítio. Havendo um íon $\mathrm{Mn}^{3+}$ (no sítio $i$ ) e um íon $\mathrm{Mn}^{4+}$ (no sítio $j$ ) separados por um oxigênio (veja a Figura 4.1), o elétron $e_{g}$ pode passar de um íon para o outro da seguinte forma: um elétron do oxigênio intermediário salta para um orbital $e_{g}$ do $\mathrm{Mn}^{4+}$ e o elétron $e_{g}$ do $\mathrm{Mn}^{3+}$ salta para fechar o buraco deixado no oxigênio. O resultado líquido é a mudança de um elétron de um sítio $i$ para um sítio $j$. Quando essa mudança acontece, o spin do elétron muda de forma que $S_{i}$ seja paralelo a $S_{j}$, com uma perda de energia proporcional ao cosseno de metade do ângulo entre os spins [92].

Embora essa teoria tenha obtido sucesso em explicar qualitativamente a MRC, alguns autores argumentam que ela sozinha não pode fornecer uma descrição completa desse fenômeno. Eles sugerem que, além dessa teoria, um entendimento completo desses materiais deve incluir correlações fortes de elétrons [96], uma forte interação elétronfônon [97] ou coexistência de fases [98]. Conseqüentemente, pode-se pensar que somente a teoria de dupla troca não consegue explicar a MRC nas manganitas. Todavia, esta ainda é uma questão em aberto. O que se sabe é que, a teoria de dupla troca tem um papel importante, tanto no estudo da MRC como para explicar a presença de um estado ferromagnético em manganitas dopadas $(x \approx 0.3)$, fornecendo a base para a descrição das manganitas com magnetoresistência colossal. 
A hamiltoniana de um modelo de spin clássico com interação de dupla troca é dada por [99]

$$
\mathcal{H}=-\sum_{\langle i, j\rangle} J \sqrt{1+\mathbf{S}_{i} \cdot \mathbf{S}_{j}}
$$

onde $\langle i, j\rangle$ indica que a soma é sobre todos os pares de primeiros vizinhos, $J$ é a constante de acoplamento ferromagnética e o spin $\mathbf{S}_{i}=\left(S_{i}^{x}, S_{i}^{y}, S_{i}^{z}\right)$ é um vetor tridimensional de comprimento unitário situado nos sítios de uma rede cúbica simples $L \times L \times L$.

Seu parâmetro de ordem é a magnetização total que é dada pela raiz quadrada do vetor da magnetização espontânea $\mathbf{M}$ dada por [100],

$$
M=\sqrt{M_{x}^{2}+M_{y}^{2}+M_{z}^{2}},
$$

onde

$$
M_{\alpha}=\frac{1}{L^{3}} \sum_{i} S_{i}^{\alpha}
$$

Como mostrado no capítulo anterior, somente dois pontos fixos para as configurações iniciais são encontrados quando se estuda sistemas fora do equilíbrio. Um deles está relacionado à configuração inicial desordenada $\left(m_{0}=0\right)$ e o outro à configuração inicial ordenada $\left(m_{0}=1\right)$. No caso do modelo de dupla troca, a configuração desordenada foi obtida através da escolha aleatória de metade dos sítios da rede como estando com um spin $S=S^{z}=(0,0,1)$ e a outra metade dos sítios com spin $S=S^{z}=(0,0,-1)$. Como resultado líquido, a magnetização inicial do sistema é dada por

$$
m_{0}=M_{z}=\frac{1}{L^{3}} \sum_{i} S_{i}^{z}=0 .
$$

Por outro lado, $m_{0}=1$ foi obtido colocando em todos os sítios da rede o spin $S=S^{z}=$ $(0,0,1)$, ou seja,

$$
m_{0}=M_{z}=\frac{1}{L^{3}} \sum_{i} S_{i}^{z}=1 .
$$

As propriedades críticas do modelo de dupla troca têm sido exaustivamente estudadas usando simulações Monte Carlo. As estimativas para os expoentes críticos es- 
táticos, encontrados no equilíbrio [99,101,102], indicam que esse modelo pertence à mesma classe de universalidade do modelo de Heisenberg clássico. Além disso, vários trabalhos experimentais sobre as propriedades críticas das manganitas perovskitas dopadas também sustentam essa afirmação [103-105].

Nós estudamos as propriedades críticas estáticas e dinâmicas do modelo de dupla troca através de simulações Monte Carlo fora do equilíbrio. As estimativas para os expoentes críticos dinâmicos $z, \theta$ e $\theta_{g}$ foram obtidas usando diferentes técnicas $[70,85]$.

Como mostrado a seguir, as simulações foram efetuadas para redes de tamanho $L=20,25,30,40,50$ e 60 com o sistema na temperatura crítica [99]

$$
T_{c}=0.74515
$$

em unidades de $J / k_{B}$, onde $k_{B}$ é a constante de Boltzmann. Como estamos trabalhando com redes tridimensionais, uma rede de tamanho linear $L=60$ possui um total de $2.16 \times$ $10^{5}$ spins que equivale a uma rede de tamanho linear $L \sim 465$ em duas dimensões. Os spins foram atualizados localmente pelo algoritmo de Metropolis [14] e os expoentes e seus respectivos erros foram estimados a partir de 5 simulações independentes com, no máximo, 10.000 amostras independentes cada uma [70,85].

\subsection{O expoente crítico dinâmico $z$}

O expoente $z$ foi estimado usando duas diferentes técnicas [70]. Inicialmente, seu valor foi obtido através do cumulante de Binder de quarta ordem dependente do tempo [veja a Eq. (3.7)] com configurações iniciais ordenadas $\left(m_{0}=1\right)$.

A Figura 4.2 mostra o cumulante de Binder como uma função do tempo para as redes de tamanho $L_{1}=40$ e $L_{2}=60$.

A melhor estimativa de $z$ obtida através do teste do $\chi^{2}$ [106] é

$$
z=1.98(3) .
$$




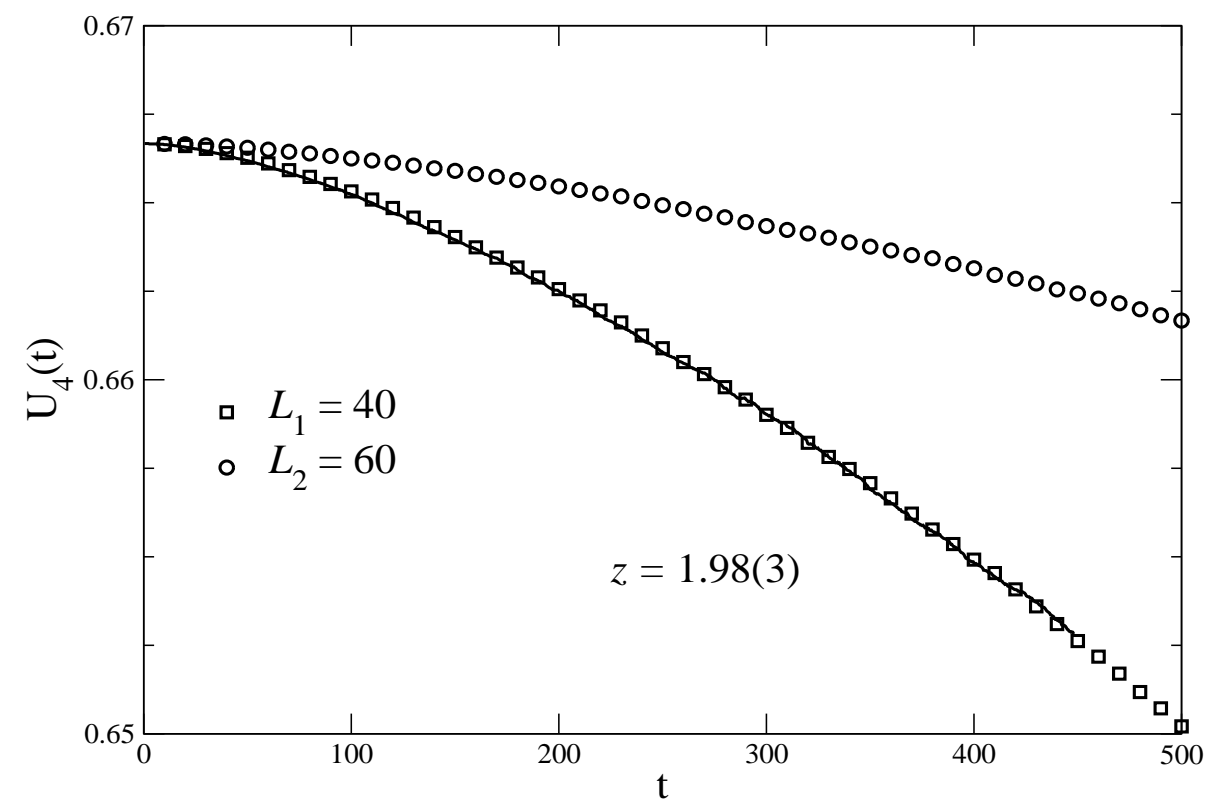

Figura 4.2: O cumulante $U_{4}(t)$ para $L_{1}=40$ e $L_{2}=60$ versus o tempo $t$. O cumulante para ambas as redes foi obtido de 5 conjuntos independentes. Para $L_{1}=40$ foram usados 5000 amostras e que para $L_{2}=60,2000$ amostras.

Este valor é consistente com o resultado obtido por Peczak e Landau [107] para o modelo de Heisenberg clássico. Trabalhando no equilíbrio, esses autores encontraram $z=1.96(7)$. O expoente $z$ também foi estimado para outras redes e os resultados são consistentes com a Eq. (3.7). Para $L_{1}=40$ e $L_{2}=25$ foi obtido $z=1.96(2)$, enquanto que para $L_{1}=60$ e $L_{2}=30$ a melhor estimativa de $z$ foi $z=1.96(4)$.

No segundo método usado neste trabalho, o expoente $z$ foi obtido combinando resultados de amostras submetidas a diferentes condições iniciais $\left(m_{0}=1\right.$ e $\left.m_{0}=0\right)$, como mostrado na Eq. (3.11).

Na Figura 4.3 a evolução temporal de $F_{2}(t)$ é mostrada em escala log-log para uma rede de tamanho $L=60$.

Da inclinação dessa curva se obtém $d / z=1.519(8)$ e conseqüentemente,

$$
z=1.975(10)
$$

Os valores de $d / z$ e $z$ para os cinco tamanhos de redes consideradas nesse trabalho são mostrados na Tabela 4.1.

Esses resultados mostram que para $L \geq 25$ os efeitos de tamanho finito são 


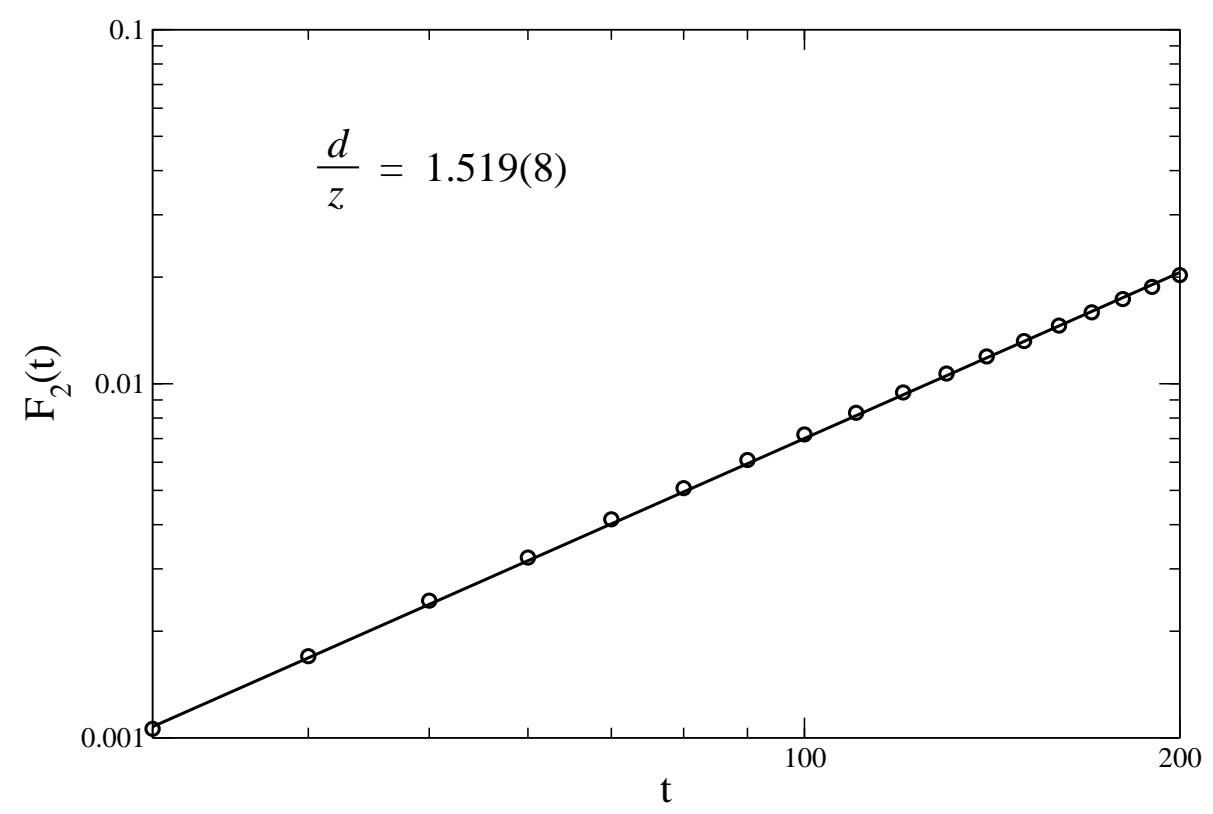

Figura 4.3: A evolução temporal de $F_{2}(t)$. As barras de erro, calculadas através de 5 conjuntos de 2000 amostras, são menores que os símbolos.

Tabela 4.1: O expoente crítico dinâmico $z$ para o modelo de dupla troca.

\begin{tabular}{ccc}
\hline \hline$L$ & $d / z$ & $z$ \\
\hline 20 & $1.499(1)$ & $2.001(1)$ \\
25 & $1.515(2)$ & $1.980(3)$ \\
30 & $1.521(5)$ & $1.972(6)$ \\
40 & $1.525(7)$ & $1.967(9)$ \\
60 & $1.519(8)$ & $1.975(10)$ \\
\hline \hline
\end{tabular}

menores que os erros estatísticos. Conseqüentemente os valores para uma rede infinita $(L=\infty)$ estão dentro das barras de erro dos resultados para $L=60$. É importante notar a maior precisão da estimativa feita com a função $F_{2}$ que reduz o intervalo de variação a $1.965 \leq z \leq 1.985$, a ser comparado com $1.95 \leq z \leq 2.01$ obtido pela técnica do cumulante de Binder generalizado.

\subsection{O expoente crítico dinâmico $\theta$}

O expoente crítico dinâmico $\theta$ foi estimado através da correlação temporal da magnetização, $C(t)$, dada pela Eq. (3.13).

A Figura 4.4 mostra a dependência temporal de $C(t)$ em escala log-log para o sistema com $L=60$. 


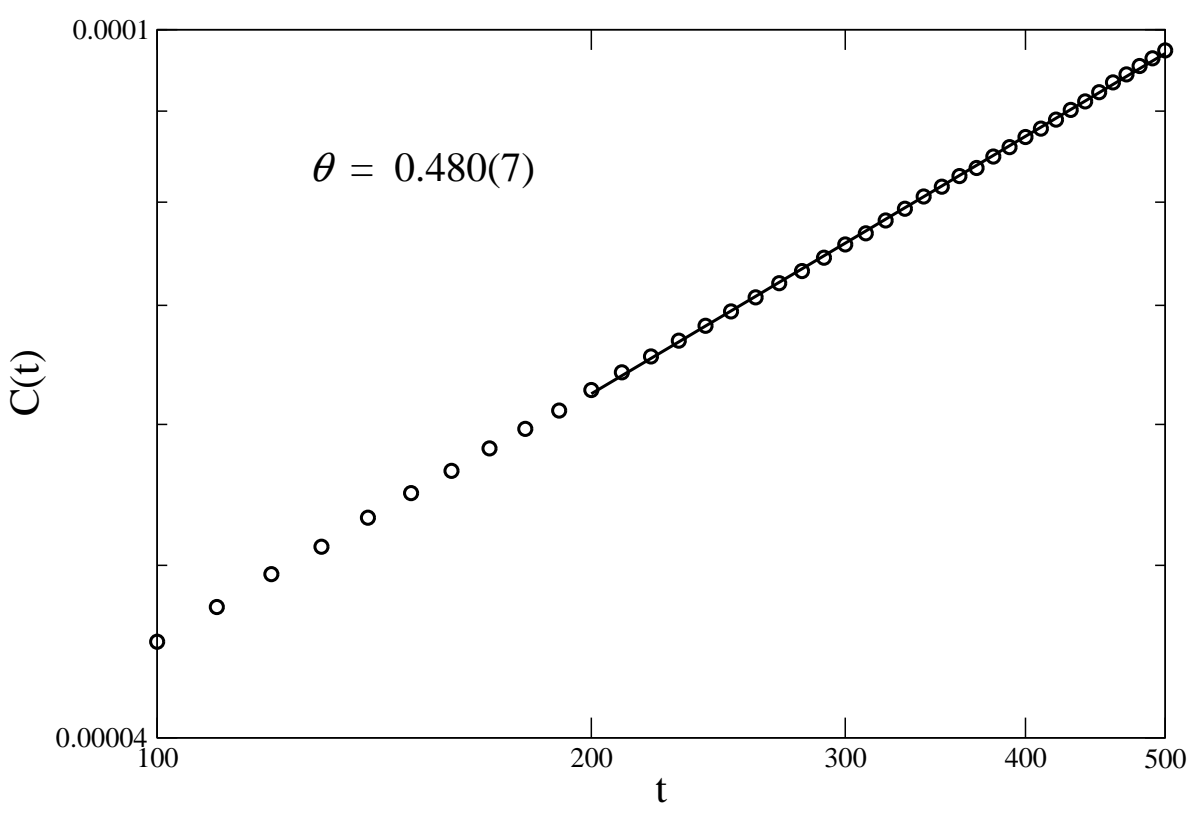

Figura 4.4: A evolução temporal de $C(t)$ em escala log-log. As barras de erro são menores que os símbolos. Cada ponto representa uma média sobre 5 conjuntos de 2000 amostras.

A Tabela 4.2 mostra as estimativas para o expoente crítico $\theta$ para cinco diferentes tamanhos de rede. Os resultados mostrados nessa tabela também indicam que para

Tabela 4.2: O expoente crítico dinâmico $\theta$ para o modelo de dupla troca.

\begin{tabular}{cc}
\hline \hline$L$ & $\theta$ \\
\hline 20 & $0.460(4)$ \\
25 & $0.473(4)$ \\
30 & $0.479(8)$ \\
40 & $0.482(4)$ \\
60 & $0.480(7)$ \\
\hline \hline
\end{tabular}

$L=20$, os efeitos do tamanho do sistema influenciam nos resultados. Já para $L \geq 25$ esses efeitos são menores que os erros estatísticos.

Como estamos trabalhando com um modelo que possui simetria contínua, é válido explicar aqui como obter $\langle M(0)=0\rangle$, que é a única condição necessária para se obter, a partir da Eq. (3.13), um comportamento do tipo $t^{\theta}$. Neste caso, existem duas possibilidades para a configuração inicial do sistema que, como explicado no capítulo anterior, é totalmente aleatória: os spins podem estar orientados em um único eixo (o eixo $z$ por exemplo), ou seja, $\mathbf{S}=\left(0,0, S^{z}\right)$, ou estarem orientados aleatoriamente no espaço, $\mathbf{S}=\left(S^{x}, S^{y}, S^{z}\right)$. Embora tenhamos verificado que estas duas possibilidades conduzem ao mesmo resultado, optamos pela segunda alternativa por ser mais geral e não 
acrescentar tempo computacional. Todavia, como veremos na próxima seção, quando é necessário que a magnetização inicial do sistema seja pequena e bem definida, a segunda possibilidade se torna ineficiente, induzindo além de um gasto computacional maior, uma possível imprecisão nos resultados.

\section{$4.4 \mathrm{O}$ expoente $\theta_{g}$ da persistência global}

O expoente crítico dinâmico $\theta_{g}$, que governa o comportamento da probabilidade de persistência global $P(t)$ na criticalidade, foi obtido através das duas técnicas [85] mostradas no capítulo anterior: o comportamento tipo lei de potência da Eq. (3.14) e o colapso das curvas para diferentes tamanhos de rede (veja a Eq. (3.17)).

No primeiro método, a relação de escala dada pela Eq. (3.14) é usada para obter $\theta_{g}$ como uma função de $m_{0}$. Como já foi explicado, nesse caso é necessário trabalhar com um valor pequeno e preciso da magnetização inicial, $m_{0} \sim 0$. A estimativa final de $\theta_{g}$ é então obtida quando se extrapola essas séries para o limite em que $m_{0} \rightarrow 0$. Todavia, se tentarmos obter o valor de $m_{0}$ da mesma forma que fizemos na seção anterior, precisaremos colocar um limite em sua precisão uma vez que a variável de spin é contínua, o que torna impossível obter um valor exato de $m_{0}$. Isto acontece porque os spins estão livres para se mover em qualquer direção e por mais que procuremos, de forma aleatória, uma configuração que satisfaça a condição

$$
\frac{1}{L^{3}} \sum_{i} S_{i}^{x}=m_{0}^{x}, \quad \frac{1}{L^{3}} \sum_{i} S_{i}^{y}=m_{0}^{y}, \quad \frac{1}{L^{3}} \sum_{i} S_{i}^{z}=m_{0}^{z}
$$

não encontraremos. A alternativa viável é considerar a configuração inicial como sendo composta de spins orientados em um único eixo (o eixo $z$ por exemplo). Desta forma, para se obter um valor preciso de $m_{0}=m_{0}^{z}$ basta escolher metade dos sítios da rede como estando ocupados com spins $S=S^{z}=(0,0,1)$ e a outra metade dos sítios com spins $S=S^{z}=(0,0,-1)$. Finalmente, um valor preciso de $m_{0}$ é obtido quando se escolhe aleatoriamente $m_{0} L^{3} / 2$ sítios ocupados por $S=S^{z}=(0,0,-1)$ e os substitui por $S=S^{z}=(0,0,1)$. Para verificar a validade dessa aproximação, nós resolvemos 
simular um sistema com essas duas condições iniciais (os spins no espaço ou no eixo $z$ ). Nossos resultados foram idênticos (dentro da barra de erros) o que nos permite iniciar as simulações com os spins somente no eixo $z$ sem comprometer nossos resultados, além de tornar as simulações mais rápidas.

A Figura 4.5 mostra o decaimento da probabilidade de persistência global para $L=60$ e $m_{0}=0.00125$ em escala log-log.

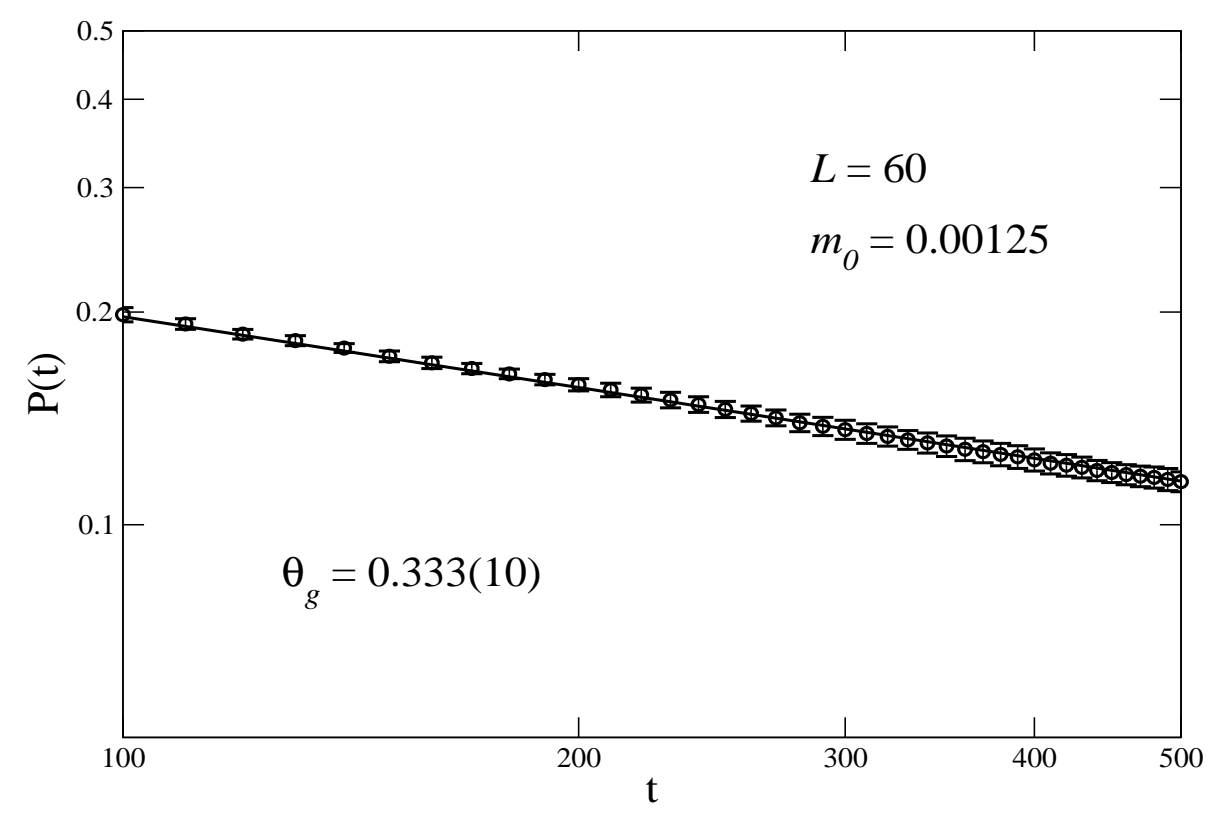

Figura 4.5: A evolução temporal da probabilidade de persistência global $P_{g}(t)$ para uma rede de tamanho $L=60$ e $m_{0}=0.00125$. Cada ponto e sua respectiva barra de erro foram calculados a partir de 5 conjuntos com 5000 amostras cada.

Já a Figura 4.6 exibe o comportamento do expoente $\theta_{g}$ para $m_{0}=0.005,0.0025$, 0.00125, bem como uma extrapolação linear que leva ao valor

$$
\theta_{g}=0.336(9)
$$

A Tabela 4.3 mostra os valores de $\theta_{g}$ em função de diferentes magnetizações iniciais $m_{0}$ para outras redes. Os resultados obtidos através das extrapolações lineares de $m_{0} \rightarrow 0$ são mostrados na última coluna.

As estimativas de $\theta_{g}$ para as redes ímpares $L=25$ e $L=35$ foram obtidas para valores diferentes de $m_{0}$. As magnetizações iniciais $m_{0}=0.0064,0.0032$ e 0.0016 $\left(m_{0} \approx 0.0056,0.0028\right.$ e 0.0014$)$ foram usadas para $L=25(L=35)$ e o valor extrapolado 


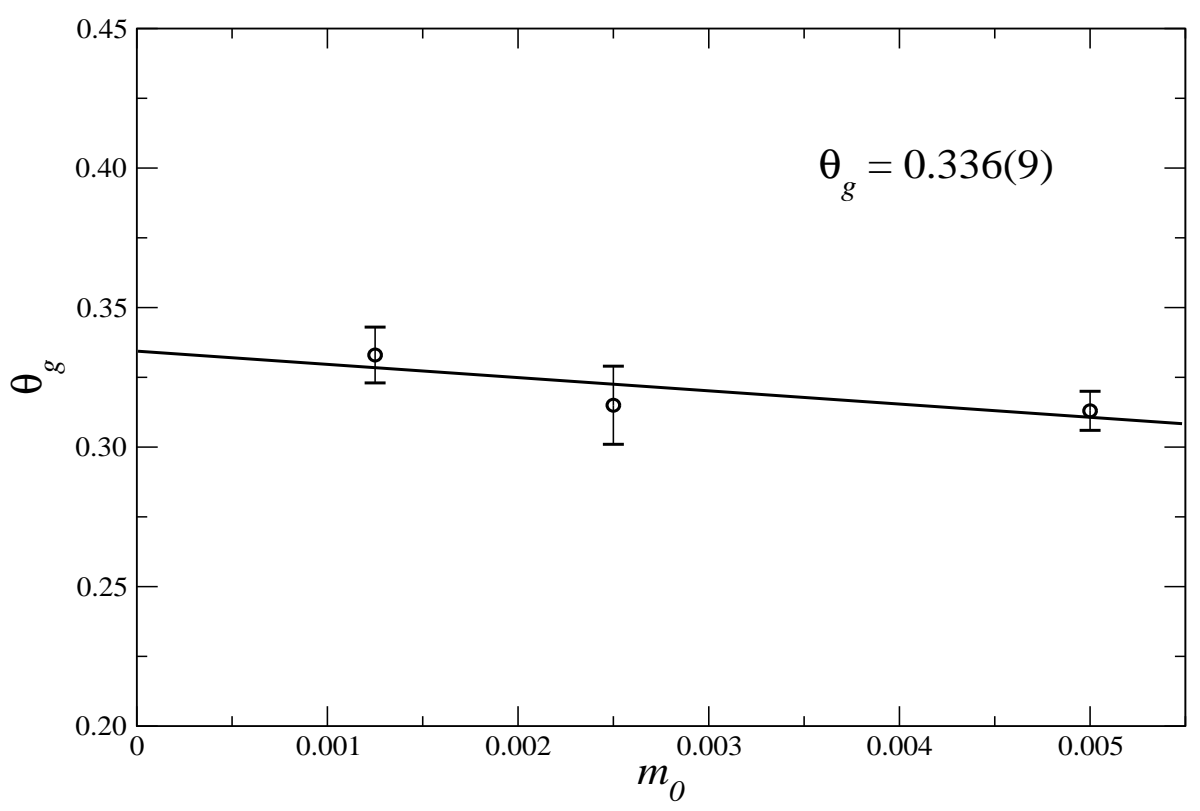

Figura 4.6: O expoente crítico dinâmico $\theta_{g}$ como uma função da magnetização inicial $m_{0}$ para redes cúbicas com $L=60$.

encontrado foi $\theta_{g}=0.337(5)\left(\theta_{g}=0.338(5)\right)$.

Tabela 4.3: O expoente de persistência global $\theta_{g}$ obtido através do comportamento em lei de potências para diferentes magnetizações iniciais $m_{0}$ para redes pares.

\begin{tabular}{ccccc}
\hline \hline$L$ & $m_{0}=0.005$ & $m_{0}=0.0025$ & $m_{0}=0.00125$ & Valor extrapolado \\
\hline 20 & $0.315(14)$ & $0.326(8)$ & $0.337(12)$ & $0.342(4)$ \\
30 & $0.315(5)$ & $0.322(12)$ & $0.335(9)$ & $0.339(5)$ \\
40 & $0.315(9)$ & $0.321(31)$ & $0.336(28)$ & $0.339(7)$ \\
50 & $0.319(10)$ & $0.325(11)$ & $0.336(14)$ & $0.338(6)$ \\
60 & $0.313(7)$ & $0.315(14)$ & $0.333(10)$ & $0.336(9)$ \\
\hline \hline
\end{tabular}

No segundo método, o expoente $\theta_{g}$ é obtido através da relação de escala de tamanho finito dada pela Eq. (3.17). Como já mostrado anteriormente, para obter $\theta_{g}$ com essa técnica não é necessária uma preparação cuidadosa de $m_{0}$. Todavia é necessário ter em mãos o expoente $z$, que nesse caso é dado pela Eq. (4.8), $z=1.975(10)$.

A Figura 4.7 mostra o colapso das curvas obtidas para $L_{1}=50$ e $L_{2}=60$. Os círculos abertos mostram o colapso da rede maior reescalada no tempo.

A melhor estimativa de $\theta_{g}$ para essas duas redes foi

$$
\theta_{g}=0.335(9)
$$




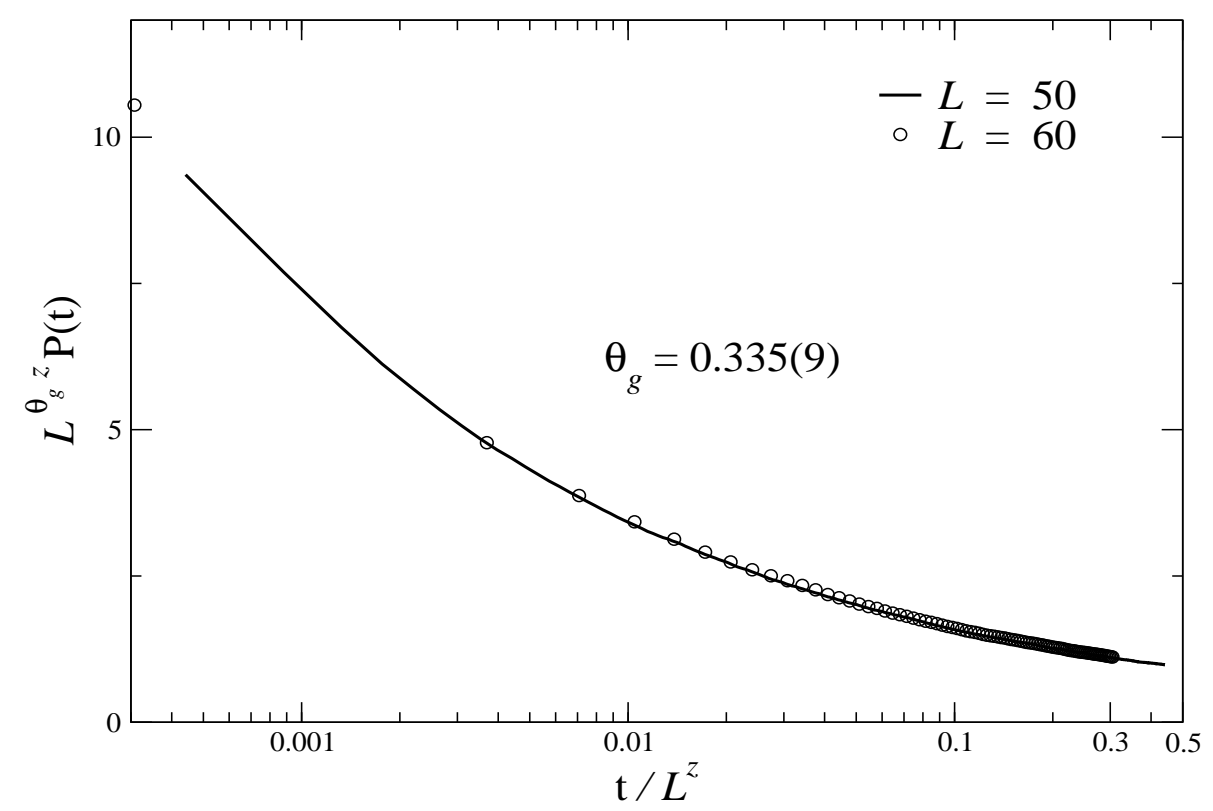

Figura 4.7: O colapso da probabilidade de persistência escalada versus o tempo escalado para $L_{1}=50$ e $L_{2}=60$. As curvas foram obtidas a partir de 5 conjuntos independentes de 5000 amostras.

Os valores obtidos para outras redes são mostrados na Tabela 4.4.

Tabela 4.4: O expoente de persistência global $\theta_{g}$ a partir do melhor colapso para o modelo de dupla troca.

\begin{tabular}{cc}
\hline \hline$L_{2} \longmapsto L_{1}$ & $\theta_{g}$ \\
\hline $60 \longmapsto 50$ & $0.335(9)$ \\
$60 \longmapsto 40$ & $0.333(13)$ \\
$60 \longmapsto 30$ & $0.329(14)$ \\
$50 \longmapsto 35$ & $0.337(11)$ \\
$40 \longmapsto 25$ & $0.330(12)$ \\
$40 \longmapsto 20$ & $0.332(12)$ \\
\hline \hline
\end{tabular}

Esses resultados estão muito bons quando comparados com as estimativas obtidas diretamente através da lei de potências (veja a Tabela 4.3).

\subsection{Os expoentes críticos estáticos $\nu$ and $\beta$}

Como mostrado no capítulo anterior, o expoente estático $\nu$ pode ser obtido através da derivada do logaritmo da magnetização, Eq. (3.19), em relação a $\tau$ na temperatura crítica.

Na Figura 4.8 o comportamento da Eq. (3.19) é mostrado em escala log-log 
para $L=60$.

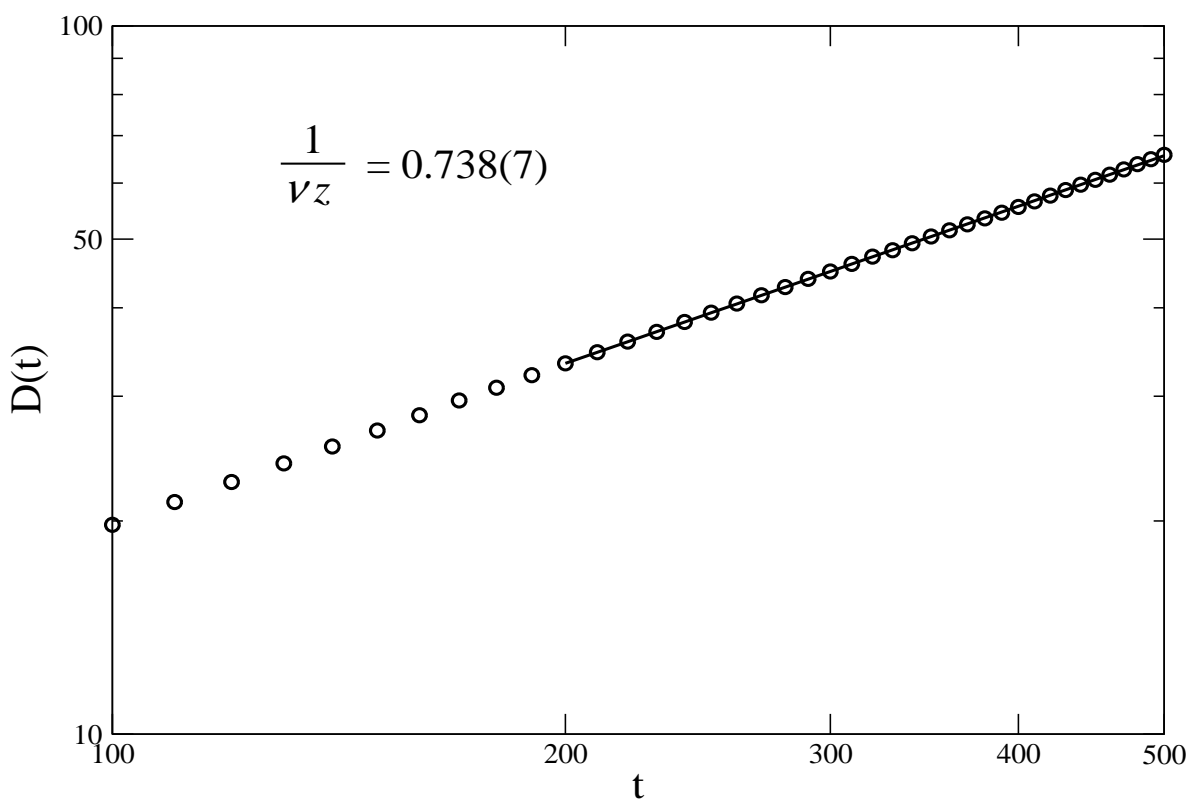

Figura 4.8: A evolução temporal da derivada $\left.\partial_{\tau} \ln M(t, \tau)\right|_{\tau=0}$ em escala log-log. As barras de erro são menores que os símbolos. Cada ponto representa uma média sobre 5 conjuntos de 2000 amostras.

Da inclinação dessa curva pode-se estimar o expoente crítico dinâmico $1 / \nu z$.

Os resultados para os cinco tamanhos de rede são mostrados na Tabela 4.5. Usando o

Tabela 4.5: Os expoentes críticos $1 / \nu z$ e $\beta / \nu z$ para o modelo de dupla troca.

\begin{tabular}{ccc}
\hline \hline$L$ & $1 / \nu z$ & $\beta / \nu z$ \\
\hline 20 & $0.766(6)$ & $0.276(3)$ \\
25 & $0.734(5)$ & $0.267(3)$ \\
30 & $0.748(7)$ & $0.267(2)$ \\
40 & $0.743(5)$ & $0.264(1)$ \\
60 & $0.738(7)$ & $0.263(2)$ \\
\hline \hline
\end{tabular}

expoente $z$ obtido de $U_{4}(t, L)$, Eq. (4.7), e a estimativa de $1 / \nu z$ para $L=60$, obtém-se

$$
\nu=0.68(2)
$$

enquanto que para a relação de escala $F_{2}(t)$, Eq.(4.8), o resultado obtido foi

$$
\nu=0.686(10) .
$$

Tendo agora os valores de $1 / \nu z$ em mãos, é possível obter o expoente $\beta$ que é 
encontrado através da lei de escala para a magnetização (Eq. (3.20)).

Na Figura 4.9 a evolução temporal da magnetização é mostrada em escala $\log -\log$ para $L=60$.

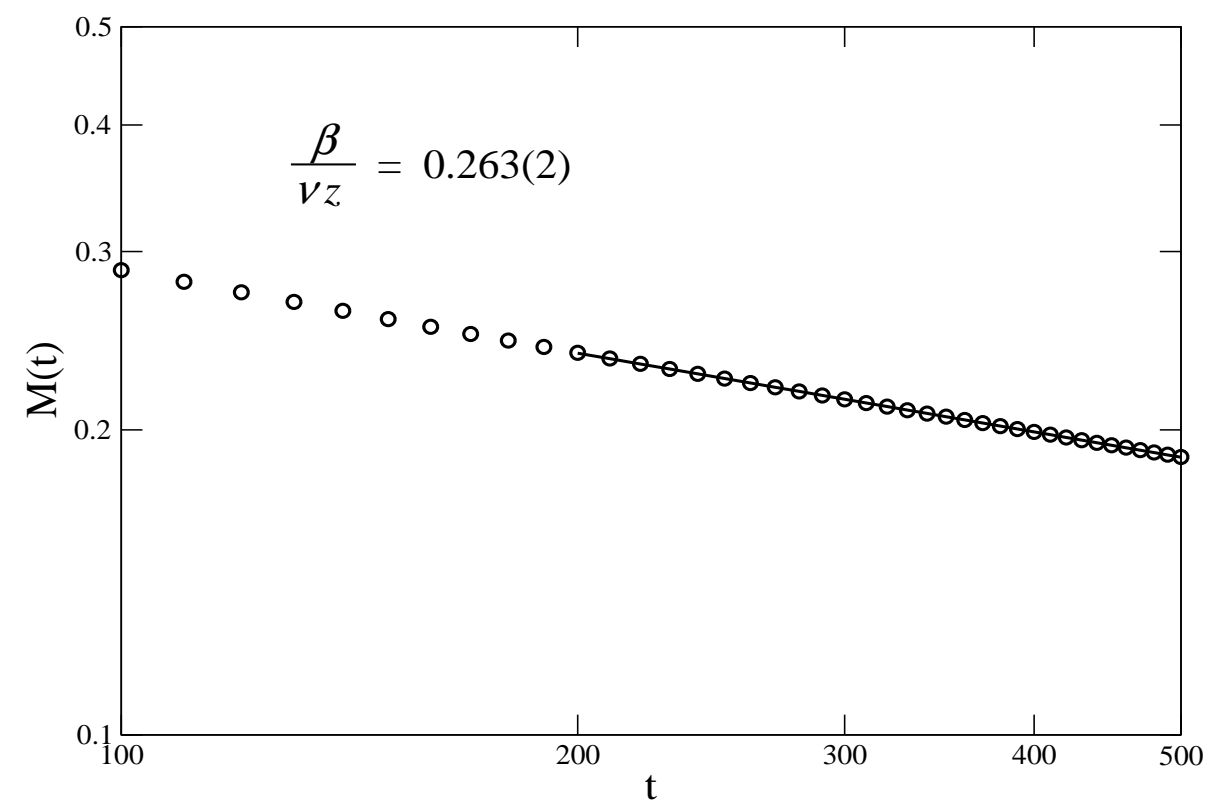

Figura 4.9: A evolução temporal da magnetização para amostras inicialmente ordenadas $\left(m_{0}=1\right)$. As barras de erro, calculadas através de 5 conjuntos de 2000 amostras, são menores que os símbolos.

As estimativas para o expoente $\beta / \nu z$ para os cinco tamanhos de rede são mostradas na Tabela 4.5.

Usando os resultados obtidos para $1 / \nu z$ com $L=60$ (Tabela 4.5), encontra-se

$$
\beta=0.356(6)
$$

As estimativas para os expoentes estáticos $\nu$ e $\beta$ estão em boa concordância com os resultados teóricos da referência [99] $(\nu=0.6949(38)$ e $\beta=0.3535(30))$, referência [101] $(\nu=0.7036(23)$ e $\beta=0.3616(31))$ e referência [108] $(\nu=0.704(6)$ e $\beta=0.362(4))$, bem como com os resultados experimentais da referência [103] $(\beta=0.374(6))$ [104] e da referência $(\beta=0.37(4))$.

Usando, por exemplo, o resultado da Eq. (4.11) e as estimativas dos expoentes $\theta, z, \beta$ e $\nu$ obtidos acima para as redes de tamanho $L=60$, pode-se verificar através da 
Eq. (3.15), o aspecto não-Markoviano do fenômeno considerado, desde que

$$
\theta_{g}=0.335(9) \text { e } \alpha_{g}=-\theta+\frac{d}{z^{2}}-\frac{\beta}{\nu z}=0.026(17)
$$

Esses resultados mostram que o expoente de persistência global também é independente dos outros expoentes críticos. Todavia, a diferença entre os resultados de $\theta_{g}$ e $\alpha_{g}$ da Eq. (4.15) é maior do que aqueles observados quando modelos de spins discretos foram analisados (veja a Tabela 4.6).

Tabela 4.6: Os expoentes $\theta_{g}$ e $\alpha_{g}$ para vários modelos.

\begin{tabular}{ccc}
\hline \hline Modelos & $\theta_{g}$ & $\alpha_{g}$ \\
\hline Modelo de Ising bidimensional [74] & $0.236(3)$ & $0.212(2)$ \\
Modelo de Potts com 3 estados [74] & $0.350(8)$ & $0.324(3)$ \\
Modelo de Blume-Capel [76] & $1.080(4)$ & $0.904(21)$ \\
Modelo de Ising tridimensional [57] & $0.41(2)$ & $0.380(3)$ \\
Modelo de dupla troca (Veja a Eq. (4.15)) & $0.335(9)$ & $0.026(17)$ \\
\hline \hline
\end{tabular}




\section{Capítulo 5}

\section{O modelo de Heisenberg clássico}

\subsection{Introdução}

O modelo de Heisenberg é uma generalização do modelo de Ising e o caso $n=3$ do modelo $n$-vetorial ou modelo $O(n)$. Ele é freqüentemente usado para estudar o ferromagnetismo, bem como as propriedades termodinâmicas de sistemas magnéticos. Como no modelo de Ising, os momentos magnéticos, ou spins, do modelo de Heisenberg são restritos ao comprimento unitário, mas por outro lado, eles podem se orientar livremente no espaço.

A hamiltoniana do modelo de Heisenberg clássico e isotrópico é dada por

$$
\mathcal{H}=-J \sum_{\langle i, j\rangle} \mathbf{S}_{i} \cdot \mathbf{S}_{j}
$$

onde $J>0$ é a constante de acoplamento ferromagnética e $\mathbf{S}_{i}=\left(S_{i}^{x}, S_{i}^{y}, S_{i}^{z}\right)$ é um vetor tridimensional de magnitude unitária localizado em cada sítio $i$ da rede. A notação $\langle i, j\rangle$ indica que a soma está restrita a pares de primeiros vizinhos da rede.

Idêntico ao que foi mostrado na seção anterior, o parâmetro de ordem do modelo de Heisenberg é dado por [100],

$$
M=\sqrt{M_{x}^{2}+M_{y}^{2}+M_{z}^{2}},
$$


onde

$$
M_{\alpha}=\frac{1}{L^{3}} \sum_{i} S_{i}^{\alpha}
$$

e sua configuração inicial desordenada ou ordenada é obtida com o uso das Eqs. (4.4) e (4.5), respectivamente.

A temperatura crítica deste modelo foi estimada através de vários métodos, por exemplo, simulações Monte Carlo [108-112] e expansões em série [113,114]. Todavia, neste trabalho um outro valor da temperatura crítica foi usado para encontrar as propriedades críticas dinâmicas do modelo de Heisenberg. Trata-se da estimativa encontrada por Chen et al. [101] através da análise dos dados do histograma múltiplo [47],

$$
T_{c}=1.44292(8)
$$

em unidades de $J / k_{B}$. As simulações Monte Carlo em tempos curtos foram executadas sobre redes cúbicas simples $L \times L \times L$ com condições periódicas de contorno. Afim de verificar os efeitos de tamanho finito, redes de tamanho linear $L=30$, 40 e 50 foram consideradas. Os spins foram atualizados localmente (durante a evolução temporal do sistema) pelo algoritmo de Metropolis.

Nesse estudo, cada expoente e seu respectivo erro foram obtidos através de 5 simulações independentes, cada uma consistindo de 3000 amostras.

\subsection{O expoente crítico dinâmico $z$}

O expoente $z$ do modelo de Heisenberg também foi obtido por meio das mesmas técnicas empregadas no modelo de dupla troca: a técnica que combina resultados obtidos de amostras submetidas a diferentes configurações iniciais, $F_{2}(t)$ (veja a Eq. (3.11)), e a outra que consiste no estudo do colapso do cumulante de Binder de quarta-ordem dependente do tempo para duas redes de tamanhos diferentes, $U_{4}(t)$ (veja a Eq. (3.7)).

A evolução temporal de $F_{2}$ para uma rede $L=50$ é mostrada em escala log-log na Figura 5.1. 


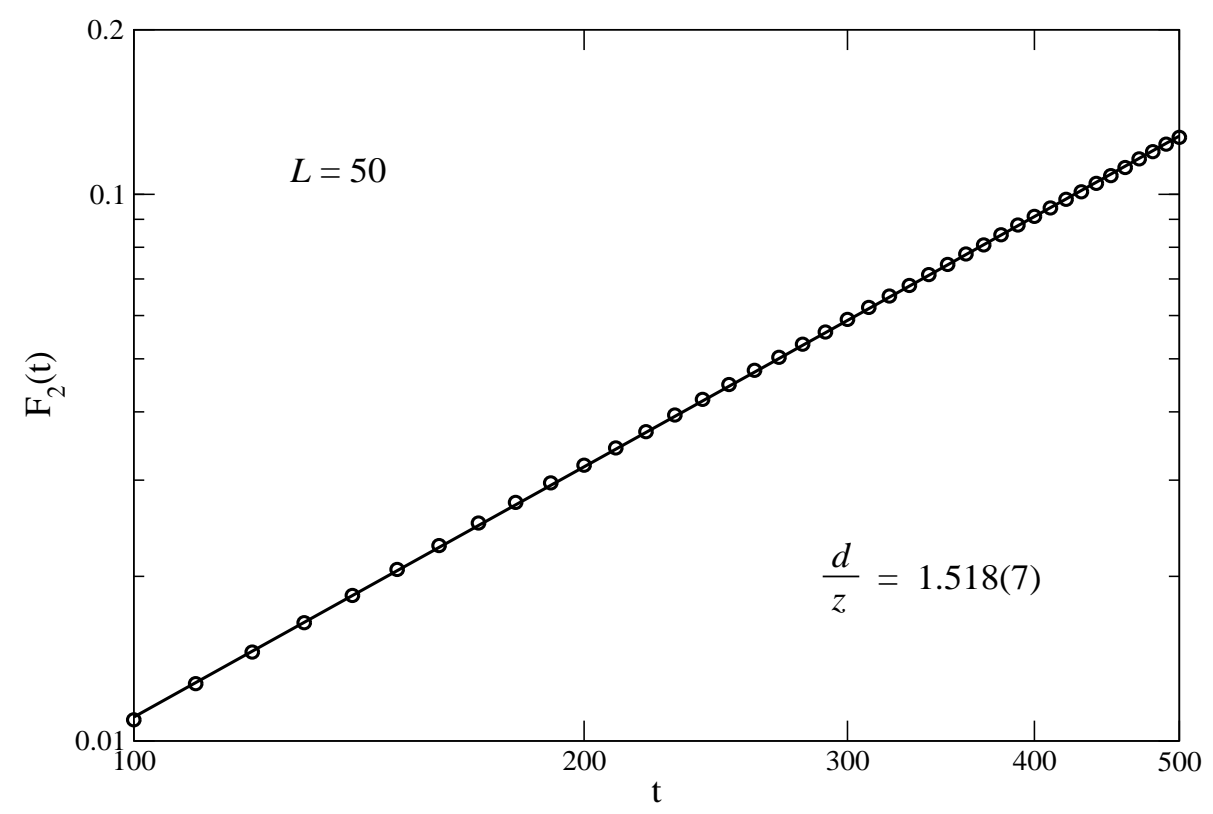

Figura 5.1: A evolução temporal de $F_{2}$ para uma rede de tamanho $L=50$. As barras de erro, calculadas através de 5 conjuntos de 3000 amostras, são menores que os símbolos.

A inclinação desta curva fornece

$$
\frac{d}{z}=1.518(7)
$$

ou seja,

$$
z=1.976(9)
$$

Este resultado está em boa concordância com os valores obtidos por Peczak e Landau usando técnicas de equilíbrio, $z=1.96(7)$ [107] e $z=1.96(6)$ [115] mas apresenta um erro muito menor. Além disso, esse valor está em completa concordância com as estimativas obtidas através de simulações Monte Carlo em tempos curtos do modelo de dupla troca, $z=1.975(10)$ (veja a Eq. (4.8)).

Os valores obtidos para $L=30(z=1.979(10))$ e $L=40(z=1.972(9))$ indicam que os efeitos de tamanho finito são menores do que os erros estatísticos.

Na segunda abordagem, o expoente $z$ foi obtido através do colapso de $U_{4}(t)$ somente para configurações iniciais ordenadas $\left(m_{0}=1\right)$.

A Figura 5.2 mostra o cumulante de Binder como uma função do tempo para as redes $L_{1}=40$ e $L_{2}=50$. 


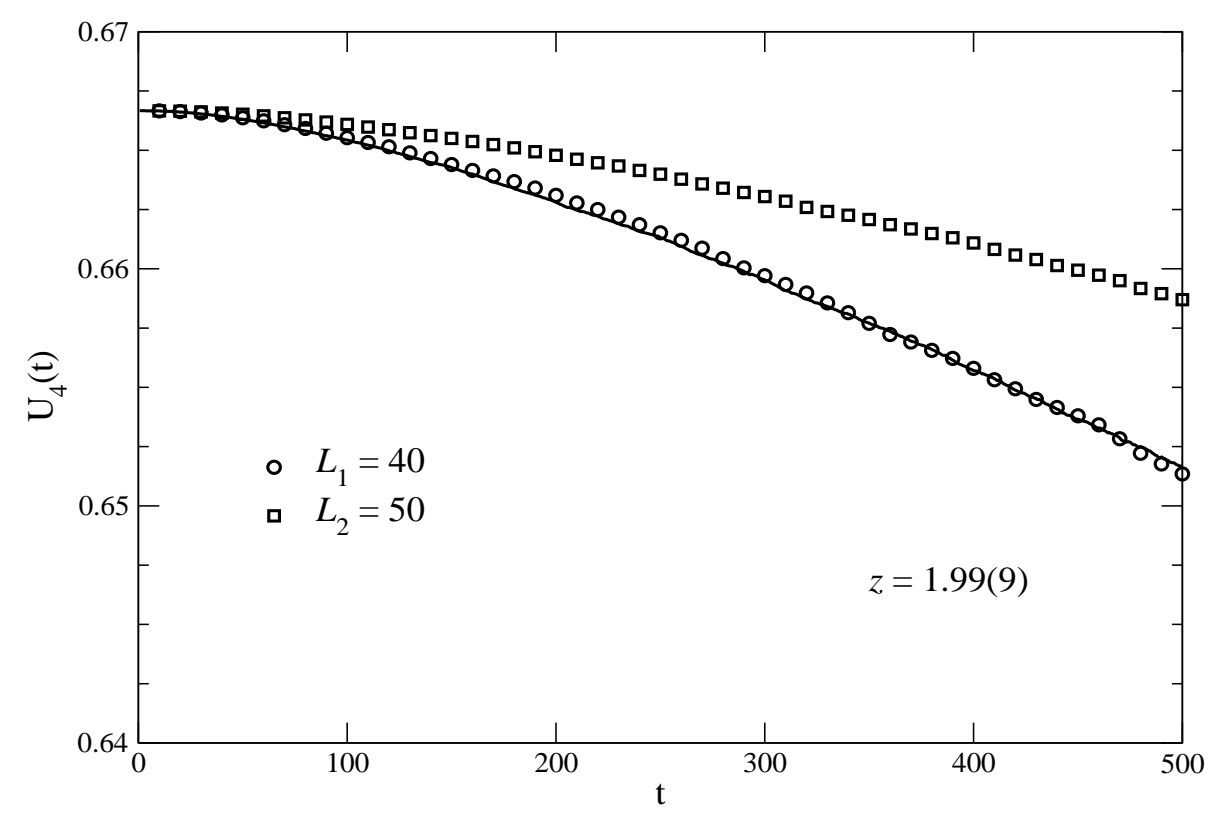

Figura 5.2: O cumulante $U_{4}(t)$ para $L_{1}=40$ e $L_{2}=50$ versus o tempo $t$ com estados iniciais $m_{0}=1$. A linha mostra a rede $L_{2}=50$ reescalada no tempo. O cumulante para ambas as redes foi obtido a partir de 5 conjuntos independentes de 3000 amostras cada.

A linha mostra o colapso da maior rede reescalada no tempo. A melhor estimativa de $z$, obtida através do teste do $\chi^{2}$ [106], para $L_{1}=40$ e $L_{2}=50$ é

$$
z=1.99(9)
$$

O valor obtido para $L_{1}=30$ e $L_{2}=50$ foi $z=1.96(2)$ e para $L_{1}=30$ e $L_{2}=40$ foi $z=1.97(5)$. Esses resultados estão em boa concordância com os valores obtidos a partir de $F_{2}(t)$.

Este resultado, quando comparado com $z=1.98(3)$ obtido para o modelo de dupla troca, apresenta um erro muito maior, que poderia ser explicado pela diferença no tamanho das redes e no número de amostras para esses dois modelos. Todavia, como já mostrado para $F_{2}$ e como será visto em seguida, essa diferença na rede e no número de amostras não é importante quando se usa as demais técnicas (os erros são comparáveis), mostrando que embora o cumulante seja uma técnica bastante empregada no equilíbrio, nas simulações em tempos curtos ela parece ser menos precisa. 


\subsection{O expoente crítico dinâmico $\theta$}

O expoente crítico dinâmico $\theta$ do modelo de Heisenberg foi obtido através da relação de escala dada pela Eq. (3.2) e através da correlação temporal da magnetização dada pela Eq. (3.13).

A Figura 5.3 mostra o comportamento em lei de potências da magnetização (veja a Eq. (3.2)) para $L=50$ e $m_{0}=0.002$ em escala log-log.

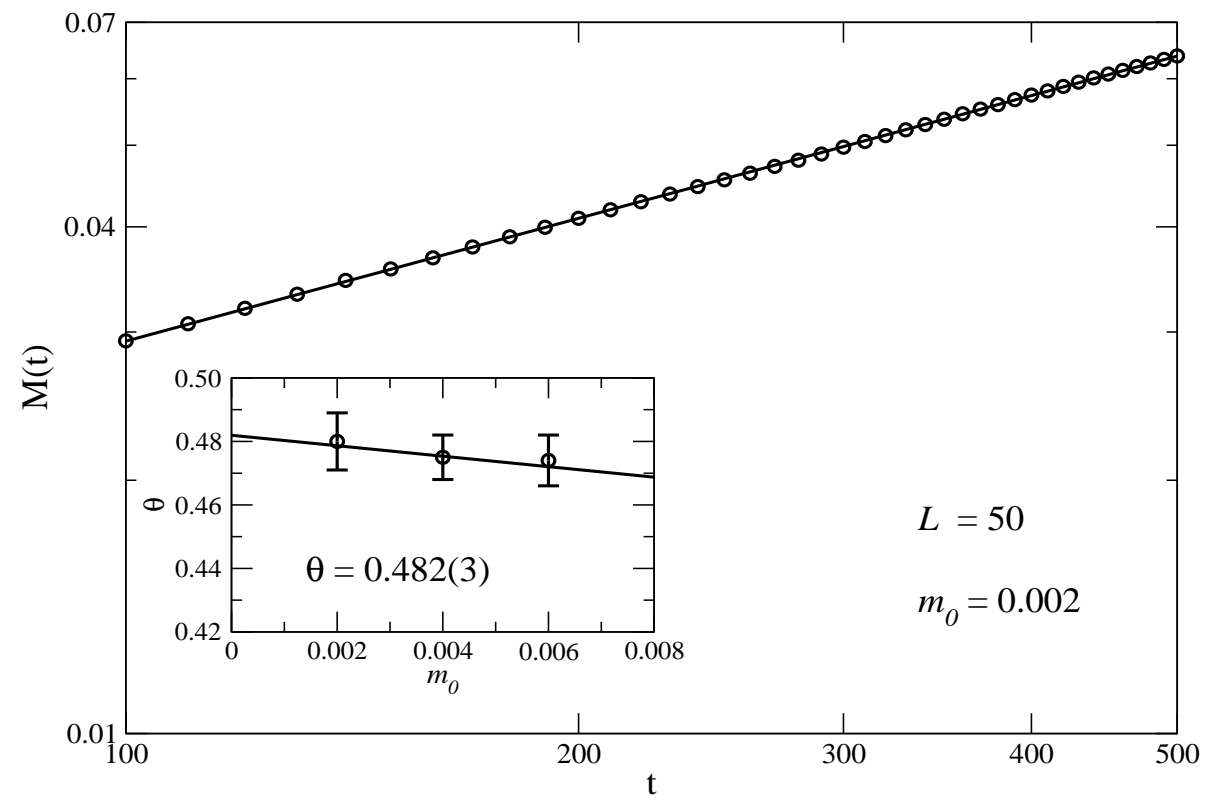

Figura 5.3: A evolução temporal da magnetização para uma rede $L=50$ e $m_{0}=0.002$. As barras de erro, calculadas a partir de 5 conjuntos de 3000 amostras, são menores que os símbolos. O gráfico no interior mostra o expoente $\theta$ para três magnetizações iniciais diferentes, bem como seu valor extrapolado.

O gráfico interno exibe o expoente $\theta$ para três diferentes magnetizações iniciais, $m_{0}=0.006,0.004$ e 0.002, bem como seu valor extrapolado,

$$
\theta=0.482(3)
$$

A Tabela 5.1 apresenta as estimativas de $\theta$ em função de $m_{0}$ para os três tamanhos de rede considerados e os resultados obtidos através das extrapolações lineares para $m_{0} \rightarrow 0$ são apresentados na última coluna dessa tabela.

A segunda abordagem leva em consideração a correlação temporal da magnetização dada pela Eq. (3.13), $C(t)$. Sua dependência temporal é mostrada em escala 
Tabela 5.1: O expoente crítico dinâmico $\theta$ encontrado a partir da Eq. (3.2) para diferentes magnetizações iniciais $m_{0}$.

\begin{tabular}{ccccc}
\hline \hline$L$ & $m_{0}=0.006$ & $m_{0}=0.004$ & $m_{0}=0.002$ & Valor extrapolado \\
\hline 30 & $0.473(6)$ & $0.475(6)$ & $0.479(8)$ & $0.481(2)$ \\
40 & $0.476(9)$ & $0.477(10)$ & $0.483(12)$ & $0.485(3)$ \\
50 & $0.474(8)$ & $0.475(7)$ & $0.480(9)$ & $0.482(3)$ \\
\hline \hline
\end{tabular}

$\log -\log$ na Figura 5.4 para o sistema com $L=50$.

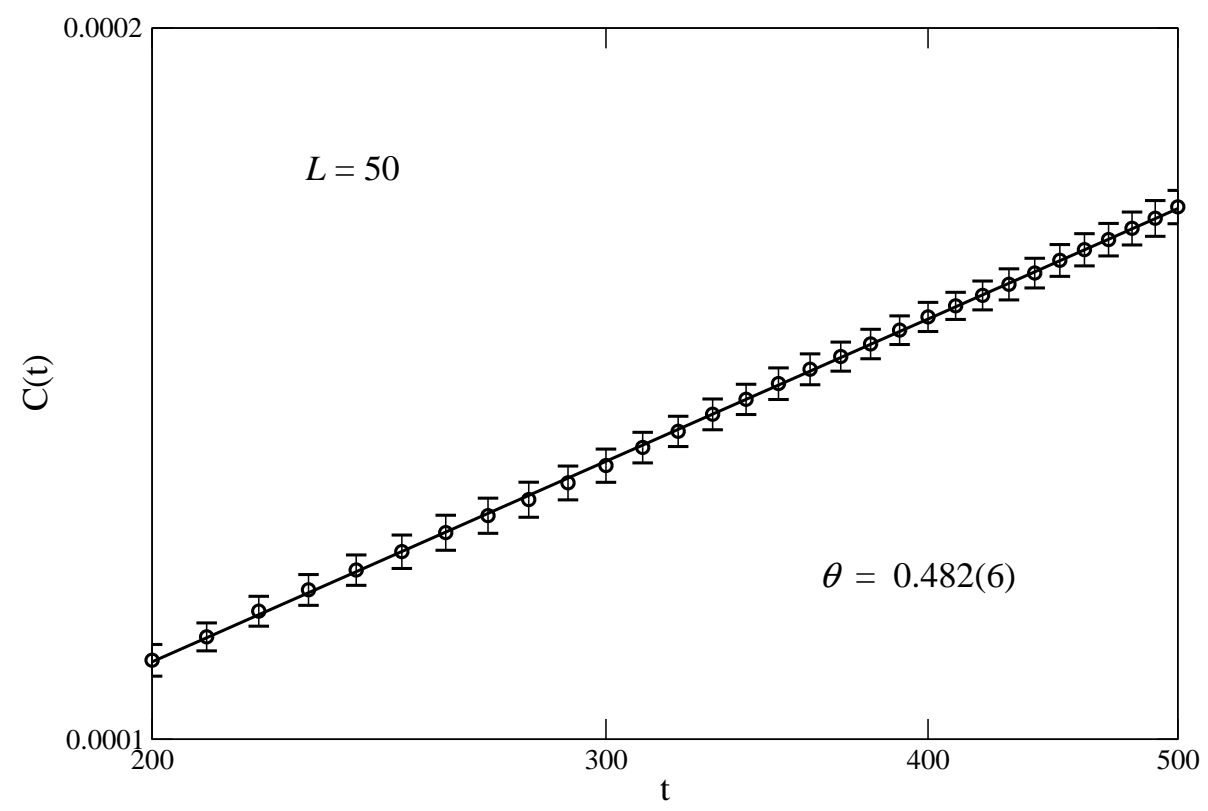

Figura 5.4: A correlação temporal da magnetização para amostras $\operatorname{com}\langle M(t=0)\rangle=0$. As barras de erro foram calculadas a partir de 5 conjuntos de 3000 amostras.

A inclinação dessa curva dá

$$
\theta=0.482(6) \text {. }
$$

Já os resultados para $L=30$ e $L=40$ foram respectivamente $\theta=0.475(11)$ e $\theta=0.485(14)$

Esses resultados, juntamente com os valores obtidos para $z$, quando comparados com os valores obtidos para o modelo de dupla troca, já indicam que ambos os modelos pertencem á mesma classe de universalidade. Como será mostrado mais adiante, todos os outros expoentes críticos dão suporte à essa afirmação. 


\subsection{O expoente $\theta_{g}$ da persistência global}

A evolução temporal da probabilidade de persistência global do modelo de Heisenberg foi estudada usando as duas abordagens descritas no Capitulo 3, ou seja, a aplicação direta da Eq. (3.14) e por meio do colapso das curvas para diferentes tamanhos de rede (veja a Eq. (3.17)).

Na primeira abordagem, a Eq. (3.14) é usada para obter $\theta_{g}$ em função de $m_{0}$ e a estimativa final de $\theta_{g}$ é então obtida quando se extrapola essas séries para o limite em que $m_{0} \rightarrow 0$.

O comportamento da probabilidade de persistência global para $L=50$ e $m_{0}=$ 0.002 é mostrada na Figura 5.5 em escala log-log.

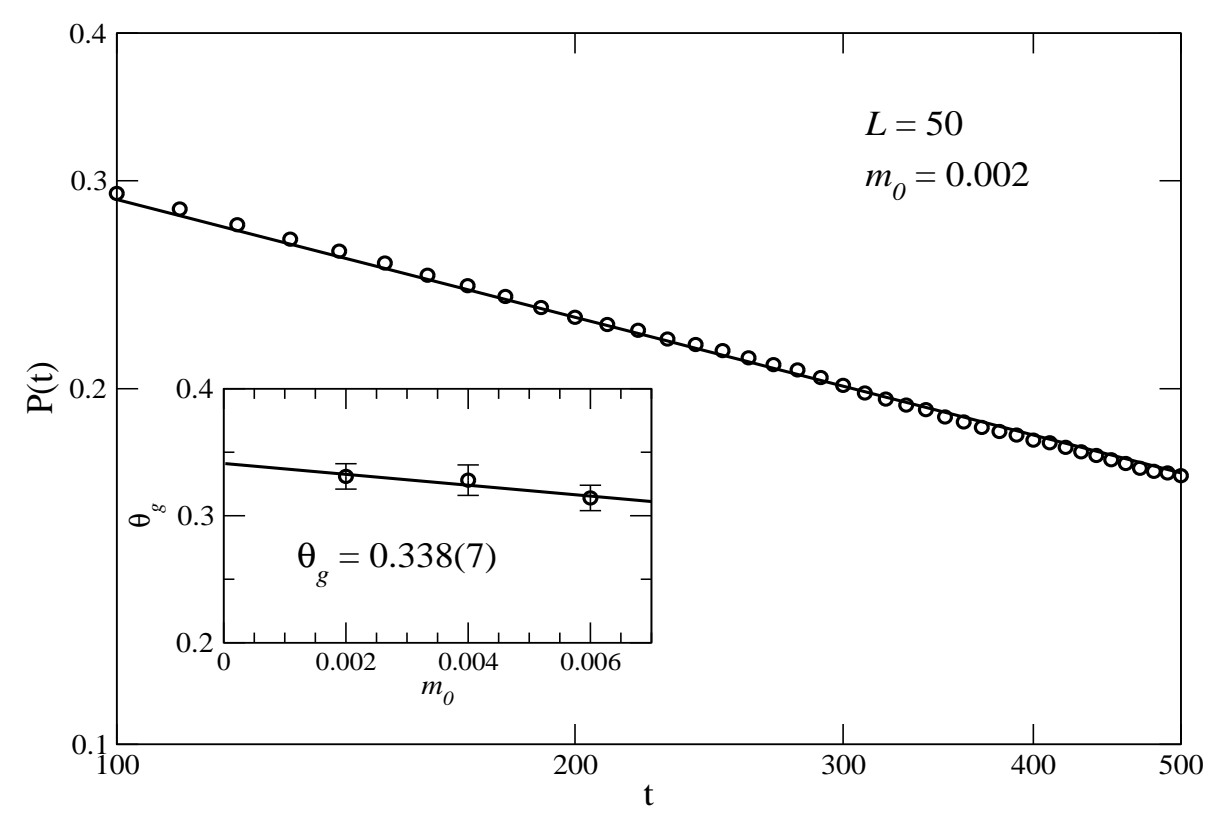

Figura 5.5: A evolução temporal da probabilidade de persistência global $P_{g}(t)$ para uma rede de tamanho $L=50$ e $m_{0}=0.002$. As barras de erro foram calculadas através de 5 conjuntos de 3000 amostras.

O gráfico no seu interior exibe o comportamento do expoente $\theta_{g}$ para $m_{0}=$ 0.006, 0.004 e 0.002, bem como o ajuste linear que leva ao valor,

$$
\theta_{g}=0.338(7)
$$

a ser comparado com $0.336(9)$ obtido para o modelo de dupla troca. 
A Tabela 5.2 apresenta as estimativas para $\theta_{g}$ em função de diferentes magnetizações iniciais $m_{0}$ para outros tamanhos de rede. Os resultados obtidos através de extrapolações lineares são mostrados na última coluna.

Tabela 5.2: O expoente de persistência global $\theta_{g}$ encontrado a partir da Eq. (3.14) para diferentes magnetizações iniciais $m_{0}$.

\begin{tabular}{ccccc}
\hline \hline$L$ & $m_{0}=0.006$ & $m_{0}=0.004$ & $m_{0}=0.002$ & Valor extrapolado \\
\hline 30 & $0.318(9)$ & $0.327(10)$ & $0.331(12)$ & $0.339(4)$ \\
40 & $0.319(12)$ & $0.328(14)$ & $0.330(9)$ & $0.336(3)$ \\
50 & $0.314(10)$ & $0.328(12)$ & $0.331(10)$ & $0.338(7)$ \\
\hline \hline
\end{tabular}

Já na segunda abordagem, o colapso de curvas com diferentes tamanhos de rede [veja a Eq. (3.17)] é necessário para obter o expoente $\theta_{g}$. Nesse caso é necessário o uso do expoente $z$, que para a maior rede e pelo método mais preciso, $F_{2}(t)$, é $z=1.976(9)$.

A Figura 5.6 mostra o colapso das curvas obtidas para $L_{1}=40$ e $L_{2}=50$.

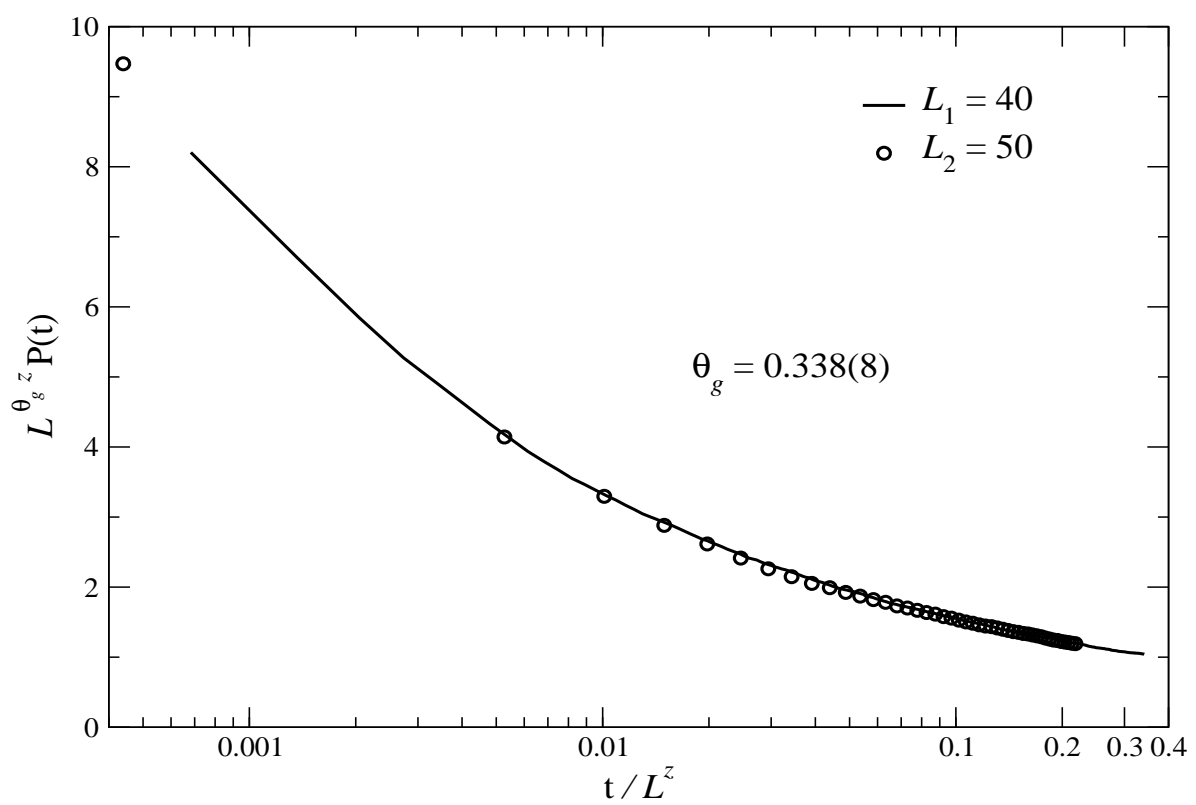

Figura 5.6: O colapso da probabilidade de persistência global para $L_{1}=40$ e $L_{2}=50$. As curvas foram obtidas a partir de 5 conjuntos de 3000 amostras cada.

Os círculos abertos mostram o colapso da maior rede reescalada no tempo. A melhor estimativa para $\theta_{g}$ para $L_{1}=40$ e $L_{2}=50$ foi

$$
\theta_{g}=0.338(8)
$$

Os valores encontrados para outros tamanhos de rede são mostrados na Tabela 5.3. 
Tabela 5.3: O expoente de persistência global $\theta_{g}$ para o melhor colapso das curvas $L_{1}$ e $L_{2}$.

\begin{tabular}{cc}
\hline \hline$L_{2} \longmapsto L_{1}$ & $\theta_{g}$ \\
\hline $50 \longmapsto 40$ & $0.338(8)$ \\
$50 \longmapsto 30$ & $0.334(7)$ \\
$40 \longmapsto 30$ & $0.337(9)$ \\
\hline \hline
\end{tabular}

Os resultados obtidos para o expoente de persistência global do modelo de Heisenberg estão em ótima concordância com as estimativas obtidas para o modelo de dupla troca, $\theta_{g}=0.335(9)$.

\subsection{Os expoentes críticos estáticos $\nu$ and $\beta$}

Levando em consideração amostras com configurações iniciais ordenadas, os expoentes críticos estáticos $\beta$ e $\nu$ podem ser obtidos através de relações de escala para a magnetização (Eq. (3.20)) e sua derivada (Eq. (3.19)), respectivamente.

A Figura 5.7 mostra o comportamento temporal da derivada da magnetização em escala log-log para $L=50$.

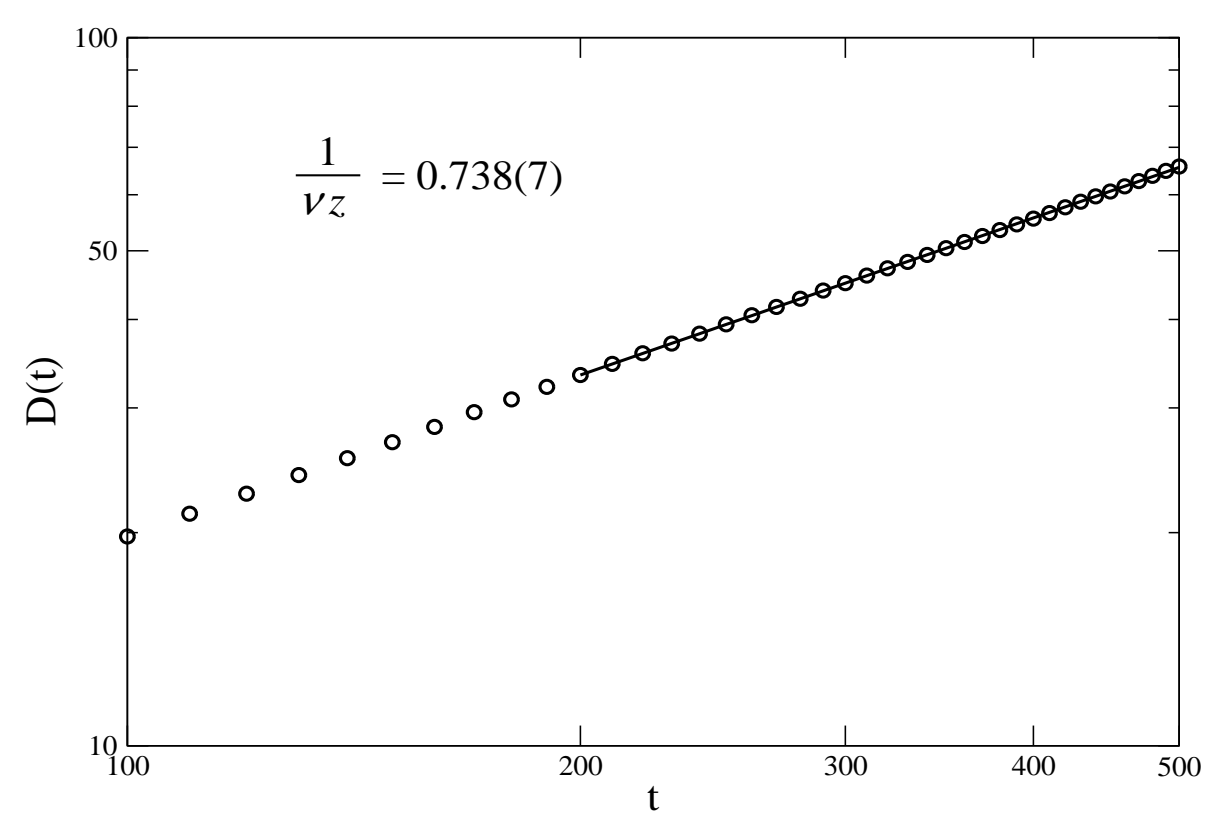

Figura 5.7: A evolução temporal da derivada $\left.\partial_{\tau} \ln M(t, \tau)\right|_{\tau=0}$ em escala log-log. As barras de erro são menores que os símbolos. Cada ponto representa uma média sobre 5 conjuntos de 3000 amostras.

Da inclinação dessa curva pode-se estimar o expoente crítico dinâmico $1 / \nu z$. 
Usando o expoente $z$ obtido anteriormente a partir da Eq. (5.6), o expoente $\nu$ pode ser facilmente obtido. Para $L=50$ o valor estimado foi

$$
\nu=0.687(6)
$$

enquanto que para $L=30$ e $L=40$ os resultados foram $\nu=0.688(10)$ e $\nu=0.690(9)$, respectivamente.

Com os valores de $1 / \nu z$ em mãos, é possível estimar o expoente $\beta$ através do decaimento da magnetização na temperatura crítica, (veja a Eq. (3.20)). Esse comportamento é mostrado na Figura 5.8 em escala log-log para $L=50$.

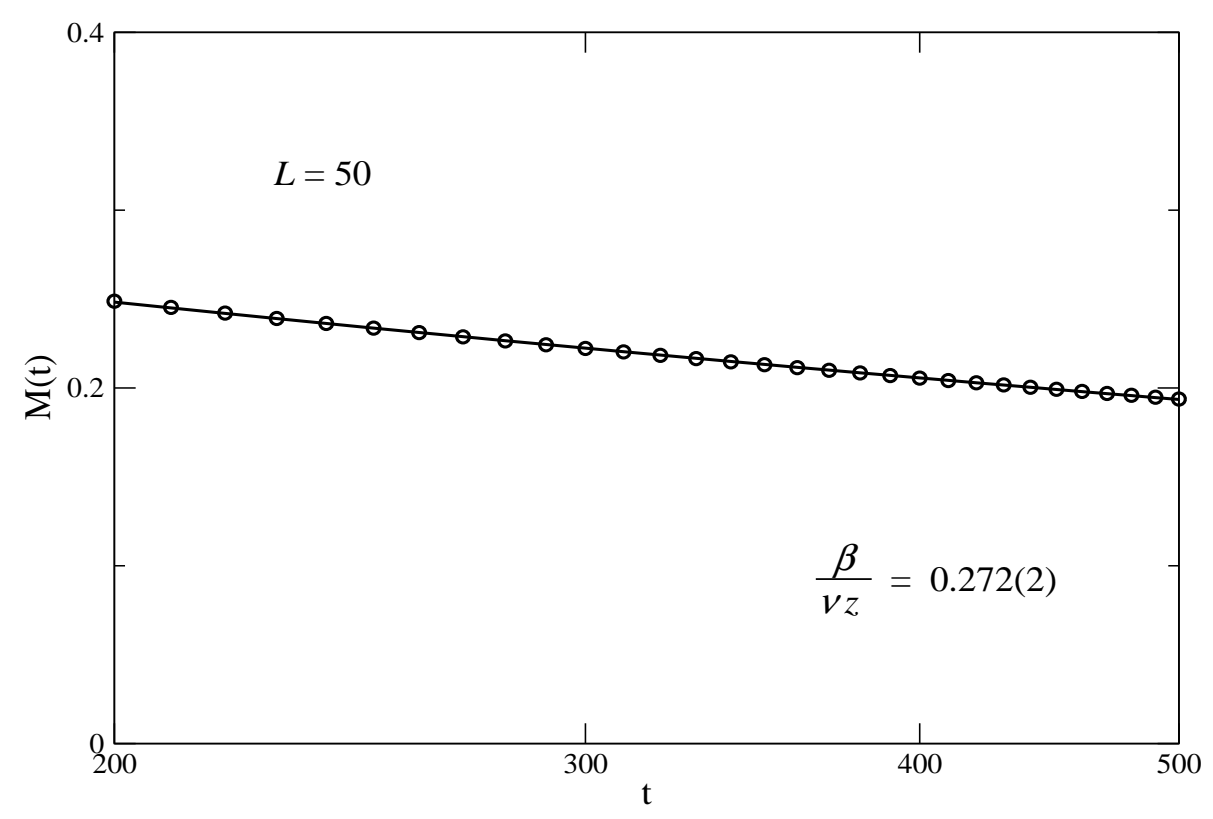

Figura 5.8: A evolução temporal da magnetização para amostras inicialmente ordenadas $\left(m_{0}=1\right)$. As barras de erro, calculadas através de 5 conjuntos de 3000 amostras, são menores que os símbolos.

O ajuste linear desta curva dá o valor $\beta / \nu z=0.266(2)$, levando ao valor

$$
\beta=0.361(2)
$$

O resultado para $L=30$ e $40 \beta=0.362(8)$ e $0.361(7)$, respectivamente. Esses resultados estão em ótima concordância com os valores encontrados na literatura $[99,101,103,104,108]$ e com os valores obtidos para o modelo de dupla troca $(\nu=0.686(10)$ e $\beta=0.356(6))$. 


\section{Capítulo 6}

\section{O modelo Z(5)}

\subsection{Introdução}

Em mecânica estatística, modelos não triviais têm sido extensivamente estudados desde o início do século passado. Um dos modelos mais estudados é sem dúvida o modelo de Ising bidimensional [9]. Nesse modelo, a variável de spin pode assumir somente dois valores, \pm 1 . Todavia, como foi mostrado nos dois capítulos anteriores, existem vários sistemas mais ricos. Como uma generalização do modelo de Ising, outros modelos também podem ser construídos. O modelo $Z(N)$ é um exemplo cuja variável de spin pode assumir $N$ valores.

O modelo $Z(N)$ contém vários sistemas conhecidos como casos particulares, como por exemplo, o modelo de Ising $(N=2)$ e o modelo $X Y(N=\infty)$, bem como os modelos de Potts vetorial e escalar com $N$ estados e o modelo de Ashkin-Teller $(N=4)$. Para $N \leq 4$, o diagrama de fase possui uma transição de fase de segunda ordem tradicional e para $N=\infty$ o modelo exibe uma transição de fase do tipo Kosterlitz-Thouless (KT) [116]. Mas, para qual valor de $N$ esta última transição de fase aparece? Vários trabalhos relatam que a transição de fase do tipo KT aparece para $N=5$ [117-121].

O modelo $Z(5)$ bidimensional possui um rico diagrama de fase com transições de primeira ordem, incluindo o ponto de Potts com 5 estados [122], dois pontos de transição de segunda ordem nos pontos de integrabilidade de Fateev-Zamolodchikov (FZ) [119] e duas linhas de transição de ordem infinita (uma dual à outra) do tipo KT [117, 118, 121, 
123-125]. Vários trabalhos afirmam que os pontos de FZ coincidem com os pontos onde as transições do tipo KT se originam [119,120,124,126,127]. Estes pontos são conhecidos como pontos de bifurcação.

A hamiltoniana mais geral do modelo é dada por

$$
-\beta \mathcal{H}=\sum_{\langle i, j\rangle}\left\{K_{1}\left[\cos \left(\frac{2 \pi}{5}\left(n_{i}-n_{j}\right)\right)-1\right]+K_{2}\left[\cos \left(\frac{4 \pi}{5}\left(n_{i}-n_{j}\right)\right)-1\right]\right\}
$$

onde $\langle i, j\rangle$ indica que as variáveis de spin interagem somente com seus primeiros vizinhos, $i$ e $j$ rotulam os sítios de uma rede bidimensional de tamanho $L \times L, K_{1}$ e $K_{2}$ são duas constantes de acoplamento positivas e $n_{i}=0,1,2,3,4$ rotulam os graus de liberdade de cada sítio da rede.

Em relação às constantes de acoplamento, o modelo de Potts escalar com 5 estados é definido por $K_{1}=K_{2}$ e o modelo de Potts vetorial é definido por $K_{2}=0$ [127]. O interesse inicial deste trabalho é estudar o comportamento crítico usando simulações em tempos curtos no ponto de bifurcação cuja razão entre os acoplamentos é dada por

$$
\frac{K_{2}}{K_{1}}=\frac{\sqrt{5}-1}{2} \simeq 0.618034
$$

Como explicado anteriormente, este modelo tem na verdade dois pontos de bifurcação (pontos de FZ) mas eles são simétricos, tendo assim os mesmos expoentes. Além do mais, existem quatro parâmetros de ordem mas somente dois deles são independentes [128],

$$
M_{1}=\frac{1}{L^{2}}\left\langle\sum_{i}\left(\delta_{n_{i}, 1}-\delta_{n_{i}, 2}\right)\right\rangle
$$

e

$$
M_{2}=\frac{1}{L^{2}}\left\langle\sum_{i}\left(\delta_{n_{i}, 1}-\delta_{n_{i}, 3}\right)\right\rangle
$$

Os expoentes críticos e as respectivas barras de erro foram encontrados através de 5 simulações independentes, cada uma consistindo de 30000 amostras para uma rede de tamanho linear $L=240$. A evolução dinâmica dos spins é local e atualizada pelo algoritmo de banho térmico. 


\subsection{Os expoentes críticos dinâmicos $z_{1}$ e $z_{2}$}

Os expoentes críticos $z_{1}$ e $z_{2}$ para o modelo $Z(5)$ foram estimados usando-se apenas uma abordagem: a técnica que combina resultados obtidos de amostras submetidas a diferentes condições iniciais (veja a Eq. (3.11)).

A evolução temporal de $F_{2}$ para os dois parâmetros de ordem é mostrada em escala log-log na Figura 6.1 para $\mathrm{L}=240$.

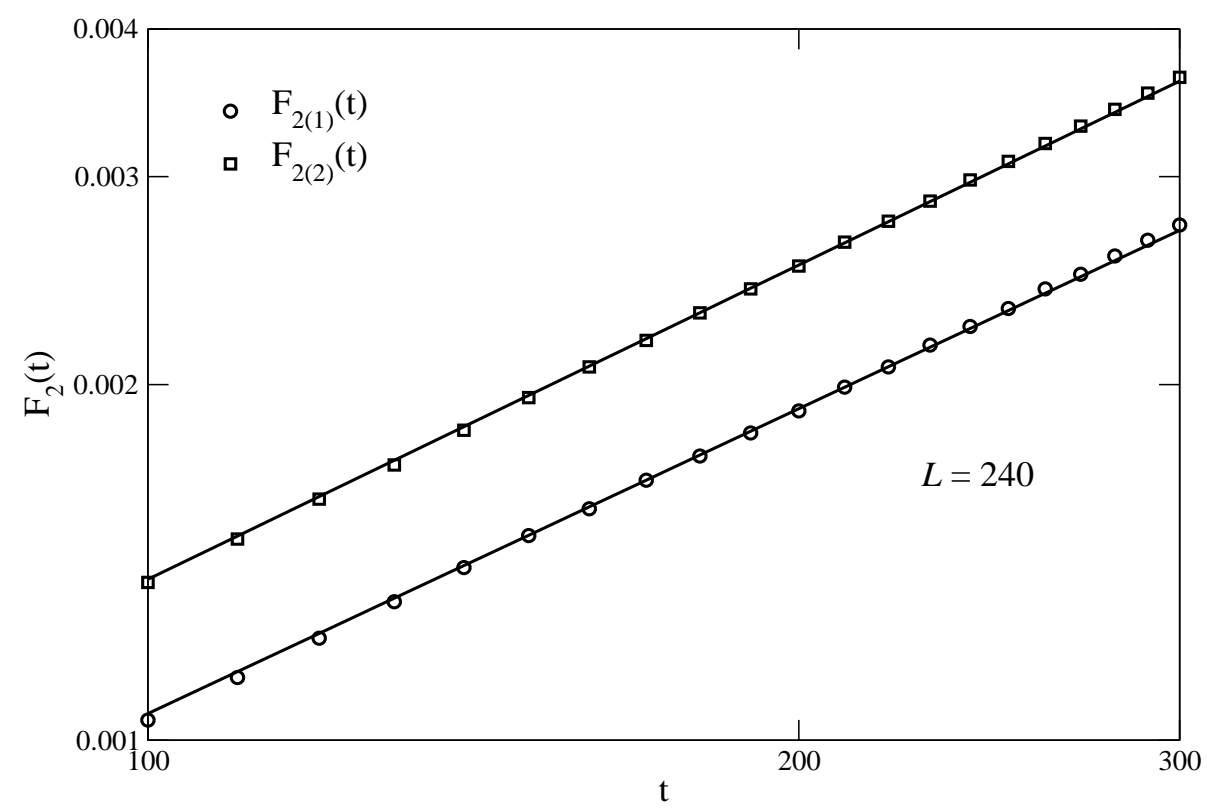

Figura 6.1: A evolução temporal de $F_{2}(t)$ para os dois parâmetros de ordem. As barras de erro são menores que os símbolos. Cada ponto representa uma média sobre 5 conjuntos de 30000 amostras.

As inclinações dessas curvas dão

$$
\frac{d}{z_{1}}=0.865(3) \quad \text { e } \quad \frac{d}{z_{2}}=0.883(2)
$$

que, considerando $d=2$, resulta em

$$
z_{1}=2.312(7) \quad \text { e } \quad z_{2}=2.264(6) .
$$

Até onde sabemos, esta é a primeira tentativa de se obter os expoentes $z$ para este modelo. 


\subsection{Os expoentes críticos estáticos $\nu, \beta_{1}$ e $\beta_{2}$}

O expoentes críticos estáticos $\nu_{1}$ e $\nu_{2}$ foram obtidos através da derivada do logarítimo da magnetização dada pela Eq. (3.19), quando o sistema parte do estado inicial ordenado.

O aumento em lei de potências da Eq. (3.19) é mostrado na Figura 6.2 para os dois parâmetros de ordem do modelo, em escala log-log.

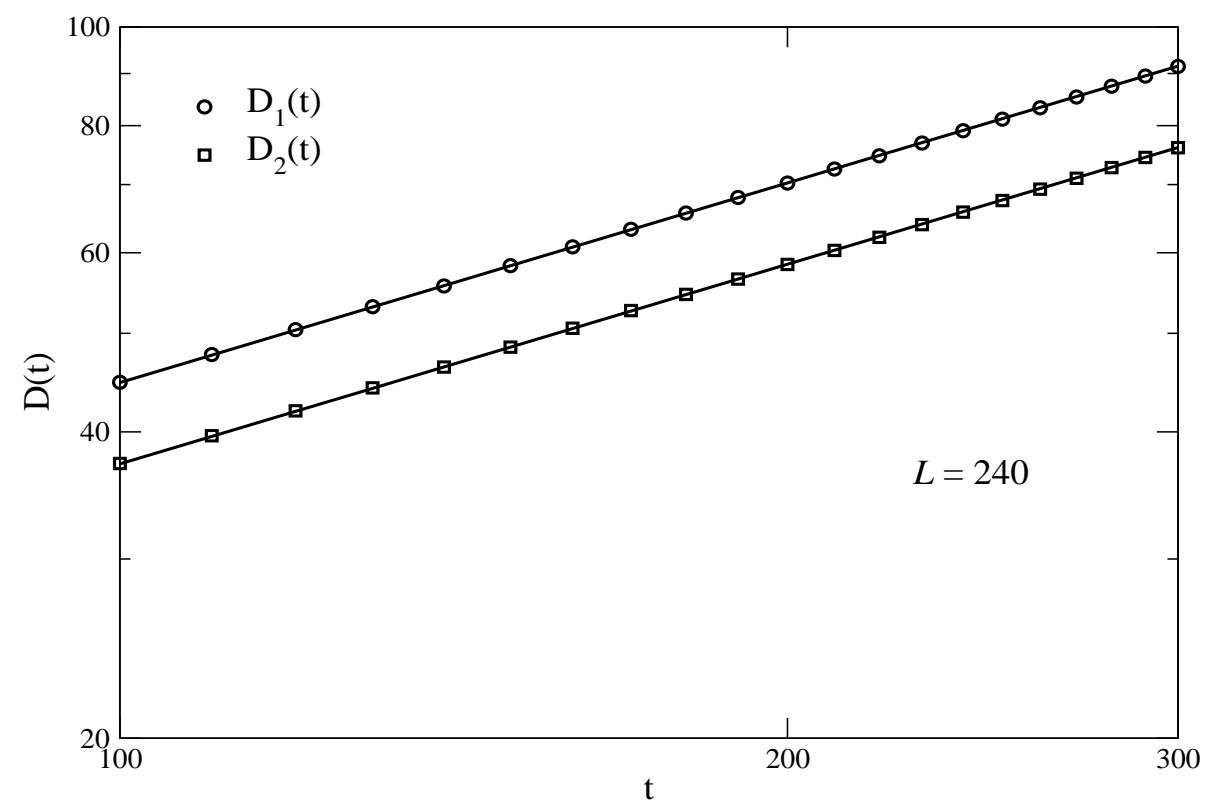

Figura 6.2: A evolução temporal da derivada $\left.\partial_{\tau} \ln M_{i}(t, \tau)\right|_{\tau=0}$ (onde $i$ se refere ao parâmetro de ordem 1 ou 2) em escala log-log no processo dinãmico iniciando de um estado ordenado $\left(m_{0}=1\right)$. As barras de erro são menores que os símbolos. Cada ponto representa uma média sobre 5 conjuntos de 30000 amostras.

Da inclinação dessas curvas, pode-se obter o expoente crítico $1 / \nu z$ para os dois parâmetros de ordem. Como é mostrado através da invariância conforme, devemos obter $\nu_{1}=\nu_{2}=\nu[128,129]$. Usando os expoentes $z_{1}$ e $z_{2}$ estimados na Seção 6.2, nós obtemos

$$
\nu_{1}=0.696(10) \quad \text { e } \quad \nu_{2}=0.698(11) .
$$

Nossos resultados estão em boa concordância entre si e com os resultados obtidos através da invariância conforme $\nu=0.7$ [128].

Os expoentes $\beta_{1}$ e $\beta_{2}$ foram estimado seguindo-se o decaimento dos parâmetros de ordem com o sistema partindo sempre de configurações iniciais ordenadas. 
Na Figura 6.3, a evolução temporal da magnetização $M_{1}(t)$ e $M_{2}(t)$ são mostradas em escala log-log para $L=240$.

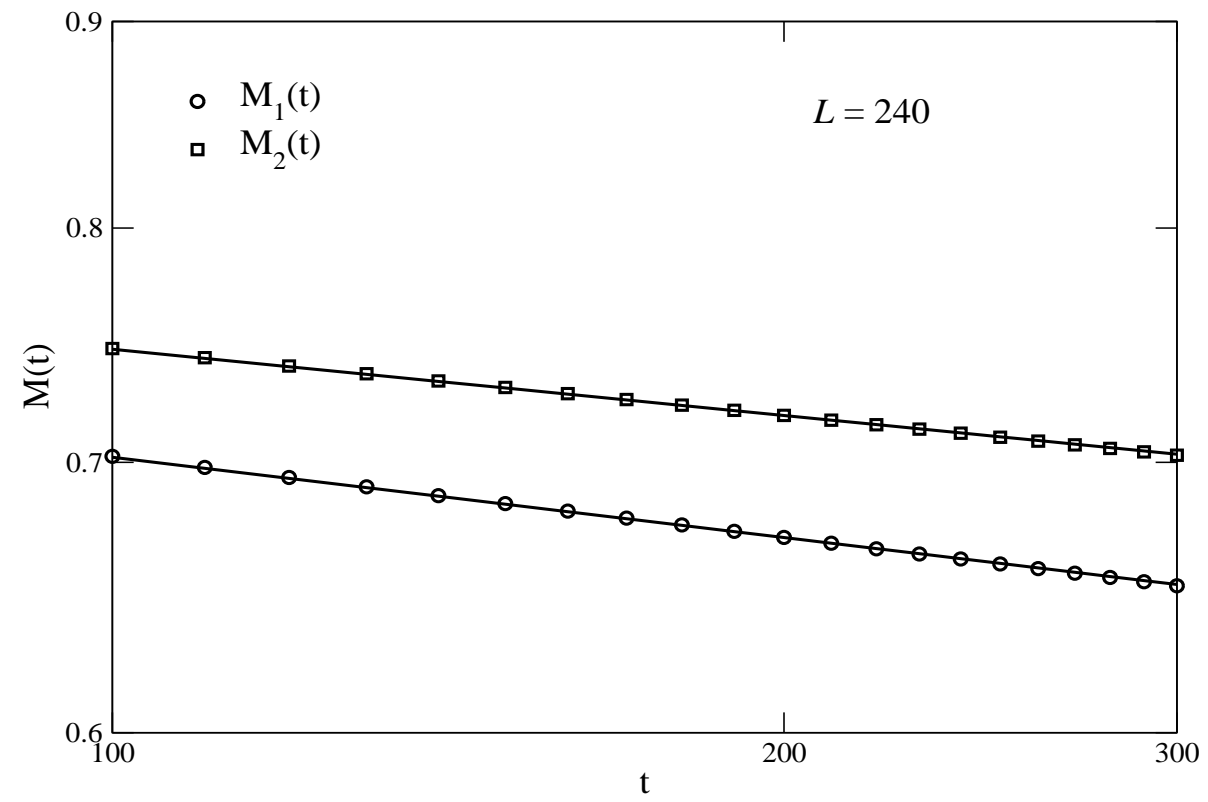

Figura 6.3: A evolução temporal das magnetizações para amostras inicialmente ordenadas $\left(m_{0}=1\right)$. As barras de erro, calculadas sobre 5 conjuntos de 30000 amostras, são menores que os símbolos.

O ajuste linear dessa curva dá os valores

$$
\frac{\beta_{1}}{\nu_{1} z_{1}}=0.073(3) \quad \text { e } \quad \frac{\beta_{2}}{\nu_{2} z_{2}}=0.053(3) .
$$

Os expoentes $\beta_{1}$ e $\beta_{2}$ são encontrados usando os resultados da Eq. (6.7). Seus valores são

$$
\beta_{1}=0.118(6) \quad \beta_{2}=0.084(6) .
$$

Nossos resultados estão em completa concordância com os valores exatos encontrados através da invariância conforme [120], $\beta_{1}=0.12$ e $\beta_{2}=0.08$.

A novidade nesse estudo que fizemos é que no modelo em questão $(Z(5))$ aparecem dois parâmetros de ordem com dois expoentes críticos estáticos associados $\left(\beta_{1} \mathrm{e}\right.$ $\left.\beta_{2}\right)$ bem como dois expoentes dinâmicos $\left(z_{1}\right.$ e $\left.z_{2}\right)$ também distintos. Como confirmação da utilidade da técnica por nós empregada, podemos citar a estimativa correta dos expoentes $\beta_{1}$ e $\beta_{2}$ (antes só calculados por invariância conforme) e o mesmo valor obtido para o expoente $\nu$ do comprimento de correlação, trabalhando com os dois parâmetros de ordem 
e os respectivos valores de $z$ (que são distintos). Esses bons resultados nos encorajam a investigar outros pontos de solubilidade dos modelos $Z(N)$. 


\section{Capítulo 7}

\section{Conclusões}

Neste trabalho, nós utilizamos a técnica de simulações Monte Carlo em tempos curtos (sistemas fora do equilíbrio) para estudar as propriedades críticas estáticas e dinâmicas dos modelos tridimensionais de dupla troca e de Heisenberg, e do modelo $Z(5)$.

O estudo da dinâmica crítica de tempos curtos, além de ser conceitualmente interessante pois evita os problemas com o critical slowing down existente em simulações no equilíbrio, permite obter, além dos expoentes críticos estáticos, o expoente dinâmico z. Todavia, além desses expoentes, essa abordagem detecta a existência de novos índices críticos: o expoente dinâmico $\theta$ que descreve a importância das condições iniciais impostas ao sistema (critical initial slip) e o expoente de persistência global $\theta_{g}$ que descreve o comportamento em lei de potências da probabilidade $P(t)$ que o parâmetro de ordem global tem de não mudar seu sinal até o tempo $t$.

Primeiramente, as simulações Monte Carlo em tempos curtos foram utilizadas para obter os expoentes críticos dinâmicos $z, \theta$ e $\theta_{g}$ e os estáticos $\beta$ e $\nu$ dos modelos tridimensionais de dupla troca e de Heisenberg. Para o modelo de dupla troca, a probabilidade de persistência global $P(t)$ foi investigada e o expoente dinâmico $\theta_{g}$ que governa seu comportamento na criticalidade foi estimado usando-se duas abordagens diferentes: a aplicação direta do comportamento em lei de potência $P(t) \sim t^{-\theta_{g}}$ e o método do colapso da função universal $L^{\theta_{g} z} P(t)$. O expoente $\theta$ foi estimado através do comportamento em lei de potências da correlação temporal da magnetização $C(t)$. Já o expoente $z$ foi encontrado através de duas técnicas diferentes: o colapso do cumulante de Binder de quarta ordem 
dependente do tempo e da função $F_{2}(t)$ que combina simulações realizadas com diferentes condições iniciais. Finalmente, os expoentes estáticos $\beta$ e $\nu$ foram encontrados através das relações de escala para a magnetização e sua derivada com respeito à temperatura $T$, na temperatura crítica $T_{c}$.

Os resultados obtidos para os expoentes $z, \beta$ e $\nu$ estão em boa concordância com os valores disponíveis na literatura. Esses resultados corroboram a afirmação de que este modelo e o modelo de Heisenberg pertencem à mesma classe de universalidade. Por outro lado, os expoentes $\theta$ e $\theta_{g}$ foram estimados pela primeira vez neste trabalho.

Para confirmar que estes modelos pertencem à mesma classe de universalidde dinâmica, resolvemos estudar a dinâmica crítica em tempos curtos do modelo de Heisenberg. Para este modelo, o expoente $z$ foi estimado com mesmas técnicas utilizadas no modelo de dupla troca. O expoente $\theta$ foi obtido através de duas técnicas: a relação de escala da magnetização $M(t) \sim m_{0} t^{\theta}$ e o subsequente limite de $m_{0} \rightarrow 0$, e a correlação temporal da magnetização. O expoente dinâmico $\theta_{g}$ foi obtido usando-se a relação de escala $P(t) \sim t^{-\theta_{g}}$ e por meio do colapso da função $L^{\theta_{g} z} P(t)$ para duas redes diferentes. Já os expoentes estáticos $\beta$ e $\nu$ foram estimados seguindo-se a evolução temporal da magnetização e de sua derivada.

Os resultados para $z, \nu$ e $\beta$ estão em boa concordância com os valores obtidos previamente por várias técnicas e autores. Já os expoentes $\theta$ e $\theta_{g}$ estão em completa concordância com os recentes resultados obtidos para o modelo de dupla troca confirmando mais uma vez a idéia de que ambos os modelos pertencem à mesma classe de universalidade.

Finalmente, estudamos o comportamento crítico dinâmico do modelo $Z(5)$ em duas dimensões, no ponto de bifurcação. Os expoentes críticos dinâmicos $z_{1}$ e $z_{2}$ foram encontrados utilizando a função $F_{2}(t)$. Já os expoentes estáticos $\beta_{1}, \beta_{2}$ e $\nu$ foram encontrados através das mesmas técnicas empregadas nos dois primeiros modelos. Apesar de não termos ainda concluido esse trabalho, nossos resultados para os expoentes estáticos estão de acordo com os valores pertinentes encontrados na literatura e os dois expoentes dinâmicos $\left(z_{1}\right.$ e $\left.z_{2}\right)$ levam aos mesmo valor de $\nu$. Ainda trabalhando com o modelo $Z(5)$, 
pretendemos utilizar outras técnicas para obter o expoente $z$ e encontrar os expoentes $\theta$ e $\theta_{g}$. Como esse modelo apresenta um rico diagrama de fases, pretendemos estudar outros pontos, além do ponto de bifurcação. Pretendemos investigar alguns pontos críticos entre as linhas autoduais (fase mole) para observar o comportamento dos expoentes estáticos e dinâmicos.

Dando prosseguimento ao nosso trabalho, pretendemos estudar a dinâmica crítica de tempos curtos dos modelos $Z(N \neq 5)$ [118, 120,126], de Ashkin-Teller [130] e de Heisenberg numa rede cúbica de corpo centrado e de face centrada [100].

Uma outra proposta seria estudar o algoritmo de Wang-Landau $[52,53]$ para obter as propriedades termodinâmicas de alguns modelos, como por exemplo, os modelos metamagnético [131] e de Ashkin-Teller. O modelo metamagnético apresenta um diagrama de fase interessante, com transições de segunda ordem e um ponto tricrítico.

Finalmente, seria interessante unir essas duas técnicas (simulações fora do equilíbrio e técnica de repesagem) para estudar alguns sistemas de spin. Esse tipo de abordagem foi usado recentemente por Lee e Okabe [132] para estudar o modelo de Ising bidimensional. Eles mostraram que, partindo de uma única temperatura, a evolução temporal das quantidades termodinâmicas poderia ser obtida para qualquer temperatura. Essa técnica foi recentemente empregada para obter o diagrama de fase do modelo tridimensional de Potts com ligações aleatórias [133]. Seu ponto tricrítico, que separa as transições de primeira e segunda ordem, foi determinado e os expoentes críticos da transição de fase contínua foram estimados. 


\section{Referências Bibliográficas}

[1] T. Andrews, Phil. Trans. R. Soc. 159, 575 (1869).

[2] J.D. Van der Waals, Sobre a Continuidade do Estado Líquido e Gasoso. Tese de Doutorado. Universidade de Leiden (1873).

[3] P.J. Weiss, Phys. Radium. 6, 667 (1907).

[4] K.G. Wilson and M.E. Fisher, Phys. Rev. Lett. 28, 240 (1972).

[5] K.G. Wilson, Rev. Mod. Phys. 47, 773 (1975).

[6] C. Domb, Adv. Phys. 19, 339 (1970).

[7] E. Ising, Z. Phys. 31, 253 (1925).

[8] R. Peierls, Proc. Cambridge Phil. Soc. 32, 477 (1936).

[9] L. Onsager, Phys. Rev. 65, 117 (1944).

[10] L.P. Kadanoff, W. Götze, D. Hamblen, R. Hecht, E.A.S. Lewis, V.V. Palciauskas, M. Rayl, J. Swift, D. Aspnes, and J. Kane, Rev. Mod. Phys. 39, 395 (1967).

[11] K.G. Wilson, Phys. Rev. B. 4, 3184 (1971).

[12] M.E. Fisher, Rev. Mod. Phys. 46, 597 (1974).

[13] N. Metropolis and S. Ulam, J. Amer. Stat. Assoc. 44, 335 (1949).

[14] N. Metropolis, A.W. Rosenbluth, M.N. Rosenbluth, A.H. Teller, and E. Teller, J. Chem. Phys. 21, 1087 (1953). 
[15] R.H. Swendsen, and J.S. Wang, Phys. Rev. Lett. 58, 86 (1987).

[16] H.K. Janssen, B. Schaub, and B. Schimittmann, Z. Phys. B. 73, 539 (1989).

[17] D.A. Huse, Phys. Rev. B. 40, 304 (1989).

[18] S.N. Majumdar, A.J. Bray, S.J. Cornell and C. Sire, Phys. Rev. Lett. 773704 (1996).

[19] Z.B. Li, X.W. Liu, L. Schülke, and B. Zheng, Physica A 245, 485 (1997).

[20] T. Tome, C.S. Simões, and J.R.D. de Felício, Mod. Phys. Lett. B 15, 1141 (2001).

[21] E. Arashiro, H.A. Fernandes, and J.R. Drugowich de Felício, e-print condmat/0603436.

[22] H.E. Stanley, Introduction to Phase Transitions and Critical Phenomena, Oxford University Press, Oxford (1971).

[23] S. Jain, Monte Carlo Simulations of Disordered Systems, Departament of Mathematics \& Computing, Londres (1992).

[24] B. Widom, J. Chem. Phys. 433898 (1965).

[25] M.J. de Oliveira, Termodinâmica, Livraria da Física, São Paulo (2005).

[26] E.A. Guggenheim, J. Chem. Phys. 13, 253, 1945.

[27] R.K. Pathria, Statistical Mechanics, Segunda Edição, B-H, Oxford (1996).

[28] A. Hall, Messeng. Math. 2, 113 (1873).

[29] Lord Rayleigh, Philosophical Magazine 47, 246 (1899).

[30] G.W. Gosset, Biometrika 6, 1 (1908).

[31] G.W. Gosset, Biometrika 6, 302 (1908).

[32] A.N. Kolmogorov, Math. Ann. 104, 415 (1931). 
[33] W. Feller, Trans. Amer. Math. Soc. 48, 488 (1940).

[34] W. Feller, Trans. Amer. Math. Soc. 58, 474 (1945).

[35] E. Amaldi, Phys. Rep. 111, 1 (1984).

[36] D.P. Landau and K. Binder, A Guide to Monte Carlo Simulations in Statistical Physics, Cambridge University Press, Cambridge (2002).

[37] U. Wolff, Phys. Rev. Lett. 68, 361 (1989).

[38] J. Machta, Y.S. Choi, A. Lucke, T. Schweizer, and L.M. Chayes, Phys. Rev. E 54, 1332 (1996).

[39] G. Johnson, H. Gould, J. Machta, and L.K. Chayes, Phys. Rev. Lett. 79, 2612 (1997).

[40] F. Niedermayer, Phys. Rev. Lett. 61, 2026 (1988).

[41] B.A. Berg and T. Neuhaus, Phys. Lett. B 267, 249 (1991).

[42] B.A. Berg and T. Neuhaus, Phys. Rev. Lett. 68, 9 (1992).

[43] B.A. Berg and T. Celik, Phys. Rev. Lett. 69, 2292 (1992).

[44] W. Janke and S. Kappler, Phys. Rev. Lett. 74, 212 (1995).

[45] J. Lee, Phys. Rev. Lett. 71, 211 (1993).

[46] A.M. Ferrenberg and R.H. Swendsen, Phys. Rev. Lett. 61, 2635 (1988).

[47] A.M. Ferrenberg and R.H. Swendsen, Phys. Rev. Lett. 63, 1195 (1989).

[48] P.M.C. de Oliveira, T.J.P. Penna, and H.J. Herrmann, Braz. J. Phys. 26, 677 (1996).

[49] P.M.C. de Oliveira, T.J.P. Penna, and H.J. Herrmann, Eur. Phys. J. B 1, 205 (1998).

[50] P.M.C. de Oliveira, Eur. Phys. J. B 6, 111 (1998).

[51] J.S. Wang and L.W. Lee, Comput. Phys. Commun. 127, 131 (2000). 
[52] F. Wang and D.P. Landau, Phys. Rev. Lett. 86, 2050 (2001).

[53] F. Wang and D.P. Landau, Phys. Rev. E 64, 056101 (2001).

[54] Z.B. Li, L. Schülke, and B. Zheng, Phys. Rev. Lett. 74, 3396 (1995).

[55] M.S. Soares, J.K.L. Silva, and F.C. Barreto, Phys Rev. B. 55, 1021 (1997).

[56] R. da Silva, N.A. Alves, and J.R. Drugowich de Felício, Phys. Lett. A 298, 325 (2002).

[57] B. Zheng, Int. J. Mod. Phys. B 12, 1419 (1998).

[58] A. Jaster, J. Mainville, L. Schülke, and B. Zheng, J. Phys. A: Math. Gen. 32, 1395 (1999).

[59] B. Zheng, Physica A, 283, 80 (2000).

[60] Z.B. Li, U. Ritschel, and B. Zheng, J. Phys. A: Math. Gen. 27, L837 (1994).

[61] L. Schülke, and B. Zheng, Phys. Lett. A. 204, 295 (1995).

[62] H.K. Janssen and K. Oerding, J. Phys. A: Math. Gen. 27, 715 (1994).

[63] R. da Silva, N.A. Alves, and J.R. Drugowich de Felício, Phys. Rev. E 66, 026130 (2002).

[64] E. Arashiro and J.R. Drugowich de Felício, Phys. Rev. E 67, 046123 (2003).

[65] R. da Silva and J.R. Drugowich de Felício, Phys. Lett. A 333, 277 (2004).

[66] H.A. Fernandes, E. Arashiro, J.R. Drugowich de Felício, and A.A. Caparica, Physica A 336, 255 (2006).

[67] C.S. Simões and J.R. Drugowich de Felício, Mod. Phys. Lett. B, 15, 487 (2001).

[68] K. Binder, Z. Phys. A 43, 119 (1981).

[69] R. da Silva, R. Dickman, and J.R. Drugowich de Felício, Phys. Rev. E 70, 067701 (2004). 
[70] H.A. Fernandes, J.R. Drugowich de Felício, and A.A. Caparica, Phys. Rev. B. 72, $054434(2005)$.

[71] T. Tomé and M.J. de Oliveira, Phys. Rev. E 58, 4242 (1998).

[72] T. Tomé, J. Phys. A: Math. Gen. 36, 6683 (2003).

[73] S.N. Majumdar and A.J. Bray, Phys. Rev. Lett. 91, 030602 (2003).

[74] L. Schulke and B. Zheng, Phys. Lett. A 233, 93 (1997).

[75] K. Oerding, S.J. Cornell, and A.J. Bray, Phys. Rev. E 56, R25 (1997).

[76] R. da Silva, N.A. Alves, and J.R. Drugowich de Felício, Phys. Rev. E 67, 057102 (2003).

[77] R. da Silva and N. Alves Jr., Physica A 350, 263 (2005).

[78] F. Ren and B. Zheng, Phys. Lett. A 313, 312 (2003).

[79] E.V. Albano and M.A. Muñoz, Phys. Rev. E 63, 031104 (2001).

[80] M. Saharay and P. Sen, Physica A 318, 243 (2003).

[81] H. Hinrichsen and H.M. Koduvely, Eur. Phys. J. B 5, 257 (1998).

[82] P. Sen and S. Dasgupta, J. Phys. A: Math. Gen. 37, 11949 (2004).

[83] B. Zheng, Mod. Phys. Lett. B 16, 775 (2002).

[84] S. Cueille and C. Sire, Eur. Phys. J. B 7, 111 (1999).

[85] H.A. Fernandes and J.R. Drugowich de Felício, Phys. Rev. E 73, 057101 (2006).

[86] R. von Helmolt, J. Wecker, B. Holzapfel, L. Schultz, and K. Samwer, Phys. Rev. Lett. 71, 2331 (1993).

[87] A.P. Ramirez, J. Phys.: Condens. Matter 9, 8171 (1997).

[88] J.M.D. Coey, M. Viret, and S. von Molnar, Adv. Phys. 48, 167 (1999). 
[89] M.B. Salomon and M. Jaime, Rev. Mod. Phys. 73, 583 (2001).

[90] L.G. Tejuca, J.L.G. Fierro, e J.M.D. Tascon, Adv. Catal. 36, 237 (1989).

[91] C. Zener, Phys. Rev. 82403 (1951).

[92] P.W. Anderson e H. Hasegawa, Phys. Rev. 100, 675 (1955).

[93] P.G. de Gennes, Phys. Rev. 118, 141 (1960).

[94] C.M. Varma, Phys. Rev. B 54, 7328 (1996).

[95] J.B. Goodenough, Phys. Rev. 100, 564 (1955).

[96] A. Asamitsu, Y. Moritomo, R. Kumai, Y. Tomioka, and Y. Tokura, Phys. Rev. B 54, 1716 (1996).

[97] A.J. Millis, P.B. Littlewood, and B.I. Shraiman, Phys. Rev. Lett. 74, 5144 (1995).

[98] J.W. Lynn, R.W. Erwin, J.A. Borchers, Q. Huang, A. Santoro, J.L. Peng, and Z.Y. Li, Phys. Rev. Lett. 76, 4046 (1996).

[99] A.A. Caparica, A. Bunker, and D.P. Landau, Phys. Rev. B. 62, 9458 (2000).

[100] K. Binder, Monte Carlo Methods in Statistical Physics, edited by K. Binder, Springer-Verlag, Berlin, (1986).

[101] K. Chen, A.M. Ferrenberg, and D.P. Landau, Phys. Rev. B 48, 3249 (1993).

[102] Y. Motome and N. Furukawa, J. Phys. Soc. Jpn. 72, 2126 (2003).

[103] M. Sahana, U.K. Rossler, Niloptal Ghosh, Suja Elizabeth, H.L. Bhat, K. Dorr, D. Eckert, M. Wolf, and K.-H. Muller, Phys. Rev. B 68, 144408 (2003).

[104] K. Ghosh, C.J. Lobb, R.L. Greene, S.G. Karabashev, D.A. Shulyatev, A.A. Arsenov and Y. Mukovskii, Phys. Rev. Lett. 81, 4740 (1998).

[105] Wei Li, H.P. Kunkel, X.Z. Zhou, Gwyn Williams, Y. Mukovskii, and D. Shulyatev, Phys. Rev. B 70214413 (2004). 
[106] W.H. Press, S.A. Teukolsky, W.T. Vetterling, and B.P. Flannery, Numerical Recipes, Cambridge University Press, London, (1986).

[107] P. Peczak e D.P. Landau, J. Appl. Phys, 67, 5427 (1990).

[108] C. Holm and W. Janke, Phys. Lett. A 173, 8 (1993).

[109] M.P. Nightingale and H.W.J. Blöte, Phys. Rev. Lett. 60, 1562 (1998).

[110] P. Peczak, A.M. Ferrenberg, and D.P. Landau, Phys. Rev. B 43, 6087 (1991).

[111] I. Dimitrović, P. Hasenfratz, J. Nager, and F. Niedermayer, Nucl. Phys. B. 350, 893 (1991).

[112] K. Chen, A.M. Ferrenberg, and D.P. Landau, J. Appl. Phys. 73, 5488 (1993).

[113] P.J. Wood and G.S. Rushbrooke, Phys. Rev. Lett. 17, 307 (1966).

[114] D.S. Ritchie and M.E. Fisher, Phys. Rev. B 52668 (1972).

[115] P. Peczak and D.P. Landau, Phys. Rev. B 47, 14260 (1993).

[116] J. M. Kosterlitz and D. J. Thouless, J. Phys. C 6, 1181 (1973).

[117] J. V. José, L. P. Kadanoff, S. Kirkpatrick, and D. R. Nelson, Phys. Rev. B 16, 1217 (1977).

[118] F. C. Alcaraz and R. Koberle, J. Phys. A: Math. Gen. 14, 1169 (1981).

[119] V. A. Fateev and A. B. Zamolodchikov, Phys. Lett. A 92, 37 (1982).

[120] F. C. Alcaraz, J. Phys. A: Math. Gen. 20, 2511 (1987).

[121] B. Bonnier, M. Hontebeyrie, and C. Meyers, Phys. Rev. B 39, 4079 (1989).

[122] R. J. Baxter, J. Phys. C 6, L445 (1973).

[123] M. den Nijs, Phys Rev. B 31, 266 (1985).

[124] B. Bonnier and K. Rouidi, Phys. Rev. B 42, 8157 (1990). 
[125] B. Bonnier, and Y. Leroyer, Phys. Rev. B 44, 9700 (1991).

[126] F. C. Alcaraz and A. L. Santos, Nucl. Phys. B275, 436 (1986).

[127] B. Bonnier, Phys. Rev. B 44, 390 (1991).

[128] C. Vanderzande, J. Phys. A: Math. Gen. 20, L549 (1987).

[129] A.B. Zamolodchikov and V.A. Fateev, Zh. Eksp. Theor. Fiz. 89, 380 (1985).

[130] J. Ashkin and E. Teller, Phys. Rev. 64, 178 (1943).

[131] K. Motizuki, J. Phys. Soc. Jpn. 14, 759 (1959).

[132] H.K. Lee and Y. Okabe, Phys. Rev. E 71, 015102 (2005).

[133] J.Q. Yin, B. Zheng, and S. Trimper, Phys. Rev. E 72, 036122 (2005). 
Apêndice A

Artigos publicados 